\title{
IMPACTO DEL DESARROLLO DE LA LÍNEA TUMORAL A549 EN EL BIENESTAR DE RATONES DE LA CEPA N:NIH(S)-Foxi ${ }^{\text {nu }}$
}

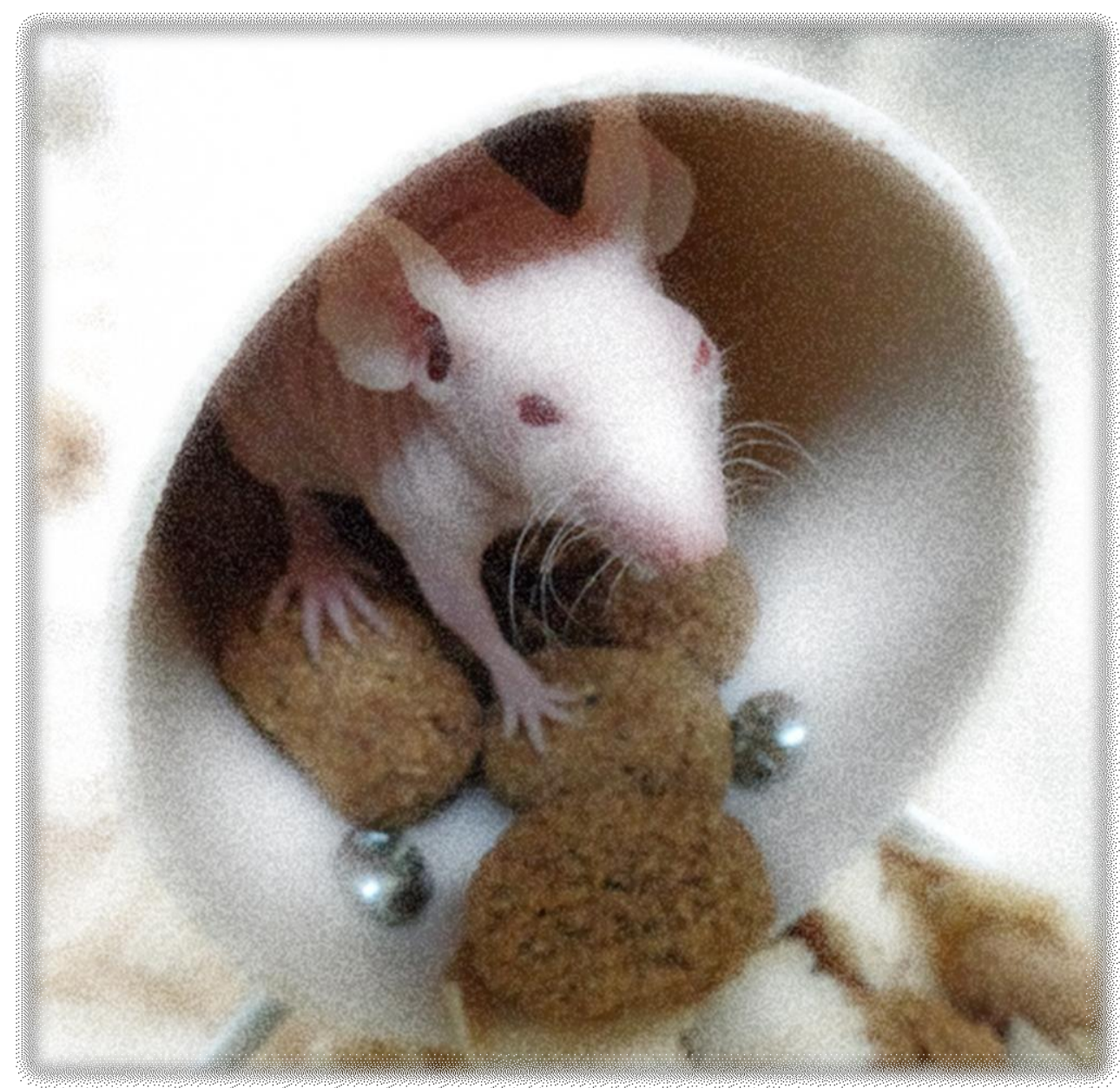

AGUSTINA RESASCO 



\author{
UNIVERSIDAD NACIONAL DE LA PLATA \\ FACULTAD DE CIENCIAS VETERINARIAS
}

Trabajo de tesis realizado como requisito para optar al título de DOCTORA EN CIENCIAS VETERINARIAS

\title{
IMPACTO DEL DESARROLLO DE LA LÍNEA TUMORAL A549 EN EL BIENESTAR DE RATONES DE LA CEPA N:NIH(S)-Fox $1^{\text {nu }}$
}

Autora: Agustina Resasco

Directora: Cecilia Carbone

Codirector: Miguel Angel Ayala

Lugar de trabajo: Laboratorio de Animales de Experimentación (LAE- FCVUNLP)

Miembros del jurado: Ricardo Ferrari

María Carla García Mitacek

Jenny Carolina Saldaña 
A todos los que trabajan diariamente para aliviarle a los animales la carga del progreso científico.

"For those who see the central issue as one of rights, or justice, or religious tradition, or fostering a caring attitude toward animals, the scientific study of animal welfare may seem irrelevant or even a harmful distraction. [...] Scientists need to understand, and be able to articulate, how science fits into the social debate"

David Fraser, 2008 


\section{Agradecimientos}

En primer lugar quisiera agradecer a la Universidad Nacional de la Plata y al CONICET por financiar mis años de trabajo. Además, esta tesis doctoral no hubiese sido posible sin el acompañamiento de todos los integrantes del Laboratorio de Animales de Experimentación (LAE-FCV-UNLP), quienes me abrieron las puertas y me dieron la libertad de trabajar en un tema que me apasiona. En particular, a mis directores Cecilia Carbone y Miguel Ángel Ayala por acompañarme a lo largo de estos 5 años y a Silvina Díaz por sumarse sobre el final de este camino. También quiero agradecerle Ana Carranza y a Rocío Foltran por ayudarme con algunos de los experimentos.

Quisiera hacer una mención especial hacia todos aquellos docentes que me encontré a lo largo de los distintos cursos de postgrado, que me ayudaron a forjar un criterio científico crítico y una visión hacia cómo comprender una Ciencia tan multidisciplinaria como la del Bienestar Animal.

Las palabras finales se las quiero dedicar a mis padres, por brindarme todas las oportunidades posibles y por acompañar siempre mis decisiones, y a Ale, con quien arrancamos juntos en este proceso, gracias por toda la ayuda y la paciencia a lo largo de estos años. 


\section{Publicaciones}

\section{Trabajos publicados en revistas con referato}

Agustina Resasco, Ana C Carranza Martin, Miguel A Ayala, Silvina L Diaz, Cecilia Carbone. Non-aversive method for subcutaneous tumour measurement in nude mice. Lab Anim. 2018 Aug 21:23677218793450. doi: 10.1177/0023677218793450. [Epub ahead of print].

\section{Presentaciones en congresos}

- Agustina Resasco, Natalia Vidal, Miguel Ayala, Silvina Diaz, Cecilia Carbone. Positive reinforcement judgment bias test for nude mice. $15^{\circ}$ Congresso da Sociedade Brasileira de Ciência em Animais de Laboratório. Junio 2018.

- Agustina Resasco, Miguel Ayala, Cecilia Carbone. Modificación de la respuesta de ratones macho con trasplante tumoral subcutáneo a la orina de hembras en celo. $1^{\circ}$ reunión de biología del comportamiento del cono sur. Agosto 2017.

- Agustina Resasco, Ana Cristina Carranza Martin, Miguel Ayala, Cecilia Carbone. Non-aversive subcutaneous tumor measurement method in nude mice. Lab Animal Science 2017 Virtual Event. Febrero 2017.

- Agustina Resasco, Ana Cristina Carranza Martin, Miguel Ayala, Cecilia Carbone. Behavioral and physiological differences between two methods of subcutaneous tumor measurements. Asociación Argentina de Ciencia y Tecnología de Animales de Laboratorio (AACyTAL), Mar del Plata. Noviembre 2016. 
- Agustina Resasco, Ana Cristina Carranza Martin, Miguel Ayala, Cecilia Carbone. Comparación entre dos métodos de medición de tumores subcutáneos en ratones nude. $14^{\circ}$ Congresso da Sociedade Brasileira de Ciencias em Animais de Laboratorio, $3^{\circ}$ Encontro Latino Americano de Ciencias em Animais de Laboratório. Porto Alegre. Mayo 2016.

- Agustina Resasco, Ana Cristina Carranza Martin, Clara Vercellini. Prueba piloto para la validación de una técnica no invasiva de medición de tumores trasplantados en ratones inmunodeficientes. XXIII Jornadas de Jóvenes Investigadores de la Asociación de Universidades Grupo Montevideo, La Plata. Agosto 2015.

- Agustina Resasco, Miguel Ayala, Cecilia Carbone. Valoración del bienestar animal en ratones inmunodeficientes con un trasplante tumoral evaluando la calidad del nido. 9nas Jornadas Internacionales de Veterinaria Práctica, Mar del Plata. Agosto 2015.

- Agustina Resasco, Fabricio Maschi, Clara Vercellini, Miguel Ayala, Cecilia Carbone. Resultados preliminares de las posibles diferencias en una prueba comportamental sencilla: burrowing test en animales enriquecidos y no enriquecidos. IV Congreso Nacional, IV Reunión Científica Regional de la Asociación Argentina de Ciencia y Tecnología de Animales de Laboratorio (AACyTAL), I Simposio de Métodos Alternativos. Ciudad Autónoma de Buenos Aires. Septiembre 2014. 


\section{Índice}

Abreviaturas

Resumen (Español)

Resumen (Inglés)

Introducción general

Procedimientos generales y diseño experimental

Evaluación del bienestar animal mediante indicadores fisiológicos

Evaluación del bienestar animal mediante indicadores comportamentales

Sesgo cognitivo en investigación oncológica

Refinamiento del modelo animal para mejorar el bienestar 89

Método fotográfico de medición de tumores no aversivo

Enriquecimiento ambiental en ratones con xenotrasplantes subcutáneos

Consideraciones finales

Glosario

Bibliografía 


\section{Abreviaturas}

AINEs: antiinflamatorios no esteroideos

CC: condición corporal

cm: centímetros

$\mathrm{cm}^{3}$ : centrímetros cúbicos

$\mathrm{CO}_{2}$ : dióxido de carbono

D.E.: desvío estándar

EA: enriquecimiento ambiental

EE: error estándar

EIA: inmunoensayo enzimático

gr: gramos

HPA: hipotálamo-hipófisis-adrenal

hs: horas

i.p.: intra-peritoneal

kg: kilogramo

LAE: Laboratorio de Animales de Experimentación

MEM: Medio Mínimo Escencial

MFnoA: medición fotográfica no aversiva 
mg: miligramos

mm: milímetros

$\mathrm{mm}^{3}$ : milímetros cúbicos

mM: milimolar

ng: nanogramos

NSF: novelty-suppressed feeding

SAM: sistema simpático-adrenomedular

SPF: libres de patógenos específicos

TT: trasplante tumoral

$\mu 1$ : microlitro

US: urine sniffing 


\section{IMPACTO DEL DESARROLLO DE LA LÍNEA \\ TUMORAL A549 EN EL BIENESTAR DE RATONES \\ DE LA CEPA N:NIH(S)-Fox $1^{\text {nu }}$}

\section{Palabras clave}

RATÓN, BIENESTAR ANIMAL, TRASPLANTE TUMORAL, COMPORTAMIENTO

\section{Resumen}

Las Ciencias del Bienestar Animal y de los Animales de Laboratorio se asocian ineludiblemente, para evaluar científicamente cómo los procedimientos experimentales y las condiciones de alojamiento impactan sobre la calidad de vida de los animales. En particular en investigación oncológica, se han redactado guías de recomendaciones pero éstas fallan en describir cómo se pueden discernir alteraciones sutiles en el bienestar. De esta forma, el objetivo principal consistió en determinar el impacto de la línea tumoral humana A549 en el bienestar de ratones del stock NLAE:NIH(S)-Fox ${ }^{n u}$ trasplantados con la misma y en evaluar el efecto del enriquecimiento ambiental sobre el desarrollo tumoral. Para alcanzarlo se evaluó por un lado la fisiología de los ratones a través de la concentración de los metabolitos de la corticosterona en materia fecal, de cambios en la condición corporal y del análisis de parámetros sanguíneos y por el otro las frecuencias de comportamientos espontáneos que realizaron en la caja donde habitaban normalmente y la performance en distintas pruebas de comportamiento. Además, para poder alcanzar dichos objetivos se desarrollaron dos nuevas metodologías: una técnica de medición de los 
tumores subcutáneos no aversiva y una prueba para para evaluar el sesgo en el juicio ante un estímulo ambiguo. En líneas generales, no se evidenciaron alteraciones significativas en los parámetros de fisiología y de comportamiento que indicarían una alteración severa en el bienestar de los ratones. Sin embargo, sí se manifestaron algunas modificaciones sutiles que convalidan la interpretación de que el trasplante tumoral no es un procedimiento inocuo para estos animales. Con respecto al enriquecimiento ambiental, resultó llamativa la diferencia en el desarrollo tumoral entre machos y hembras por lo que se postuló que la inhibición del desarrollo tumoral se debió al estrés asociado al aumento de los comportamientos agonistas en la caja como consecuencia del enriquecimiento ambiental y no por dicha modificación ambiental. 
IMPACT OF TUMOR DEVELOPMENT IN THE WELFARE OF N:NIH(S)-Fox ${ }^{\text {nu }}$ MICE TRANSPLANTED WITH A549 CELLS

\section{Keywords}

MICE, ANIMAL WELFARE, TUMOR TRASPLANT, BEHAVIOR

\section{Abstract}

Animal Welfare and Laboratory Animal Sciences are inevitably associated, to assess scientifically how experimental procedures and husbandry affect the animals' quality of life. Guidelines for oncologic research have been written, but these generally fail to describe subtle changes in welfare. Hence, the main objective was to assess the impact of tumor development in the welfare of NLAE:NIH(S)-Fox $1^{\text {nu }}$ mice transplanted with A549 cells and to evaluate the effect of environmental enrichment in tumor development. The physiology was assessed through the quantification of corticosterone metabolites in feces, body condition scoring and blood parameters and the behavior by means of behavioral tests as well as analyzing the frequency of home cage behaviors. In addition, to meet the objectives two new methodologies were described: a non-aversive photographic measurement method for subcutaneous tumors and an assay to assess judgment bias when exposed to an ambiguous stimulus. Altogether, severe alterations in the physiology and the behavior which would indicate a reduction in the animals' welfare were not detected. Nevertheless, subtle behavioral modifications were observed by which it was assumed that tumor development did generate a subtle malaise sensation to the animals. With regards to 
environmental enrichment, an interesting difference in tumor development between males and females was observed, and it was hypothesized that this difference was due to stress associated to an increase of agonistic behaviors in the home cage as a consequence of environmental enrichment. 


\section{Introducción}

La Ciencia de los Animales de Laboratorio es una especialidad dentro de la Medicina Veterinaria que se enfoca en desarrollar modelos experimentales para mejorar la calidad de vida tanto del ser humano como de otros animales (Chumbinho y col., 2012). En este sentido, la forma en que alojamos a dichos animales corresponde a un aspecto fundamental de este proceso ya que las perturbaciones ambientales pueden alterar la fisiología de los individuos y, como consecuencia, modificar las variables experimentales (Jain y Baldwin, 2003). Sin embargo, no solo es importante considerar la calidad de la experimentación biomédica sino también las obligaciones morales que poseemos hacia aquellos organismos que están bajo nuestra responsabilidad (Sørensen, 2007). Es por esta razón que el Bienestar Animal se asocia ineludiblemente con la Ciencia de Animales de Laboratorio, como forma de evaluar científicamente cómo los procedimientos experimentales y las condiciones de alojamiento impactan sobre la calidad de vida de los animales.

De esta forma, se establecieron distintos marcos regulatorios tanto para garantizar la calidad de la experimentación biomédica como para evitar el sufrimiento de los animales que se encuentran bajo nuestro cuidado (Fraser, 2008). Así, cada país fue adoptando normas referidas al uso de los animales de laboratorio, de los cuales se citan algunos ejemplos:

- Estados Unidos: los animales de laboratorio (excepto rata, ratón, aves y vertebrados de sangre fría) están protegidos bajo el "Animal Welfare Act" (Cardon y col., 
2012), cuya aplicación está regulada por el Departamento de Agricultura (USDA). Además, el Instituto Nacional de Salud (NIH), bajo la política de Cuidado Humanitario y Uso de Animales de Laboratorio (que protege a todos los vertebrados incluyendo rata y ratón), establece que cada institución que use animales con proyectos financiados por este organismo, debe proveer la conformidad con la política de Cuidado Humanitario y Uso de Animales de Laboratorio. Para la misma, las instituciones deben contar con: (1) un programa institucional para el cuidado y el uso de los animales (2) acreditación por la Asociación Internacional para la Evaluación y Acreditación del Cuidado de Animales de Laboratorio (AAALAC) y (3) un comité de ética, que debe supervisar el cuidado y uso de los animales de experimentación utilizando como referencia la "Guía para el Cuidado y Uso de los Animales de Laboratorio" (Institute for Laboratory Animal Research, 2011), editada periódicamente por el ILAR bajo contrato del NIH.

- Canadá: la jurisdicción sobre el cuidado y uso de los animales en experimentación recae sobre las provincias y siete del total poseen legislación al respecto. De esas siete, seis se basan en los estándares del Consejo Canadiense de Cuidado Animal (CCAC), una organización no gubernamental sin fines de lucro que evalúa el uso ético de los animales que se utilizan en ciencia en Canadá.

- Europa: Las regulaciones acerca del bienestar animal fueron adoptadas por todos sus países miembros. La directiva que intentó armonizar la legislación del uso de animales de laboratorio en ellos fue la 86/609/EEC de 1986 (Unión Europea, 1986). Esta fue actualizada en el 2010 (Directiva 2010/63/EU, 2010) (European Union, 
2010) para mejorar el bienestar animal, la implementación de las 3 Rs (reducción, refinamiento y reemplazo de los animales de experimentación) y la armonización entre los estados miembro. La última versión de la directiva protege a todos los vertebrados, los cefalópodos y los fetos en el último tercio de la gestación. Además, incluye la implementación de un "Comité de Bienestar Animal" para fomentar el cuidado, garantizar la aplicación de las 3Rs e implementar el uso de métodos alternativos.

- Argentina: En la actualidad la única ley vigente que ampara a los animales usados en investigación es la Ley Nacional 14346 (1954): Malos tratos contra animales (Boletín Oficial, 1954). En la misma, se establece la pena que corresponde en caso de que se le infiera sufrimiento innecesario a los animales, que las prácticas quirúrgicas deben ser realizadas por un veterinario y que no debería realizarse experimentación en animales pertenecientes a una escala zoológica mayor a la necesaria.

En cuanto a la calidad de los productos farmacéuticos (y en la que la utilización de animales de laboratorio puede llegar a ser una etapa de la producción), aquellos laboratorios cuyos productos estén destinados a consumo humano están regulados por la Administración Nacional de Medicamentos, Alimentos y Tecnología Médica (ANMAT), mientras que los dedicados a la medicina veterinaria están bajo la órbita del Servicio Nacional de Sanidad y Calidad Agroalimentaria (SENASA).

El SENASA posee una dirección de Bienestar Animal que busca armonizar la legislación del país con el Código Terrestre de la Organización Internacional para la Salud Animal (OIE). Dicho código posee un capítulo dedicado a los animales 
utilizados en experimentación y educación (Capítulo 7.8) (Organización Mundial de Sanidad Animal, 2017).

En cuanto a la ANMAT, posee la disposición N 5330/1997 (con las modificaciones de las Disp. N 690/2005 y 2124/2005) de Buenas Prácticas de Investigación en Estudios de Farmacología Clínica (ANMAT, 1997).

Además, en la actualidad existe un proyecto de ley para la protección y el bienestar de los animales utilizados con fines científicos (6758-D-2016) que posee media sanción de la Cámara de Diputados.

Más allá de las regulaciones, podríamos preguntarnos específicamente: ¿Por qué deberíamos preocuparnos por el bienestar de los animales de experimentación? Jeremy Bentham fue uno de los primeros que se aproximó a responderla cuando postuló su famosa frase: "La pregunta no es... ¿pueden razonar? o ¿pueden hablar? sino, ¿pueden sufrir?" (Bentham, 1789), y en esta oración quedó plasmada la importancia del estudio del bienestar, de la que los científicos no se animaron a promulgarse abiertamente hasta alrededor de los años 90 con exponentes tales como Dawkins y Duncan. Posiblemente debido a que, cuando se observan las evidencias científicas acerca del parecido nuestro con los ratones de experimentación, que es la especie más utilizada en investigación biomédica, resultan abrumadoras para aquellos que no deseen asumir las responsabilidades morales que acarrea el uso de un individuo biológicamente similar a la especie humana. Pero en la similitud con nuestra especie no radica la importancia del cuidado de los animales de experimentación sino justamente en lo que planteó Bentham: la importancia reside en las experiencias subjetivas, placenteras o aversivas, que es capaz de percibir un organismo vivo 
(Proctor, 2012). En definitiva, consiste en ser capaz de diferenciar aquellos individuos que son sentientes de los que no (Birch, 2017), y ese es el motivo de las interpretaciones opuestas que se realizan sobre el cuidado necesario hacia una planta, un protozoario o un mamífero: es la diferencia entre una obligación moral y una responsabilidad (aunque ambas no sean mutuamente excluyentes). Broom (2012) define a un organismo sentiente como aquel que posee al menos alguna de las siguientes habilidades: (I) evaluar las acciones de otros en relación a si mismo y a terceros, (II) recordar sus propias acciones y sus consecuencias, (III) evaluar riesgos y beneficios, (IV) poseer sentimientos y (V) tener algún grado de conciencia. Esta última, definida como el análisis complejo en el cerebro de estímulos sensoriales o de construcciones realizadas a partir de la memoria que generan un estado de autoreconocimiento y de apreciación acerca de la relación de uno con el ambiente (que en inglés se denomina "awareness" para diferenciarla del estado de conciencia propiamente dicho que se pierde por ejemplo al realizar una anestesia. (Broom, 2014).

De esta forma, la Ciencia del Bienestar Animal surge como forma de estudiar a estos individuos sentientes. Sin embargo, la misma suele ser difícil de definir, ya que los distintos enfoques sobre los cuales se basa pueden llegar a ocasionar conflictos en la interpretación de los resultados (Mason y Mendl, 1993). El bienestar animal típicamente se describe como el estado de un animal en sus intentos por enfrentarse con el medio ambiente (Broom, 1991), en el que entran en juego una serie componentes tanto físicos como psicológicos. Así surge uno de los principales debates acerca de la definición del término, en el que otros autores centraron el énfasis del bienestar únicamente en las experiencias afectivas negativas (Dawkins, 1990; Duncan y Petherick, 1992). El consenso general actual determina que el 
bienestar no se garantiza solo por la ausencia de experiencias negativas sino también por la posibilidad de experimentar al menos algunas situaciones placenteras (Boissy y col., 2007). Algunos de los puntos en discusión en la actualidad radican por ejemplo en determinar si los animales son conscientes o no de los eventos que acontecen a su alrededor (Dawkins, 2017) y en especificar qué especies son sentientes y por lo tanto cuáles deberían ser protegidas por las distintas legislaciones (Birch, 2017).

El bienestar animal depende de los procesos cerebrales que están involucrados en la apreciación subjetiva que tiene cada individuo de su estado interno y de su ambiente. Es por esto que para poder determinar el estado de los animales en términos de un bienestar bueno o deficitario debemos ser capaces de "leer sus mentes" (Van der Harst y Spruijt, 2007). La evaluación del bienestar animal es por lo tanto complicada, debido a que no nos permite obtener una respuesta directa de la misma. La interpretación de indicadores fisiológicos no siempre es sencilla de realizar, ya que situaciones que muy probablemente produzcan estados afectivos opuestos pueden desencadenar la misma respuesta fisiológica. En este sentido, pareciera que al menos algunos indicadores fisiológicos (tales como los glucocorticoides que se desencadenan ante una situación que conlleve un aumento del gasto energético) representan más un indicador de la activación del sistema que de su valencia (o sea, si el animal los percibe como si fuesen positivos o negativos) (Paul y col., 2005). Para sobrellevar esta situación, Fraser propone tres dominios sobre los cuales se pueden desprender indicadores de bienestar animal (Fraser, 2008):

FUNCIONAMIENTO BIOLÓGICO: los animales deberían poseer un correcto crecimiento y desarrollo, evitando estados patológicos. La sola presencia de un agente potencialmente 
patógeno no es determinante para afectar el bienestar de un individuo, pero cualquier modificación sobre la biología que deba generar una corrección por parte del animal para mantener las funciones normales se van a condicionar con la definición de bienestar citada al principio y por lo tanto, las alteraciones que estos introducen pueden ser usados como indicadores de bienestar animal (Broom, 2006). De la misma forma cualquier modificación que se detecte, por ejemplo en determinadas hormonas, cuando el animal deba lidiar con las modificaciones del ambiente, pueden ser usados como indicadores. El ejemplo más frecuentemente citado se corresponde con la respuesta de estrés, en la que su función principal es generar energía rápidamente para enfrentarse a los desafíos ambientales (Hubrecht y Kirkwood, 2010). Esta respuesta generalmente está asociada a dos sistemas, el simpático-adrenomedular (SAM), cuya respuesta es inmediata y produce efectos tales como la liberación de glucosa, piloerección y la dilatación pupilar, y el sistema hipotálamohipófisis-adrenal (HPA), con una respuesta más retardada, y que culmina con la generación de glucocorticoides (Moberg y Mench, 2000).

VIDA NATURAL: los animales deberían poder expresar aquellos comportamientos específicos de especie que están intrínsecamente motivados a realizar, los que se conocen como necesidades comportamentales (Duncan, 1998). Por este motivo, las consecuencias sobre el bienestar van a ser mayores cuando el animal no pueda realizar este tipo de comportamientos, más allá que las necesidades fisiológicas de los mismos se encuentren satisfechas.

ESTADOS AFECTIVOS: los estados afectivos son respuestas comportamentales y fisiológicas que varían en términos de valencia (placentero/ no placentero) e intensidad. 
Muchos autores lo utilizan en reemplazo de la palabra emoción ya que éstos no implican la percepción consciente de las mismas (Paul y col., 2005). Los animales deberían prescindir, siempre que sea posible, de estados afectivos negativos, al mismo tiempo que deberían poder experimentar estados afectivos positivos. Para evaluarlos numerosos autores se valen de metodologías provenientes de las neurociencias, tales como la prueba de campo abierto, el laberinto en cruz elevado, etc., en las que la utilización de pruebas comportamentales para evaluar la eficacia de fármacos para el tratamiento de patologías psiquiátricas se encuentran ampliamente validadas (Olsson y Dahlborn, 2002). En la actualidad también se han desarrollado metodologías, provenientes del campo de la psicología humana, que permiten evaluar estados emocionales positivos en animales tales como la prueba de sesgo cognitivo (Roelofs y col., 2016).

Del apartado anterior se desprende el carácter multidisciplinario de la Ciencia del Bienestar Animal, en la que los tres aspectos se pueden medir a partir de indicadores objetivos independientes entre sí. La decisión sobre qué indicadores tomar como referencia tiene que ver con el área del conocimiento de la cual provenga el investigador y con valores asignados a la persona en una cultura y una sociedad en particular. Las variables sobre las cuales uno establezca el énfasis muchas veces son lo suficientemente independientes como para que al mejorar los indicadores de una de ellas se obtengan resultados completamente diferentes en las otras dos (Fraser, 2003). Por este motivo es posible generar diferencias en las conclusiones obtenidas a partir de una misma situación. Para reducir este sesgo, se deberían ponderar aspectos provenientes de distintas áreas al realizar una evaluación integral del bienestar animal (Fraser, 2008). Por lo tanto, en la investigación reciente en 
bienestar animal se están aplicando enfoques multidisciplinarios para estudiar la mente animal, de forma de poder desarrollar metodologías para "preguntarle" cómo se siente y ser capaces de entender su respuesta en base al comportamiento que desarrolla. Estas herramientas se basan en cómo el animal evalúa subjetivamente su propia situación, adapta su comportamiento y selecciona la respuesta más apropiada para obtener el resultado más satisfactorio (Van der Harst y Spruijt, 2007).

\section{El ratón nude y su uso en experimentación oncológica}

El ratón nude se originó de forma espontánea en el año 1962 a partir de un macho proveniente de una colonia cerrada de ratones albinos exocriados, ubicada en Glasgow, Escocia. De los primeros estudios que se hicieron sobre los mismos, se detectó que estos ratones de vidas cortas carecían de timo y poseían recuentos leucocitarios extremadamente bajos. Estudios posteriores detectaron que la mutación que generaba esta condición tenía un origen autosómico recesivo, que las hembras son fértiles bajo condiciones microbiológicas apropiadas pero presentan dificultades para amamantar a las crías y que los machos en general son fértiles pero ésta puede verse reducida debido a infecciones del tracto genital. Estas características permitieron generar sistemas de cruzamientos a partir de hembras heterocigotas y machos homocigotas recesivos, que producen un 50\% de crías nude. El cruzamiento a partir de un macho y una hembra heterocigota también es posible, aunque en ese caso la eficiencia disminuye, generando un 25\% de crías nude (Rygaard, 1991a).

Originalmente, los xenotrasplantes se realizaban en sitios inmunológicamente privilegiados de roedores normales tales como los abazones de los hámsters (Carbone y Maschi, 2006). 
El establecimiento de colonias de ratones nude permitió que se pudieran desarrollar los primeros trabajos científicos en este modelo animal. El primer reporte en el cual se informó el trasplante de células malignas humanas en un ratón nude ocurrió en 1969 (Rygaard, 1969a). El desarrollo de xenotrasplantes no había sido posible de realizar completamente hasta ese momento, inclusive en animales a los que se les había practicado la timectomía. Esto es debido a que la aplasia de timo en los ratones nude es completa, y las alteraciones morfológicas también se detectan en aquellos órganos en los que se presentan linfocitos T, como el bazo, los linfonódulos y las Placas de Peyer (Rygaard, 1991b). Asimismo, la utilización de este modelo animal permitió el descubrimiento de las células NK, un tipo de células de la inmunidad innata que no requiere de inmunización previa para eliminar células neoplásicas o infectadas con virus (Kiessling, 1975).

Los xenotrasplantes ubicados en el subcutáneo fueron los que primero se desarrollaron en este modelo animal, debido en gran medida a que permite un seguimiento fácil del desarrollo tumoral (Imagen 1.1). La forma de crecimiento de estos tumores normalmente se produce en forma de nódulos móviles, bien irrigados y encapsulados en una fina lámina de tejido conectivo. En general no se produce inflamación a su alrededor, pero si se puede ulcerar o generar tejido necrótico en su interior (Rygaard, 1991a). Cuando se los examina microscópicamente, el tejido suele mantener las mismas características que en el paciente humano. Además, también suelen mantener las mismas características biológicas y bioquímicas que el tumor de origen, lo cual es relevante para evaluar nuevas terapias antineoplásicas (Kyriazis, 1980). 


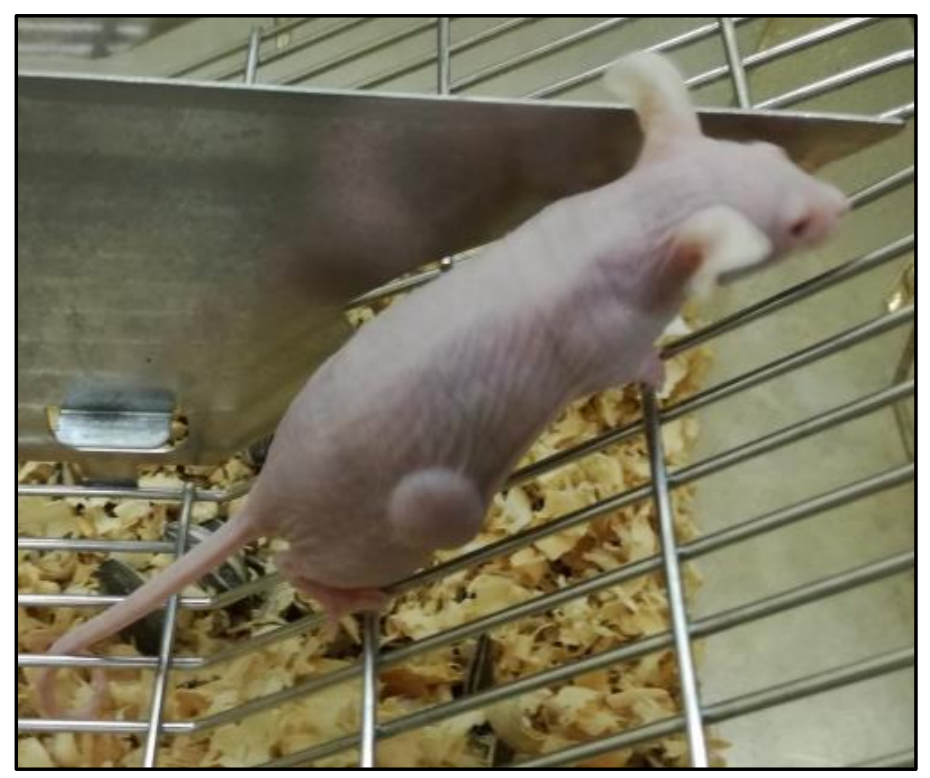

Imagen 1.1. Ratón nude con trasplante tumoral subcutáneo en el flanco derecho.

El trasplante de tumores subcutáneos se realiza inoculando las células tumorales luego de realizar un bolsillo con un trócar u otro instrumental quirúrgico. Para este fin, resulta imperativa la aplicación de un correcto protocolo de anestesia supervisado por un profesional veterinario y además, se recomienda enfáticamente la aplicación de analgesia post-operatoria (Workman, 2010). El subcutáneo en los ratones es un espacio apto para la implantación de los tumores ya que al ser la piel de esta especie sumamente laxa, permite fácilmente el crecimiento tumoral. Las células tumorales pueden ser depositadas en este lugar en forma de bloques sólidos (provenientes porciones extraídas de tumores implantados previamente en otro ratón) o a partir de suspensiones celulares. El área se encuentra bien irrigada, por lo que el suministro de sangre y el drenaje linfático se establecen inmediatamente (Rygaard, 1991a).

En la actualidad, la manifestación del efecto antitumoral en un modelo animal representa una etapa importante en los ensayos preclínicos. En particular, estos modelos animales 
siguen siendo de utilidad para evaluar el potencial citotóxico de drogas nuevas, para seleccionar drogas candidatas para la evaluación clínica, para mejorar los esquemas de dosificación y combinación con otras drogas y para estudiar la resistencia ante distintos compuestos (Kelland, 2004).

\section{Bienestar animal en experimentación oncológica}

Los esfuerzos para mejorar la investigación en modelos animales de patologías oncológicas se siguen incrementando, ya que el porcentaje de éxito de esta área cuando se desea transpolar los resultados obtenidos a estudios con humanos resulta de los más bajos del total (Begley, 2012). Para mejorar la confiabilidad de los mismos, la calidad de la investigación biomédica resulta imprescindible para aumentar dicho porcentaje de éxito. De esta forma es relevante garantizar el bienestar de animales en experimentación oncológica, no solo como una forma de asegurar el manejo ético de los ratones sino también para aumentar la validez de los resultados científicos. Dicho objetivo se logra con investigación específica orientada a dilucidar cómo afectan a los animales los factores que engloban a cada experimento, esto es investigación específica en el campo del bienestar animal, y que sirve para posteriormente refinar los procedimientos experimentales. Es por estos motivos que distintas entidades internacionales han redactado guías de recomendaciones y manuales de procedimientos para mejorar el bienestar de este modelo animal, tal como además es el objetivo de esta tesis doctoral.

La guía más exhaustiva con respecto a la utilización de animales para investigación en oncología corresponde al Comité Coordinador del Reino Unido para la Investigación en 
Cáncer (UKCCCR), que se publicó en 1998 y fue revisada en el año 2010 (UKCCCR, 1998; Workman y col., 2010). Esta establece regulaciones para determinar el punto final humanitario en base a signos clínicos tales como: la ausencia de alimentación en un período de 24-48 hs con la consiguiente deshidratación y emaciación, hipotermia, dificultad respiratoria, parálisis o debilidad de los miembros anteriores, alteración de la locomoción debido al desarrollo tumoral, presencia de vocalizaciones anormales, entre otras.

Sin embargo, la aplicación del punto final humanitario corresponde a una etapa crítica la cual se podría llegar a evitar con un correcto diseño del protocolo experimental. Las guías de recomendaciones en general fallan en describir cómo se pueden discernir alteraciones sutiles en el bienestar que si bien no implican la interrupción de una experiencia, si pueden llegar a incentivar la aplicación de medidas correctivas tales como la utilización de analgesia. En particular, se han publicado pocos trabajos científicos acerca de cómo influye el desarrollo tumoral en el bienestar de ratones con xenotrasplantes subcutáneos, lo que puede deberse a que éstos se consideran generalmente más benignos que los trasplantes ortotópicos (Miller y col., 2016). En uno de esos trabajos, en el que se realizó un trasplante heterotópico con células provenientes de un cáncer de vejiga en un paciente humano, se evaluó el efecto que tuvieron sobre el comportamiento, el peso y la sensibilidad dolorosa. Sin embargo, el desarrollo tumoral no tuvo efectos sobre ninguna de estas variables (Miller y col., 2016). En otro trabajo similar (Jacobsen y col., 2013), se inocularon dos tipos de líneas celulares de cáncer prostático y se evaluaron el peso corporal, el consumo de agua y alimento, la concentración de los metabolitos de la corticosterona en materia fecal y la puntuación obtenida a partir de un índice para evaluar el bienestar animal. A diferencia del 
trabajo anterior, en éste si encontraron una correlación entre el desarrollo tumoral y los parámetros analizados. Es por estos motivos que la conclusión acerca del impacto que tiene sobre el bienestar la experimentación oncológica cuando se utilizan xenotrasplantes subcutáneos debería realizarse sobre cada caso en particular, teniendo en cuenta las características de las líneas celulares (por ejemplo con la tasa de crecimiento y la generación de metabolitos inflamatorios) y las cepas de ratones utilizadas (por ejemplo el umbral de percepción dolorosa). Así, la descripción de distintas técnicas que pueden ser utilizadas en pruebas piloto y a lo largo de los distintos protocolos experimentales cobra importancia para refinar los procedimientos en los que se utilice este modelo animal.

\section{Identificación de puntos críticos que pueden afectar negativamente el bienestar de este modelo animal}

El resultado de la integración de las experiencias positivas y negativas son las que determinan el estado de bienestar de un animal. Así, un bienestar deficitario no se condiciona necesariamente con situaciones puntuales placenteras o aversivas, sino con el desequilibrio crónico entre estas dos que provocan que el animal no sea capaz de lidiar con el ambiente que lo rodea (Van der Harst y Spruijt, 2007). Cada protocolo experimental va a generar un desequilibrio acorde con las distintas maniobras que se deban realizar por lo que la identificación de los mismos permitirá generar planes de contingencia para evitar el sufrimiento innecesario de los ratones. Los siguientes ítems corresponden a los puntos críticos que podrían llegar a afectar el bienestar de los ratones que poseen trasplantes tumorales subcutáneos: 


\section{Alojamiento}

La estandarización ambiental consiste en mantener determinadas condiciones ambientales constantes, de forma de reducir al mínimo la variabilidad entre laboratorios (Richter y col., 2009). Así, la mayoría de los ratones de experimentación, que es la especie que concierne al presente trabajo, son mantenidos en cajas relativamente pequeñas (tipo "cajas de zapato") sólo con viruta o algún otro material absorbente de cama y agua y alimento ad libitum. Por lo tanto, bajo las condiciones estándar de alojamiento los ratones poseen muy pocas oportunidades de establecer comportamientos específicos de especie, tales como explorar, esconderse, forrajear, roer y realizar el nido (Olsson y Dahlborn, 2002). El impedimento para realizar comportamientos naturales repercute sobre el bienestar al imposibilitar al animal de satisfacer sus motivaciones internas (Mason y Burn, 2011).

\section{Manejo de los ratones}

Además del estrés crónico que genera la frustración constante por no poder generar comportamientos altamente motivados (tales como realizar conductas de huida ante una interacción agonística o permitirles la búsqueda de alimentos de variada índole) y el aburrimiento por no tener sustratos en el ambiente biológicamente relevantes sobre los cuales generar comportamientos, los roedores de experimentación se enfrentan a situaciones puntuales de estrés agudo debidas a las prácticas rutinarias de manejo, que generan alteraciones en la fisiología y en el comportamiento de los individuos (Balcombe y col., 2004). En particular, no sólo el procedimiento en sí resulta aversivo para el animal sino la baja predictibilidad de los eventos estresantes asociados al manejo diario (Koolhaas y col., 2011). 
La sujeción a través de la base de la cola es una de las maniobras que más se utilizan sobre esta especie, por ejemplo para cambiarlos de caja o previo a la completa inmovilización. Este procedimiento aparentemente inofensivo tiene implicancias sumamente profundas en la investigación biomédica, al punto de aumentar la ansiedad en pruebas comportamentales en las que se evalúa esta variable (Gouveia y Hurst, 2013), fallar en la performance en pruebas que tienen un componente de aprendizaje (Gouveia y Hurst, 2017) y cambiar completamente la respuesta de los ratones a las recompensas, un comportamiento que se suele asociar a estados depresivos en humanos (Clarkson y col., 2018). Al respecto se ha demostrado que los ratones prefieren la sujeción "en copa” (sujetándolos con ambas manos formando un cuenco) o utilizando un túnel (Hurst y West, 2010).

\section{Dolor}

El dolor en animales se define como una experiencia sensorial aversiva causada por un daño potencial o real y que promueve reacciones motoras y vegetativas de protección, lo que resulta en comportamientos para evitar dicha amenaza y que además puede llegar a alterar el comportamiento específico de especie (Zimmerman, 1986). De esta forma, el dolor implica un componente emocional por lo que se lo diferencia de nocicepción, que es el mecanismo fisiológico a través del cual se transmite información proveniente de los nociceptores hacia el cerebro. La forma en que las distintas especies manifiestan el dolor va a depender de la especie en cuestión y de la presencia del observador humano, por lo cual su evaluación muchas veces resulta complicada y requiere de un entrenamiento previo. La reducción del peso corporal y del consumo de agua y alimento han sido usados como indicadores sencillos de dolor, sobre todo en el período post-operatorio (Jacobsen y col., 
2012). De la misma forma, la respuesta a la terapia analgésica puede ser un indicador de que un procedimiento resulta doloroso para el animal, pero ello requeriría ser capaz de distinguir indicadores de dolor previo. La respuesta fisiológica ante un dolor agudo podría llegar a utilizarse para este fin, pero en roedores de laboratorio y en particular en ratones estos indicadores son difíciles de medir debido al pequeño tamaño de los mismos y también, tal como fue descripto en el apartado anterior, la restricción del movimiento que muchas veces es necesaria para tomar muestras y que muy probablemente modifica dichas variables.

Procedimiento quirúrgico (dolor agudo): el procedimiento de trasplante tumoral claramente va a producir una injuria sobre los tejidos por lo que, al activarse los nociceptores correspondientes, se va a generar dolor. Sin embargo, esto se puede anticipar realizando un procedimiento anestésico y analgésico adecuado a esta cirugía. Debido al correcto manejo analgésico y a que la técnica de trasplante tumoral corresponde un procedimiento menor, inferimos que el efecto que puede tener sobre el bienestar animal es relativamente leve. De todas formas, los animales se deberían controlar diariamente para descartar efectos adversos indeseables que puedan llegar a manifestar un aumento del estímulo doloroso tales como: disminución de la condición corporal, complicaciones de la herida quirúrgica (presencia de inflamación, supuración o necrosis), apariencia general del animal (descargas nasales u oculares debidas a la disminución del acicalamiento), cambios en el comportamiento debidos al desarrollo tumoral (alteración en la marcha, dolor o aumento del acicalamiento en el lugar de desarrollo tumoral), características y tamaño tumoral. Las posturas antiálgicas también pueden indicarnos que la terapia analgésica no 
fue aplicada correctamente (Wright-Williams y col., 2007). La presencia de dolor más sutil muchas veces es difícil de evaluar en esta especie, sin embargo se han realizado avances para determinarlo. Así por ejemplo se ha descripto una forma para evaluar el dolor basado en las expresiones faciales, en el que se toman distintas unidades de medida para poder obtener un índice global de la expresión dolorosa (Langford y col., 2010). Además, se han utilizado indicadores comportamentales tales como la motivación para realizar el nido, que se desarrollarán en más profundidad en los capítulos siguientes.

Desarrollo tumoral (dolor crónico): el dolor crónico puede ser difícil de manejar debido a que la administración prolongada de antiinflamatorios no esteroideos (AINEs) acarrea numerosos efectos colaterales; se diferencia del anterior en que generalmente se debe a la degeneración o destrucción tisular (tal como en osteoartritis o en cáncer) y no mejora en el tiempo. Los modelos animales de dolor oncológico hasta el momento se han centrado en aquellos que provocan la destrucción de órganos altamente dolorosos (como es el caso del osteosarcoma) (Pacharinsak y Beitz, 2008). Contrariamente a lo que se podría llegar a observar al extrapolar en estudios en humanos, en modelos de cáncer pancreático se observó una baja manifestación de comportamientos asociados al dolor hasta estadios avanzados del mismo (Lindsay y col., 2005), lo que claramente demuestra la dificultad de evaluarlo.

\section{Objetivos}

A partir del marco teórico desarrollado hasta el momento, se desprenden los siguientes objetivos para esta tesis doctoral. 


\section{Objetivo general}

Determinar el impacto del desarrollo de la línea tumoral humana A549 en el bienestar de ratones del stock NLAE:NIH(S)-Fox $1^{\text {nu }}$ trasplantados con la misma y evaluar el efecto del enriquecimiento ambiental sobre el desarrollo tumoral.

\section{Objetivos especificos}

1. Evaluar cambios en la fisiología de los ratones del stock NLAE:NIH(S)- Fox $1^{n u}$ trasplantados con la línea tumoral humana A549, compatibles con una reducción global de su bienestar.

2. Estudiar, a través de un etograma, las frecuencias de comportamientos en ratones del stock NLAE:NIH(S)- Fox $1^{n u}$ con un trasplante de la línea tumoral humana A549 en la caja donde normalmente habitan.

3. Evaluar las diferencias en la performance en distintas pruebas conductuales (burrowing/urine sniffing/novelty suppressed feeding/nesting/sesgo cognitivo) del stock NLAE:NIH(S)- Fox $1^{n u}$ con un trasplante de la línea tumoral humana A549.

4. Evaluar las diferencias en el desarrollo tumoral en ratones del stock NLAE:NIH(S)Fox $^{\text {nu }}$ mantenidos en cajas enriquecidas y no enriquecidas. 


\section{Procedimientos generales y diseño experimental}

Excepto que se especifique lo contrario en algún apartado en particular, los materiales y procedimientos que fueron comunes a la mayoría de los experimentos y que abarcaron a esta tesis doctoral se describen a continuación.

\section{Materiales y métodos}

Animales

Se utilizaron ratones machos y hembras nude de entre 3 y 4 semanas de edad del stock NLAE:NIH(S)-Fox $1^{\text {nu }}$, provenientes del Laboratorio de Animales de Experimentación de la Facultad de Ciencias Veterinarias, UNLP. Los mismos estuvieron libres de los siguientes microorganismos controlados regularmente, por lo cual se consideraron SPF (Libres de Patógenos Específicos):

Virus: parvovirus del ratón, virus diminuto del ratón, reovirus tipo 3, virus de la hepatitis del ratón, encefalomielitis del ratón.

Bacterias: Citrobacter rodentium, Clostridium piliformis, Corynebacterium Kutscheri, Corynebacterium bovis, Klebsiella oxytoca, Klebsiella pneumoniae, Pasteurella pneumotropica, Proteus miriabilis, Pseudomonas aeruginosa, Salmonella spp., Staphilococcus aureus, Streptococcus pneumoniae, Streptococcus $\beta$ hemolítico. 
Parásitos: Apisculuris tetráptera, Entamoeba muris, Eimeria spp, Giardia muris, Hymenolepis spp., Myobia musculi, Mycoptes musculinus, Notoedres spp., Polyplax spp., Psorergates spp., Radfordia spp., Spironucleus muris, Trichomonas spp., Syphacia obyelata, Sarcoptes scabiei.

\section{Alojamiento}

Los animales se alojaron en la sala de experimentación del LAE-FCV-UNLP, bajo condiciones SPF, en un rack ventilado marca Lab Products, en cajas individualmente ventiladas modelo "Super Mouse $750^{\mathrm{TM}}\left(480 \mathrm{~cm}^{2}\right)$ ", con 34 cambios de aire por hora con presión positiva. Las cajas fueron provistas de lecho de marlo de maíz; agua y alimento extrusado para rata y ratón marca Cooperación (Cooperación, Alicooper S.A., Santa Fe, Argentina) ad libitum. Excepto en los casos que se especifique lo contrario, todas las cajas fueron provistas de papel tipo tissue para permitirle a los ratones construir el nido. Todos estos insumos fueron esterilizados mediante autoclave a $121^{\circ} \mathrm{C}$ y las cajas se cambiaron una vez por semana. Los animales se mantuvieron a una temperatura ambiente de $22 \pm 2{ }^{\circ} \mathrm{C}$ con un ciclo lumínico de 12:12 hs luz/oscuridad (las luces se encendieron a las 7 am).

\section{Técnica de trasplante tumoral}

Se utilizó la línea celular A549, originaria de un adenocarcinoma de pulmón humano. Para inocular los ratones, se utilizó tejido tumoral de esta línea tumoral proveniente de otro ratón que fue trasplantado previamente con dicho tejido. Se obtuvieron los fragmentos del mismo de aproximadamente $3 \mathrm{~mm}^{3}$ que se transfirieron a aproximadamente $10 \mathrm{ml}$ de Medio Mínimo Escencial (MEM) antes de ser inoculados en el flanco derecho o izquierdo 
utilizando un trócar.

Para el procedimiento los ratones se anestesiaron con ketamina/xilacina en dosis de 100-10 $\mathrm{mg} / \mathrm{kg}$ i.p., respectivamente. No se les realizó ayuno previo y la temperatura ambiente se mantuvo a $25^{\circ} \mathrm{C}$ para prevenir la hipotermia. La analgesia intraoperatoria se proveyó mediante la xilacina (administrada para la anestesia) y 1\% de lidocaína aplicada en el sitio de la inoculación. Como este fue un procedimiento menor, sólo se administró una única dosis de tramadol $(10 \mathrm{mg} / \mathrm{kg})$ antes de que termine el procedimiento y se realizó un seguimiento de los animales con el fin de evitar el sufrimiento innecesario de los mismos.

La cirugía se realizó en un flujo laminar con materiales quirúrgicos esterilizados mediante autoclave de vapor. Antes de comenzar el procedimiento, la piel se limpió con iodopovidona. Se efectuó una incisión pequeña (de aproximadamente 0,4 cm) en el flanco y posteriormente se realizó un túnel subcutáneo de aproximadamente $1,5 \mathrm{~cm}$ antes de depositar el fragmento tumoral.

Debido a que sólo se realizó una incisión pequeña, los márgenes de la herida quirúrgica permanecieron cerca y por consiguiente, no fue necesario suturarla. La duración total del procedimiento fue de aproximadamente 5 minutos y posteriormente, los ratones permanecieron sobre una almohada térmica hasta que se recuperaron de la anestesia. Se administró oxígeno, en caso de ser necesario, ante la presencia de mucosas cianóticas.

Los animales se supervisaron diariamente hasta la finalización de cada experimento para controlar posibles complicaciones del procedimiento quirúrgico y signos de sufrimiento tales como: condición corporal, complicaciones asociadas a la herida quirúrgica (presencia de inflamación, necrosis, drenaje de fluidos o supuración), apariencia general del ratón y comportamiento (descargas nasales u oculares debidas a la falta de acicalamiento, presencia 
de ratones durmiendo por fuera del nido, calidad del nido, aumento de la agresión), cambios comportamentales debidos específicamente al crecimiento del tumor (marcha o locomoción alterada, aumento del acicalamiento o nocicepción en el sitio del tumor), apariencia general de la piel; características y tamaño tumoral.

\section{Tamaño tumoral}

Los tumores se midieron con un calibre o con el nuevo método de medición fotográfico no aversivo (descripto en los capítulos posteriores). Para determinar el volumen tumoral se tomaron dos medidas a cada tumor: el diámetro mayor se consideró el largo y el diámetro menor el ancho. Posteriormente, el volumen tumoral se calculó a partir de la fórmula modificada para la determinación del volumen de un elipsoide $\left[1 / 2 \mathrm{x}\right.$ largo $\mathrm{x}$ ancho $\left.{ }^{2}\right]$ (Tomayko y Reynolds, 1989).

Determinación de los metabolitos de la corticosterona en materia fecal

Las muestras se procesaron de acuerdo con el protocolo de Touma y col. (Touma y col., 2004) con leves modificaciones: se pesó 0,1 g de materia fecal húmeda, a la que se les agregó $1 \mathrm{ml}$ de metanol al 80\%. Las muestras fueron incubadas a temperatura ambiente $\left(21^{\circ} \mathrm{C}\right)$ durante 120 minutos en agitador orbital. Una vez transcurrido ese tiempo, las muestras se agitaron en vórtex durante 10 segundos y finalmente, se centrifugaron a $\sim 500 \mathrm{~g}$ durante 20 minutos, a fin de separar los detritos. El sobrenadante se almacenó a $-20^{\circ} \mathrm{C}$ hasta su posterior procesamiento. 
Se realizaron inmunoensayos enzimáticos (EIA) sobre diluciones seriadas de un pool de extractos de materia fecal, obteniendo curvas de desplazamiento paralelas a la curva de estándares correspondiente a la hormona de interés $\left(\mathrm{r}^{2}=0,96\right)$. Se estableció, de esta manera, que la dilución adecuada para la determinación de los metabolitos de corticosterona presentes en las muestras, era de 1:11. Por lo cual, una alícuota del sobrenadante fue diluida con buffer fosfato ( $\mathrm{pH} 7)$ previo al dosaje.

La concentración de metabolitos de corticosterona presentes en los extractos fecales se determinó utilizando la técnica de EIA con un anticuerpo policlonal y sus correspondientes conjugados de peroxidasa para la detección de corticosterona (corticosterona CJM006, Department of Population Health and Reproduction, Coralie Munro, UC Davis, CA, USA).

Los inmunoensayos fueron realizados de acuerdo a la técnica descripta por Munro y Lasley (Munro y Lasley, 1988). Para ello se utilizaron microplacas de fondo plano (Nunc Maxisorp, VWR, Mississauga, ON, Canadá) recubiertas con $50 \mu 1$ de anticuerpo diluido en solución buffer de recubrimiento ( $50 \mathrm{mM}$ de buffer bicarbonato, $\mathrm{pH}$ 9.6, dilución 1:15000); las placas luego se cubrieron con selladores de acetato para evitar la evaporación, y se incubaron durante la noche a $4^{\circ} \mathrm{C}$. Luego de 16-24 horas, a fin de eliminar las moléculas de anticuerpo no unido, las placas fueron lavadas con una solución de Tween 20 al 0,02 \% utilizando un lavador automático de microplacas (Bio-Tek Elx $50 \mathrm{~V}$, Bio-Tek Instruments). Inmediatamente después del lavado, se añadieron por duplicado a la microplaca $50 \mu 1$ de los extractos fecales, de los estándares y de los controles, seguido por la adición de $50 \mu 1$ del conjugado de peroxidasa correspondiente a la hormona de interés (dilución 1:70000). A continuación, las placas se cubrieron e incubaron a temperatura ambiente $\left(21^{\circ} \mathrm{C}\right)$ durante 2 
hs en agitador orbital. Posteriormente, éstas se lavaron y secaron con papel secante, agregando inmediatamente $100 \mu 1$ de solución sustrato $(50 \mathrm{mM}$ de citrato, $1,6 \mathrm{mM}$ de peróxido de hidrógeno, $0,4 \mathrm{mM}$ de 2,20-azino-di-(3-etilbenzotiazolin sulfónico) sal de diamonio, $\mathrm{pH}$ 4). Finalmente, se midió la absorbancia a $405 \mathrm{~nm}$ utilizando un lector de microplacas (Thermo Electron Corporation, USA). La sensibilidad del ensayo fue de 0,078 $\mathrm{ng} / \mathrm{ml}$.

\section{Diseño experimental}

\section{Experimento 1}

Determinación de variables comportamentales y fisiológicas en hembras nude. Para este experimento se utilizaron 58 hembras nude. En cada uno de los períodos de tiempo indicados (15-30-45 días postrasplante) se procedió a realizar una serie de pruebas según la siguiente cronología: primero se llevó a cada ratón individualmente a una caja idéntica a la que habitan normalmente con lecho de marlo de maíz, donde se filmó el comportamiento espontáneo durante 20 minutos, cada ratón permaneció alojado individualmente en esa misma caja y en la última hora de ese mismo día se colocaron los dos discos de algodón. Al día siguiente, luego de analizar la calidad del nido y la condición corporal se realizó el "burrowing test" y al finalizar, se recolectaron todos los pellets de materia fecal de cada caja. Al finalizar se volvieron a juntar manteniendo los grupos originales. A los 45 días postrasplante se realizó misma secuencia pero además al finalizar se agregaron dos nuevos test que se hicieron los días siguientes: el "Novelty Supressed Feeding (NSF)" test y el "Urine Sniffing (US)" test. Al finalizar se sacrificaron los ratones mediante inhalación de 
dióxido de carbono e inmediatamente después se recolectó sangre para realizar el hemograma mediante punción cardíaca.

\begin{tabular}{|c|c|c|c|c|}
\hline 0 días & 15 días & 30 días & \multicolumn{2}{|l|}{45 días } \\
\hline & & & & Hemograma \\
\hline $\begin{array}{l}\text { Trasplante } \\
\text { tumoral }\end{array}$ & $\begin{array}{l}\text { - Burrowing test } \\
\text { - Nesting test } \\
\text { - Comportamiento } \\
\text { espontáneo en la caja } \\
\text { - Condición corporal }\end{array}$ & $\begin{array}{l}\text { - Burrowing test } \\
\text { - Nesting test } \\
\text { - Comportamiento } \\
\text { espontáneo en la caja } \\
\text { - Condición corporal }\end{array}$ & \multicolumn{2}{|c|}{$\begin{array}{l}\text { - Burrowing test } \\
\text { - Nesting test } \\
\text { - Comportamiento } \\
\text { espontáneo en la caja } \\
\text { - Condición corporal } \\
\text { - Corticosterona (MF) } \\
\text { - NSF test } \\
\text { - US test }\end{array}$} \\
\hline
\end{tabular}

Figura 2.1. Línea temporal del experimento 1.

Experimento 2

Determinación de variables comportamentales y fisiológicas en machos nude (Figura 2.2). Se tuvo que utilizar un diseño experimental distinto ya que en animales adultos de este género se producen peleas cuando se alteran los grupos. A los 45 días se procedió a realizar, en 40 machos nude, los distintos ensayos de forma similar a como se realizaron con las hembras: primero se llevó a cada ratón individualmente a una caja idéntica a la que habitan normalmente con marlo de maíz, donde se filmó el comportamiento espontáneo durante 20 minutos, en donde también se evaluó la condición corporal. Los días posteriores se realizaron las siguientes pruebas en días sucesivos: el "burrowing test", el "Novelty Supressed Feeding" (NSF) test (en donde también se recolectaron los pellets de materia fecal para determinar la concentración de los metabolitos de la corticosterona) y el "Urine Sniffing" (US) test. Al finalizar se sacrificaron los ratones mediante inhalación de dióxido de carbono. 


\begin{tabular}{|c|c|c|c|}
\hline 0 días & 15 días & 30 días & 45 días \\
\hline $\begin{array}{l}\text { Trasplante } \\
\text { tumoral }\end{array}$ & Condición corporal & Condición corporal & $\begin{array}{l}\text { - Burrowing test } \\
\text { - Comportamiento } \\
\text { estpontáneo en la caja } \\
\text { - NSF test } \\
\text { - US test } \\
\text { - Corticosterona (MF) } \\
\text { - Condición corporal }\end{array}$ \\
\hline
\end{tabular}

Figura 2.2. Línea temporal del experimento 2.

Experimento 3

Evaluación del bienestar de ratones nude machos y hembras mediante la técnica de sesgo cognitivo (Figura 2.3). Se utilizaron 19 machos y 22 hembras nude, la mitad de los cuales recibieron el trasplante tumoral y permanecieron alojados en grupos de cinco animales por caja hasta los 30 días pos-trasplante. Transcurrido dicho período se procedió a entrenar a los ratones para discernir los distintos estímulos que se les presentaron en la técnica de sesgo cognitivo. A los 16 días de comenzado dicho entrenamiento se expuso a los animales al estímulo ambiguo para poder inferir su estado emocional a partir de la interpretación de dicho evento.

\begin{tabular}{|c|c|c|}
\hline 0 días & 30 días & 46 días \\
\hline $\begin{array}{l}\text { Trasplante } \\
\text { tumoral }\end{array}$ & Inicio entrenamiento & $\begin{array}{l}\text { Exposición al } \\
\text { estímulo ambiguo }\end{array}$ \\
\hline
\end{tabular}

Figura 2.3. Línea temporal del experimento 3. 


\section{Experimento 4}

Comparación del bienestar en 20 ratones hembra con trasplantes tumorales subcutáneos utilizando dos técnicas de medición de tumores (Calibre vs el Método Fotográfico de Medición no Aversivo) mediante el análisis del efecto inmediato que tuvieron ambos métodos sobre la glucosa sanguínea y el comportamiento en una prueba para evaluar estados de ansiedad. Además al finalizar se evaluó la variabilidad intra-observador de ambos métodos y se los comparó con un método de referencia (Figura 2.4).

\begin{tabular}{|lccc|}
\hline 0 días & $4^{\circ}$ semana & $5^{\circ}$ semana & $6^{\circ}$ semana \\
\hline $\begin{array}{l}\text { Trasplante } \\
\text { tumoral }\end{array}$ & & $\begin{array}{l}\text { Peso tumoral y } \\
\text { volumen de } \\
\text { desplazamiento } \\
\text { de agua }\end{array}$ \\
\hline
\end{tabular}

Figura 2.4. Línea temporal del experimento 4.

\section{Experimento 5}

Evaluación del efecto a largo plazo sobre el bienestar de ratones nude con trasplantes tumorales subcutáneos utilizando dos técnicas de medición de tumores, Calibre vs el Método Fotográfico de Medición no Aversivo (Figura 2.5). Se utilizaron 20 hembras y 16 machos nude. Se evaluó a lo largo de cuatro semanas el efecto inmediato que tuvieron ambas técnicas sobre la interacción voluntaria de los ratones con el experimentador y en los metabolitos de la corticosterona en materia fecal (esta última 24 horas post-medición). 


\begin{tabular}{|c|c|c|c|c|}
\hline 0 días & $2^{\circ}$ semana & $3^{\circ}$ semana & $4^{\circ}$ semana & $5^{\circ}$ semana \\
\hline $\begin{array}{l}\text { Trasplante } \\
\text { tumoral }\end{array}$ & 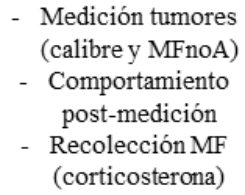 & 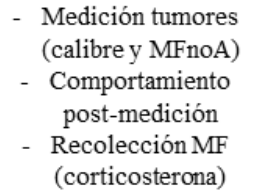 & $\begin{array}{c}\text { - Medición tumores } \\
\text { (calibre y MFnoA) } \\
\text { - Comportamiento } \\
\text { post-medición } \\
\text { - } \begin{array}{c}\text { Recolección MF } \\
\text { (corticosterona) }\end{array}\end{array}$ & $\begin{array}{c}\text { - Medición tumores } \\
\text { (calibre y MFnoA) } \\
\text { - Comportamiento } \\
\text { post-medición } \\
\text { - Recolección MF } \\
\text { (corticosterona) }\end{array}$ \\
\hline
\end{tabular}

Figura 2.5. Línea temporal del experimento 5.

\section{Experimento 6}

Refinamiento de las condiciones de alojamiento en ratones nude con trasplantes tumorales subcutáneos: efecto sobre el desarrollo tumoral (Figura 2.6). Se evaluó a lo largo de cinco semanas, en 20 hembras y 20 machos nude, el volumen tumoral en ratones alojados en cuatro tipos de condiciones ambientales.

\begin{tabular}{|c|c|c|c|c|c|c|}
\hline 0 días & 30 días & 44 días & 51 días & 58 días & 65 días & \multirow[b]{2}{*}{$\begin{array}{l}\text { Peso ratón, } \\
\text { bazo, tumor }\end{array}$} \\
\hline & & & & & & \\
\hline $\begin{array}{l}\text { Inicio } \\
\text { enriquecimiento } \\
\text { ambiental }\end{array}$ & $\begin{array}{l}\text { Trasplante } \\
\text { tumoral }\end{array}$ & $\begin{array}{c}\text { - Peso ratón } \\
\text { - Volumen tumoral } \\
(\text { MFnoA })\end{array}$ & $\begin{array}{c}\text { - Peso ratón } \\
\text { - Volumen tumoral } \\
\text { (MFnoA) }\end{array}$ & $\begin{array}{c}\text { - Peso ratón } \\
\text { - Volumen tumoral } \\
(\text { MFnoA })\end{array}$ & $\begin{array}{r}\text { - Peso } \\
\text { - Volumen } \\
(\mathrm{MF}\end{array}$ & $\begin{array}{l}\text { atón } \\
\text { tumoral } \\
\text { oA) }\end{array}$ \\
\hline
\end{tabular}

Figura 2.6. Línea temporal del experimento 6.

\section{Análisis estadístico}

Para realizar los cálculos estadísticos se utilizaron los programas R 3.3.0, RSstudio (2016)

e InfoStat (2015).

Transformación de datos: 
- Datos cuantitativos continuos: se evaluó la normalidad de los mismos mediante la prueba de normalidad de Shapiro-Wilks. En caso de que valores no hayan sido normales se realizó una transformación logarítmica de los mismos.

- Datos cuantitativos discontinuos: para evitar el sesgo que produce la distribución de Poisson en estas variables, los valores comportamentales se transformaron utilizando la raíz cuadrada: $[\sqrt{ }(x+1)]$.

En caso de que la transformación de los datos no haya permitido alcanzar la normalidad de los mismos, se procedió a analizar las distintas variables con metodologías no paramétricas. Las mismas se describen para cada caso en particular.

\section{Aspectos éticos}

Los trabajos de experimentación realizados en el marco de esta Tesis Doctoral fueron aprobados por el Comité para el Cuidado y Uso de los Animales de Laboratorio (CICUAL) de la Facultad de Ciencias Veterinarias de la Universidad Nacional de La Plata (FCVUNLP), con el número de protocolo 42-1-14T. Además, se adhirió con la Guía para el Cuidado y Uso de los Animales de Laboratorio ("The Guide") (Institute of Laboratory Animal Resources Committee, 2011) y la Guía para el Uso y Bienestar de los Animales en Investigación en Cáncer (Workman y col., 2010c). 


\section{Evaluación del bienestar animal mediante indicadores fisiológicos}

La salud y el funcionamiento apropiado de los distintos sistemas del cuerpo fueron (y continúan siendo) un conjunto de indicadores utilizados para evaluar el bienestar animal (Fraser, 2008). De esta forma, el compromiso de la integridad física debido a enfermedades, heridas o alteraciones morfológicas es una metodología sencilla para reconocer y cuantificar una disminución en el mismo (Dawkins, 2006). Además, la determinación del estatus sanitario y del punto final humanitario mediante indicadores prácticos, rápidos y no invasivos es imprescindible para los experimentos en los que se utilizan animales de laboratorio (Ullman-Culleré y Foltz, 1999). El peso se corresponde a uno de estos indicadores, y en las guías de recomendaciones en investigación oncológica una disminución de este parámetro por encima del $20 \%$ es indicador de eutanasia (Workman y col., 2010c). Sin embargo, el desarrollo tumoral puede ser un factor de confusión por lo que la condición corporal podría ser un parámetro más confiable cuando se desea analizar cómo varió el peso en función del tiempo.

Conjuntamente con los indicadores de salud física, la respuesta de estrés constituye otro indicador clásico cuando se desea evaluar el estado de un animal en relación al medio que lo rodea. Esto es debido a que el estrés es un término empleado para describir tanto a aquellos factores que requieren mecanismos de adaptación como la respuesta del organismo a esos desafíos (Mormède y col., 2007). De esta forma, el término "estrés" muchas veces genera confusiones en su definición ya que se utiliza para describir el estímulo que genera 
la respuesta, la respuesta propiamente dicha y la experiencia subjetiva asociada a la respuesta de estrés (Levine y Ursin, 1991). La magnitud depende por un lado de las expectativas que fueron adquiridas a lo largo de la vida del animal y por el otro del abanico de respuestas que dispone el individuo. El estrés propiamente dicho es una respuesta de alarma, esto es, un incremento en la activación de los sistemas involucrados para generar una respuesta apropiada a los distintos desafíos. Por lo tanto, dicha reacción es imprescindible para la supervivencia y sólo genera efectos patológicos cuando ésta es sostenida a lo largo del tiempo (Eriksen y col., 2005).

La respuesta de estrés está conformada principalmente por dos elementos: el sistema simpático-adrenomedular (SAM) y el sistema hipotálamo-hipófisis-adrenal (HPA) (Moberg y Mench, 2000). De esta forma, la activación del sistema nervioso autónomo ante un estímulo estresante afecta una serie diversa de sistemas biológicos, que incluye los sistemas cardiovascular y digestivo, las glándulas exócrinas y la médula adrenal. Como resultado, se generan cambios por ejemplo en la presión sanguínea, la frecuencia cardíaca, el metabolismo de la glucosa y la actividad gastrointestinal. Sin embargo, debido a que estos cambios son de corta duración, podría asumirse que el efecto que tiene a largo plazo la activación del SAM sobre el bienestar animal no sería significativo (Moberg y Mench, 2000). Por el contrario, las hormonas secretadas por el sistema HPA generan efectos extensos y a largo plazo en el organismo. Así, prácticamente todas las funciones biológicas se ven afectadas por el estrés, e incluyen la respuesta inmune, la reproducción, el metabolismo, el comportamiento, entre otras (Moberg y Mench, 2000). El mismo constituye el eje hormonal más estudiado y consecuentemente, los cambios en la 
circulación plasmática de los glucocorticoides hormonales (cortisol o corticosterona, según la especie) muchas veces se han equiparado con la respuesta de estrés. Sin embargo, también se ha descripto que la secreción de otras hormonas tales como la prolactina y la hormona de crecimiento son igualmente sensibles ante un estresor. Igualmente, tanto la hormona liberadora de tirotropina (TSH) como las gonadotrofinas (luteinizante-LH y folículo estimulante-FSH) están moduladas directa o indirectamente por el estrés (Moberg y Mench, 2000).

En particular la corticosterona, el principal glucocorticoide en roedores, se libera según el ritmo circadiano, con picos máximos durante las primeras horas del período de oscuridad y mínimos las primeras horas del ciclo lumínico (Atkinson y Waddell, 1997). Sus metabolitos fecales presentan la misma curva de liberación, pero con un retraso de entre 6 y 9 horas (Cavigelli y col., 2005). Esta curva puede verse alterada, aumentando su liberación, ante una situación de estrés agudo (Zimmermann y Critchlow, 1967). Así, el efecto biológico inmediato presente en los desafíos agudos fue extensamente estudiado, y la respuesta de alarma generada ante la mayoría de los estresores activa los sistemas de forma relativamente estandarizada. Sin embargo, si el estímulo se sostiene por un tiempo lo suficientemente prolongado, los niveles sistémicos de corticoides regresan al nivel basal aunque se detecte una activación sostenida del eje HPA (Linklater y col., 2010). Debido a que la mayoría de los factores que atentan en contra del bienestar de los animales de experimentación son de tipo crónico, se debería atender principalmente a elucidar los mecanismos de readaptación que produce el organismo (Korte y col., 2007). De esta forma, aquellos animales que deben enfrentar situaciones que sobrepasan sus capacidades de 
adaptación pueden llegar a desarrollar úlceras gástricas, hipertensión, falla cardíaca, inmunosupresión y cambios en la bioquímica del cerebro (Ursin y Eriksen, 2010).

\section{Materiales y métodos}

\section{Tamaño tumoral}

Los tumores se midieron a los 15, 30 y 45 días utilizando un calibre tal como fue descripto en el capítulo anterior.

\section{Condición corporal}

La condición corporal (CC) se determinó según la escala propuesta por Ullman-Culleré (1999), que consiste en la división en cinco grupos según distintas características físicas (Imagen 3.1), que se describen a continuación:

- CC 1: el ratón está emaciado, las prominencias óseas se observan fácilmente con muy poca o ninguna cobertura muscular, se observa claramente la segmentación de las vértebras.

- CC 2: el ratón está sub-nutrido, la segmentación de la columna es evidente, los huesos dorsales de la pelvis son palpables

- CC 3: estado nutricional ideal, las vértebras y los huesos dorsales de la pelvis no son prominentes pero se palpan con una leve presión

- CC 4: levemente por encima del peso ideal, no se observa la segmentación de las vértebras y éstas son palpables sólo utilizando una presión firme 
- CC 5: el animal está obeso, desaparece la estructura ósea por debajo de los músculos y la grasa subcutánea.

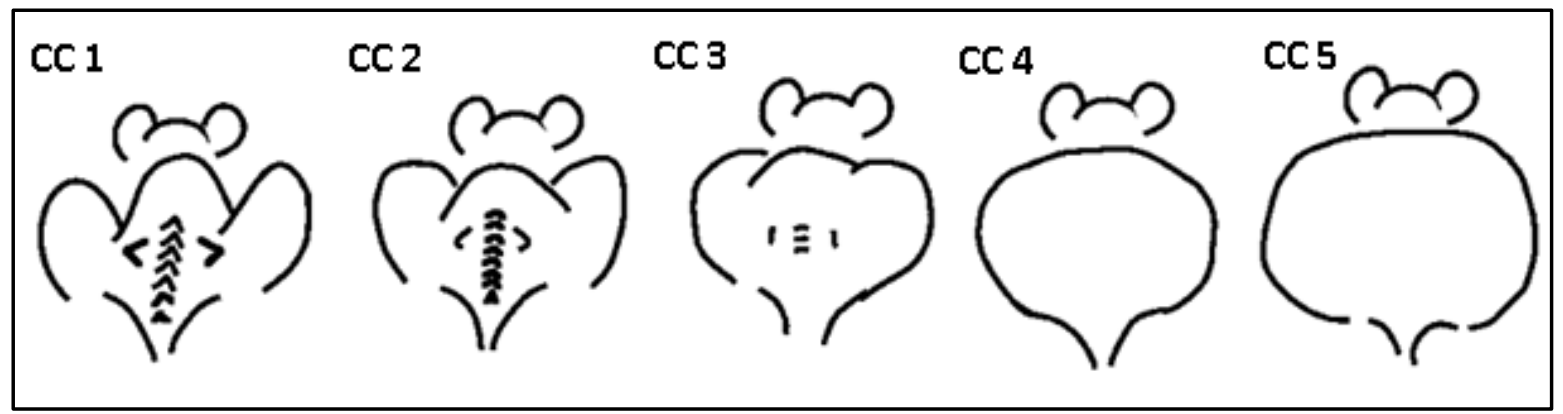

Imagen 3.1. Condición corporal en ratón (CC 1-5). Adaptado de Ullman-Culleré y Foltz, 1999

Determinación de los metabolitos de la corticosterona en materia fecal

Para la obtención de materia fecal para el análisis de los metabolitos de la corticosterona, se colocaron a los ratones (en los diferentes puntos de tiempo) individualmente en una caja limpia con lecho de marlo de choclo. Trascurridas 24 hs se recolectaron todos los pellets de materia fecal y se mantuvieron a $-20^{\circ} \mathrm{C}$ hasta su análisis mediante la técnica que fue descripta en el capítulo anterior.

\section{Hemograma}

Transcurridos los 45 días, se tomaron al azar 5 hembras por grupo para realizarles un hemograma. Para este propósito las mismas se sacrificaron mediante la inhalación con $\mathrm{CO}_{2}$ e inmediatamente se extrajo $0,5 \mathrm{ml}$ de sangre mediante punción intracardíaca en un tubo con anticoagulante. Las muestras se mantuvieron refrigeradas y se enviaron 
inmediatamente para su análisis al Servicio Central de Laboratorio del Hospital Escuela de la Facultad de Cs Veterinarias de la UNLP.

Análisis estadístico

Se analizaron las diferencias en el desarrollo tumoral entre machos y hembras para cada punto de tiempo mediante la prueba no paramétrica de Mann-Whitney. Los datos obtenidos en el hemograma fueron analizados mediante Análisis de la Varianza (ANOVA). Para el caso de los metabolitos de la corticosterona en materia fecal, el sexo y el grupo fueron agregados como factores en el ANOVA.

\section{Resultados}

Todos los ratones presentaron una condición corporal de 3 a lo largo del período experimental. Los volúmenes tumorales a lo largo del tiempo pueden verse en el gráfico 3.1. No hubo diferencias en el desarrollo tumoral entre sexos a los 15 días post-inoculación $(\mathrm{W}=161 ; \mathrm{p}=0,209)$, pero sí existieron en los dos períodos de tiempo posteriores (a los 30 días: $\mathrm{W}=138 ; \mathrm{p}=0,046$ y a los 45 días postrasplante: $\mathrm{W}=125 ; \mathrm{p}=0,015)$. 


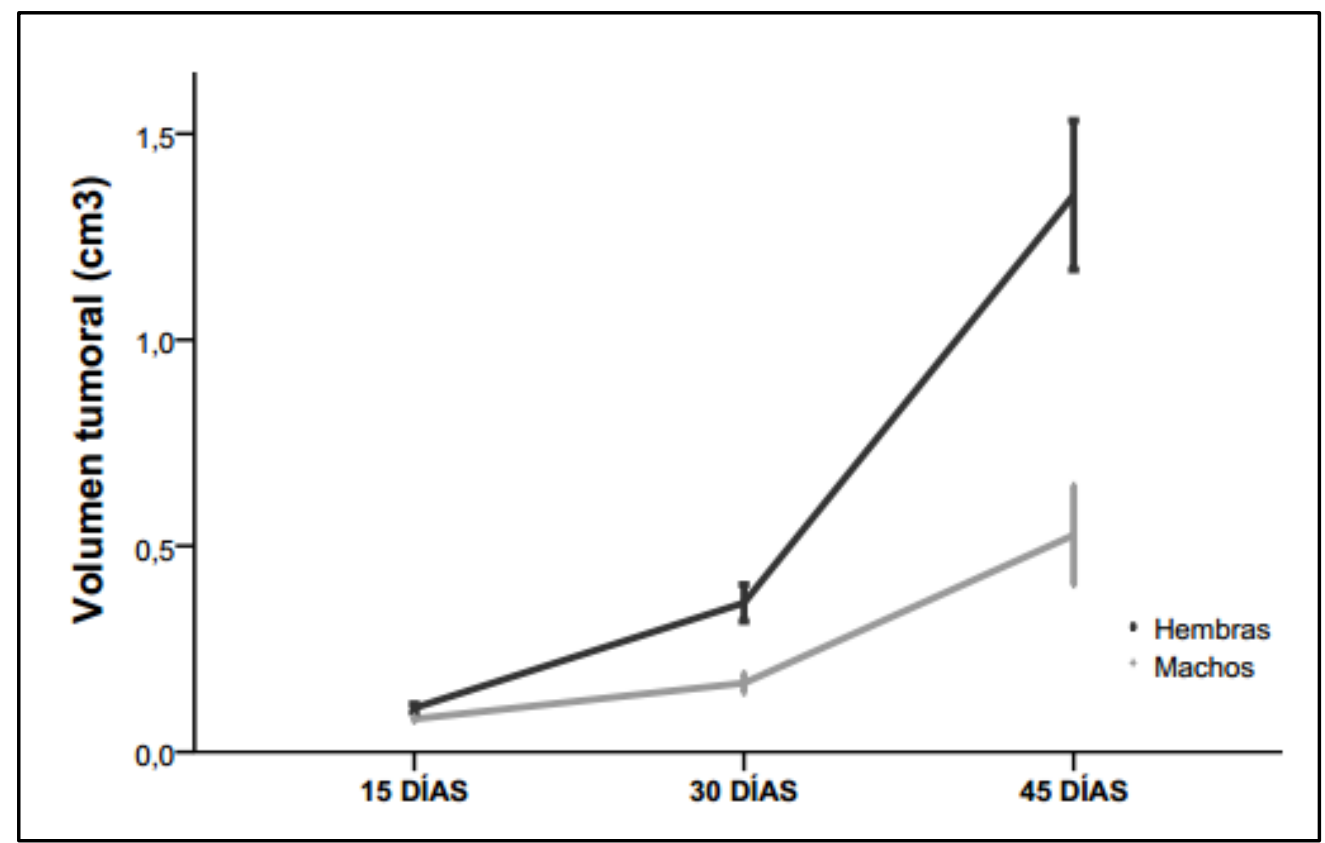

Gráfico 3.1. Tamaño tumoral en machos y hembras a los 15,30 y 45 días postrasplante

Se obtuvieron muestras de materia fecal tanto en machos como en hembras a los 45 días pos-trasplante para realizar el análisis de los metabolitos de la corticosterona. Los resultados obtenidos, así como el análisis estadístico posterior pueden observarse en la tabla 3.1. Al respecto, no se detectaron diferencias estadísticamente significativas entre los grupos.

\begin{tabular}{cccccc}
\hline Grupo & Sexo & Media & D.E. & Estadístico & p-valor \\
\hline \multirow{2}{*}{ Control } & Hembras & 59,63 & 19,60 & & \\
& Machos & 59,05 & 10,28 & & $\mathrm{~F}_{(2,54)}=$ \\
\multirow{2}{*}{ Tumor } & Hembras & 62,54 & 30,03 & 0,48 & 0,622 \\
& Machos & 48,85 & 13,35 & & \\
\hline
\end{tabular}

Tabla 3.1. Concentración de los metabolitos de la corticosterona 45 días postrasplante 
Finalmente, se obtuvieron muestras de sangre en hembras, principalmente para analizar posibles diferencias en la función inmune asociadas al desarrollo tumoral. Los resultados pueden observarse en la tabla 3.2.

\begin{tabular}{|c|c|c|c|c|}
\hline \multirow{2}{*}{ Parámetro } & \multicolumn{2}{|c|}{ Media + D.E. } & \multirow{2}{*}{ Estadístico } & \multirow{2}{*}{ p-valor } \\
\hline & Control & Tumor & & \\
\hline Hematocrito (\%) & $44,20 \pm 4,15$ & $43,20 \pm 4,15$ & $\mathrm{~F}_{(1,9)}=0,15$ & 0,719 \\
\hline $\begin{array}{l}\text { Sólidos totales } \\
(\mathrm{g} / \mathrm{dl})\end{array}$ & $6,24 \pm 0,17$ & $6,32 \pm 0,44$ & $F_{(1,9)}=0,15$ & 0,718 \\
\hline Hematíes (total/ $\mu \mathrm{l})$ & $\begin{array}{l}6800000 \pm \\
2962262\end{array}$ & $\begin{array}{c}7812000 \pm \\
767932\end{array}$ & $\mathrm{~F}_{(1,9)}=0,55$ & 0,480 \\
\hline Hemoglobina (\%) & $14,48 \pm 1,31$ & $14,06 \pm 1,21$ & $\mathrm{~F}_{(1,9)}=0,28$ & 0,612 \\
\hline H.C.M & $18,13 \pm 0,72$ & $18,02 \pm 0,50$ & $\mathrm{~F}_{(1,9)}=0,08$ & 0,972 \\
\hline V.C.M. (fL) & $55,29 \pm 1,20$ & $55,31 \pm 0,74$ & $F_{(1,9)}=0,00$ & 0,927 \\
\hline C.H.C.M. (\%) & $32,78 \pm 1,04$ & $32,58 \pm 0,87$ & $\mathrm{~F}_{(1,9)}=0,11$ & 0,746 \\
\hline $\begin{array}{l}\text { Plaquetas } \\
\text { (total } / \mu \mathrm{l})\end{array}$ & $\begin{array}{c}954200 \pm \\
421494\end{array}$ & $\begin{array}{l}1322600 \pm \\
136756,35\end{array}$ & $\mathrm{~F}_{(1,9)}=3,46$ & 0,1001 \\
\hline $\begin{array}{l}\text { Leucocitos } \\
(\text { total } / \mu \mathrm{l})\end{array}$ & $11160 \pm 6493$ & $9360 \pm 5311,59$ & $\mathrm{~F}_{(1,9)}=0,23$ & 0,644 \\
\hline $\begin{array}{c}\text { Neutrófilos en } \\
\text { cayado (total/ } \mu \mathrm{l})\end{array}$ & $\begin{array}{c}102,60 \pm \\
157,44\end{array}$ & $45,60 \pm 78,81$ & $\mathrm{~F}_{(1,9)}=0,52$ & 0,489 \\
\hline $\begin{array}{c}\text { Neutrófilos } \\
\text { segmentados } \\
\text { (total/ } \mu \mathrm{l})\end{array}$ & $2622,20 \pm 1520$ & $\begin{array}{c}4107,20 \pm \\
2397,45\end{array}$ & $\mathrm{~F}_{(1,9)}=1,37$ & 0,275 \\
\hline Eosinófilos & 0 & 0 & - & - \\
\hline Basófilos & 0 & 0 & - & - \\
\hline Linfocitos & $\begin{array}{l}7838,8 \pm \\
5781,53\end{array}$ & $\begin{array}{c}5146,4 \pm 3869 \\
01\end{array}$ & $\mathrm{~F}_{(1,9)}=0,75$ & 0,412 \\
\hline Monocitos & $\begin{array}{c}120,40 \pm \\
105,66\end{array}$ & $60,80 \pm 86,27$ & $\mathrm{~F}_{(1,9)}=0,95$ & 0,357 \\
\hline
\end{tabular}

Tabla 3.2 hemograma en hembras con y sin trasplante tumoral y valores estadísticos asociados a dichos datos. 


\section{Discusión}

En el presente capítulo se analizaron las diferencias a nivel fisiológico que pudieron haberse desarrollado producto del crecimiento tumoral. Además, se analizó cómo influyó el sexo en el volumen tumoral siendo éste el dato más relevante que se obtuvo a partir de estas primeras inferencias. De esta forma, se observó que a partir de los 30 días pos-trasplante y hasta el final de la experiencia, el desarrollo tumoral en las hembras fue mayor que en los machos. Si bien los mecanismos por los cuales se pudo haber generado dicha variación exceden los alcances de esta tesis doctoral, en trabajos previos en los que se utilizó la misma línea tumoral (A549) se observó que los estrógenos aumentaron la proliferación celular y la angiogénesis (Jarzynka y col., 2006), dos elementos que claramente contribuyen a aumentar el tamaño tumoral. Inclusive, en humanos las mujeres son más susceptibles a desarrollar neoplasias en pulmón que los hombres (Verma y col., 2011).

Con respecto a los otros parámetros analizados no se observaron diferencias relevantes. Así por ejemplo, la condición corporal se mantuvo estable a lo largo de todo el período de tiempo. De la misma forma, no hubo diferencias significativas en la concentración de los metabolitos de la corticosterona en materia fecal, ni tampoco en las células de la respuesta inmune contabilizadas en el hemograma. Esto posiblemente se debió a que la percepción del animal del estresor no fue lo suficientemente relevante, lo que se pudo haber correspondido con el crecimiento lento de esta línea celular. La respuesta de estrés, que fue considerada en principio como un concepto puramente fisiológico (Selye, 1936), se desencadena por factores psicológicos: el animal no se estresará si percibe la amenaza en su ambiente como tal, esté esta presente o no; y la inespecificidad de la respuesta de estrés 
descripta por Selye se debe principalmente a que los distintos estresores desencadenan las mismas respuestas emocionales (Veissier y col., 2012).

\section{Conclusiones}

A partir de los resultados obtenidos se puede descartar una alteración significativa en los parámetros fisiológicos debidos al desarrollo tumoral. Además, dadas las diferencias entre sexos podría inferirse que las hembras serían un mejor modelo animal para desarrollar en el laboratorio cuando se necesitan altas tasas de crecimiento tumores ya que esto podría facilitar la detección del efecto citotóxico de nuevas drogas antineoplásicas. 


\section{Evaluación del bienestar animal mediante indicadores comportamentales}

En el capítulo anterior, se evaluaron indicadores clásicos de bienestar animal, en los cuales se asume que la alteración de la homeostasis (en este caso debido a la presencia de la masa tumoral), puede llegar a dificultar la habilidad del animal para lidiar con las distintas amenazas ambientales y por lo tanto, disminuir su bienestar. Sin embargo, una de las mayores dificultades que se presentan con este tipo de indicadores corresponde a que las mismas no nos revelan cómo el animal percibe dichas alteraciones. Así, la respuesta homeostática puede llegar a ser lo suficientemente eficiente como para que el animal no sea consciente del evento injuriante que está sucediendo en su propio cuerpo. Por otro lado, también hay que considerar que la aparición de signos clínicos asociados a estados patológicos puede ser sutil o inexistente, debido a la poca manifestación de signos de debilidad que se produce en esta especie (Matsumiya y col., 2012). De esta forma, los signos clínicos evidentes de sufrimiento, tales como los descriptos en las guías de recomendaciones para la investigación en cáncer (Workman y col., 2010) aparecen cuando los animales presentan un sufrimiento inaceptable para los estándares regulatorios y por lo tanto exigen una intervención inmediata del profesional veterinario para aplicar el punto final humanitario.

Manifestaciones más sutiles de dolor (antes de presenciarse los signos clínicos de sufrimiento que requieran la aplicación del punto final humanitario) pueden llegar a 
presenciarse en los roedores de laboratorio por ejemplo en modelos ortotópicos pertenecientes a estudios oncológicos (Roughan y col., 2004). Sin embargo, estos signos han sido inexistentes cuando se han evaluado las manifestaciones comportamentales de los signos de dolor en modelos heterotópicos de trasplantes subcutáneos (Miller y col., 2016). Además, todavía no se han utilizado indicadores comportamentales más modernos como las expresiones faciales en modelos de dolor oncológico en ratones (Langford y col., 2010). Uno de los principales inconvenientes que se desprenden del análisis comportamental de este modelo animal radica en que, de provocarle dolor al animal, este sería de tipo crónico (Whittaker y Howarth, 2014) y por lo tanto, su inicio debería ser paulatino para irse incrementando a medida que progresa el desarrollo tumoral. La ausencia de cambios abruptos en el comportamiento podría ser uno de los factores que impidan una detección temprana en la reducción del bienestar. Inclusive, este aumento paulatino de la masa tumoral podría generar que los animales no la perciban como una amenaza a su integridad física y por lo tanto, la respuesta de estrés asociada a dicho desarrollo podría no desarrollarse en absoluto (Mason, 1971).

Los comportamientos que pueden observados de forma sencilla y no invasiva pueden ser indicadores más sensibles del estado interno de un animal, comparados con las herramientas clásicas de control clínico. Las observaciones en la caja donde normalmente habitan los ratones son particularmente ventajosas ya que implican un mínimo estrés del animal y por lo tanto consiguen reducir los efectos indeseados que pueden desencadenarse a partir de las pruebas comportamentales clásicas tales como estrés generado por la 
novedad, analgesia inducida por el estrés, y otros cambios en la fisiología y en el comportamiento causados por el ambiente desconocido (Jirkof, 2014).

Entre estos, existen comportamientos específicos de especie que el animal está intrínsecamente motivado a realizar, más allá que las necesidades fisiológicas asociadas a la función de cada comportamiento se encuentren satisfechas, que se conocen como necesidades comportamentales (Duncan, 1998). El grado de motivación de estos comportamientos en un momento dado está determinado por una combinación entre el estado fisiológico y los estímulos externos presentes, y determina la probabilidad y la intensidad con la que los animales ejecutarán un comportamiento (Mason y Burn, 2011). Pareciera que las emociones juegan un rol preponderante en el desarrollo de las necesidades comportamentales (Mason y Burn, 2011). Así, en el proceso inconsciente de toma de decisiones, la búsqueda de estados placenteros ocurre simultáneamente mientras se evitan situaciones que puedan provocar dolor o sufrimiento, a partir de circuitos neuronales de dolor y placer que poseen múltiples puntos de encuentro (Leknes y Tracey, 2008). Mediante la utilización de pruebas de comportamiento se puede inferir cómo un animal evalúa su propia situación y adapta su comportamiento para seleccionar la respuesta más eficiente (esto es, la más gratificante) (Van der Harst y Spruijt, 2007). El resultado de la integración de las experiencias positivas y negativas son las que determinan el estado de bienestar de un animal. De esta forma, cuando las experiencias negativas sobrepasan a las positivas el animal intentará compensarlas aumentando la sensibilidad a las recompensas aunque finalmente el estrés crónico se desencadena en anhedonia (que es insensibilidad a las recompensas, una característica típica de la depresión) (Van der Harst y Spruijt, 2007). 
En particular los comportamientos complejos e intrínsecamente motivados han demostrado ser de utilidad para evaluar el dolor, el distrés y el sufrimiento de los ratones de laboratorio (Jirkof, 2014). Esto es debido a que los mismos, al no ser esenciales para la supervivencia, suelen ser los primeros en disminuir cuando los desafíos ambientales amenazan la integridad del individuo y por lo tanto su ausencia puede indicar una reducción en el bienestar (Boissy y col., 2007). Por ejemplo, la performance en la construcción del nido y de la madriguera, han sido postulados (Jirkof, 2014) como dos de estos tipos de comportamientos complejos que no son esenciales para la supervivencia en el ambiente del laboratorio pero que si son imprescindibles para evitar a los depredadores, mantener la temperatura corporal, mantener una reserva de alimentos, entre otras funciones, en los animales silvestres (Latham y Mason, 2004; Deacon, 2012; Gaskill y col., 2013). Así, se observó una disminución en la motivación para realizar estos dos comportamientos tanto en múltiples estados patológicos como enfermedades infecciosas, enfermedad de Alzheimer, Parkinson, entre otras (Van de Weerd y col., 1997; Deacon y col., 2002; Deacon, 2012; Jirkof, 2014).

\section{Materiales y métodos}

\section{Burrowing test}

Se utilizó un tubo de PVC de $200 \mathrm{~mm}$ de largo y $68 \mathrm{~mm}$ de diámetro, cerrado en un extremo y elevado $30 \mathrm{~mm}$ en el otro mediante tornillos de $50 \mathrm{~mm}$ de largo (Imagen 4.1). Este tubo se llenó con 200 gr de pellets de alimento y se colocó en la caja donde se mantienen los animales. La prueba consistió en pesar el alimento extraído del tubo luego de 
2 horas de haber sido ubicado el dispositivo (Deacon, 2006).

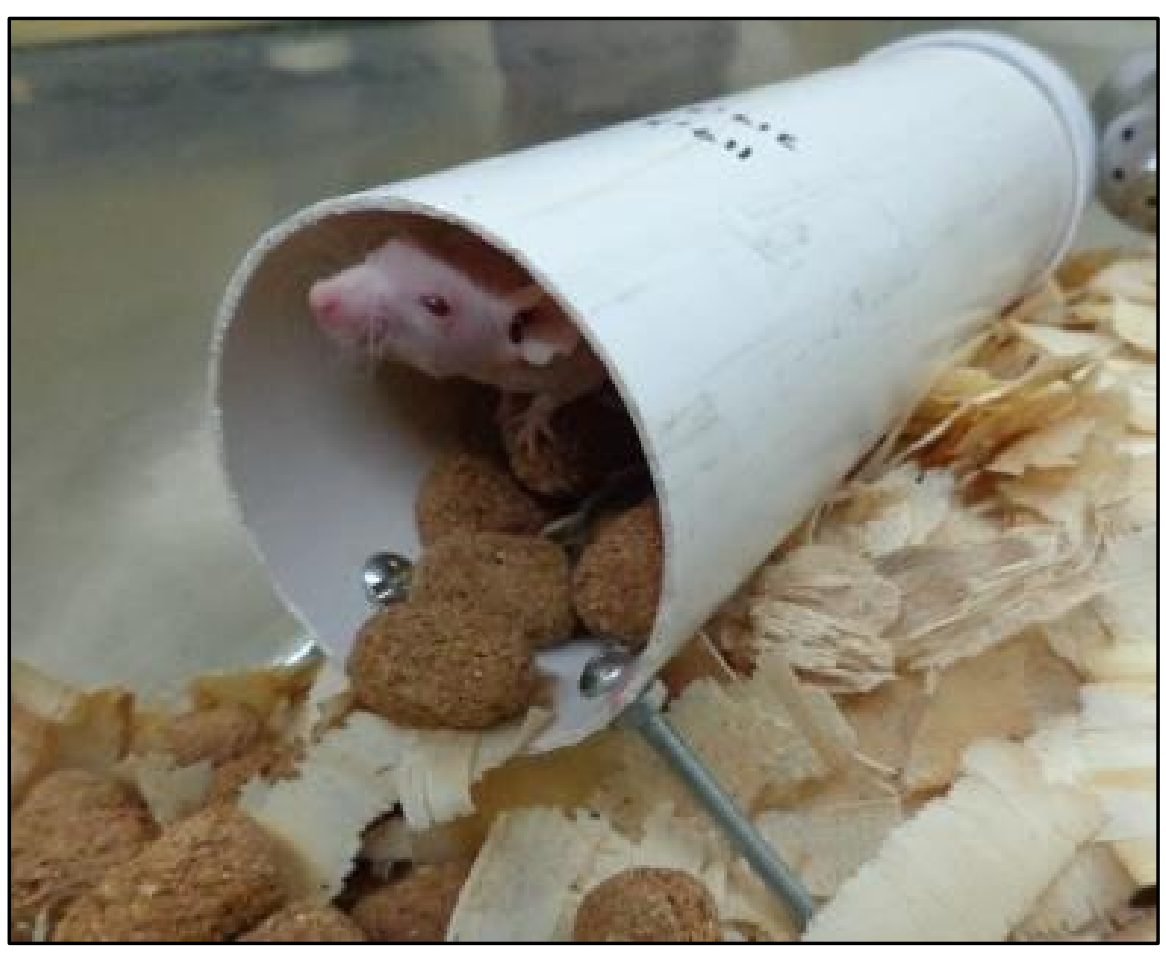

Imagen 4.1. Burrowing test.

Nesting

Para la evaluación de la calidad del nido se utilizó una adaptación del protocolo de Deacon (2006) en el que se colocaron en la caja dos discos de algodón al final de la fase lumínica. La calidad del nido producido se evaluó al principio de la siguiente fase lumínica usando una escala cualitativa del 1 al 4, que se describe en las siguientes imágenes (Imágenes 4.24.5). 


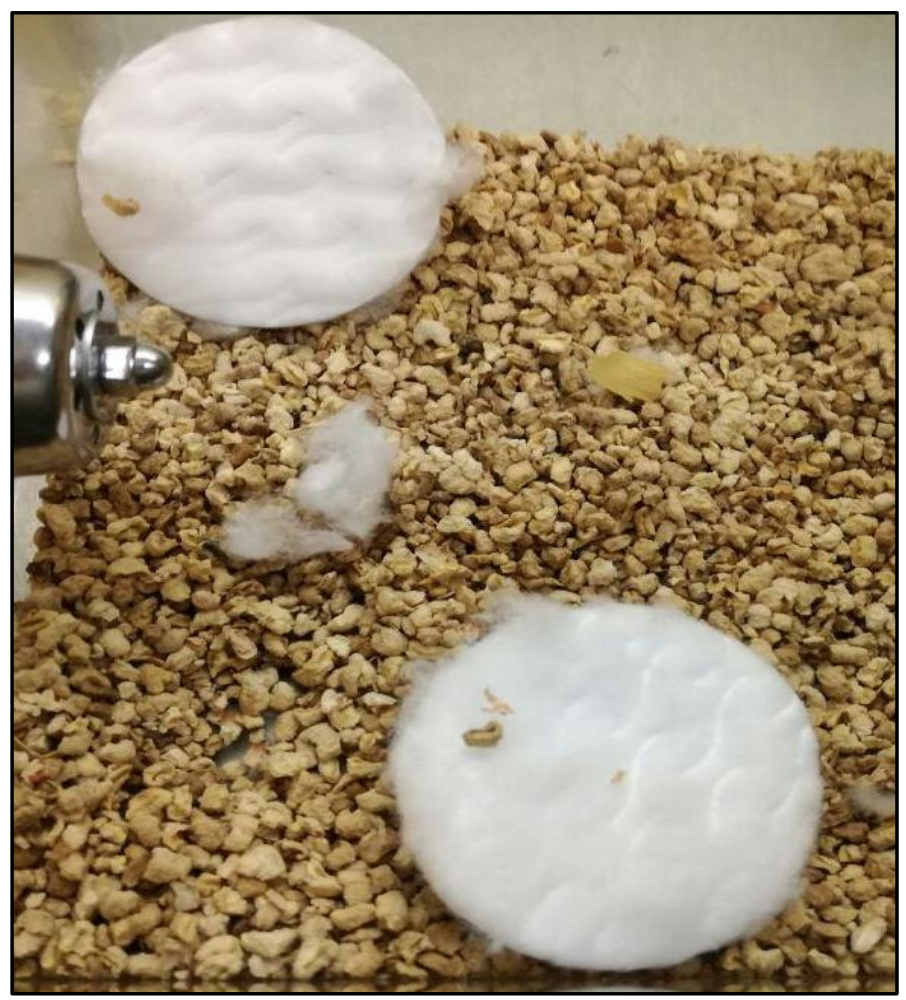

Imagen 4.2. Nido calidad 1: menos del $10 \%$ de la superficie de los discos de algodón modificada.

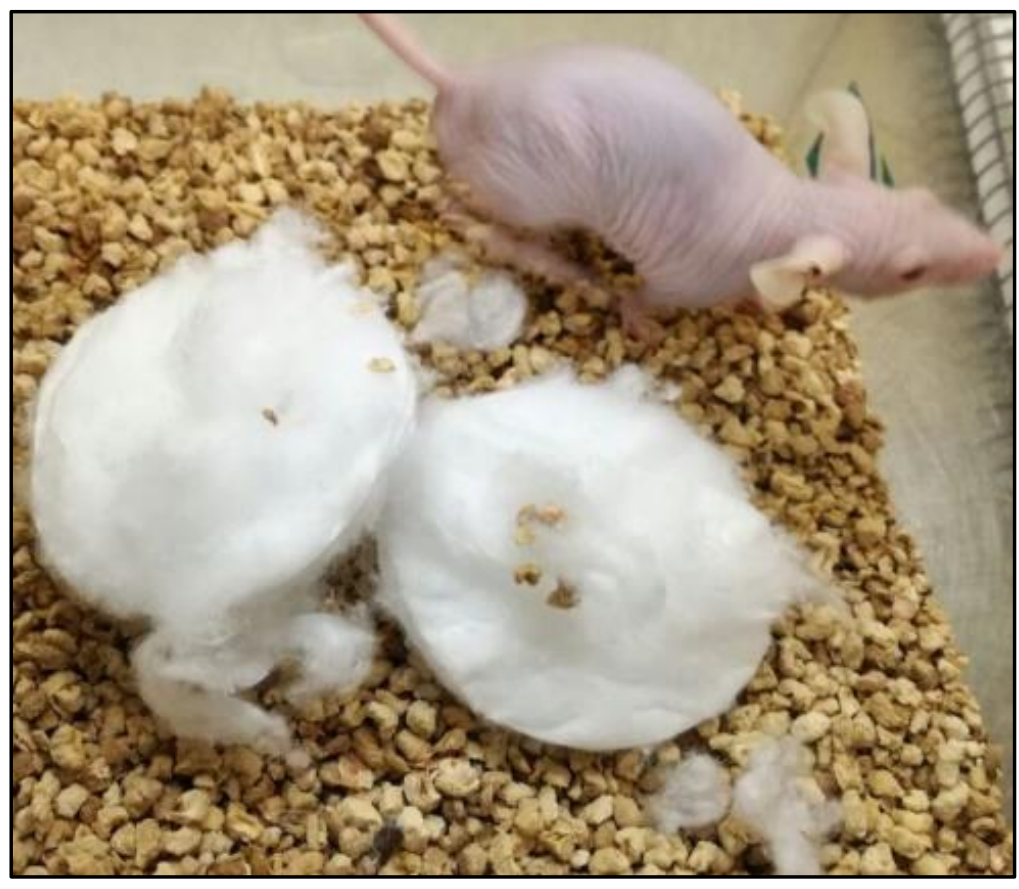

Imagen 4.3. Nido calidad 2. Más del 10\% de la superficie de los discos de algodón modificada. 


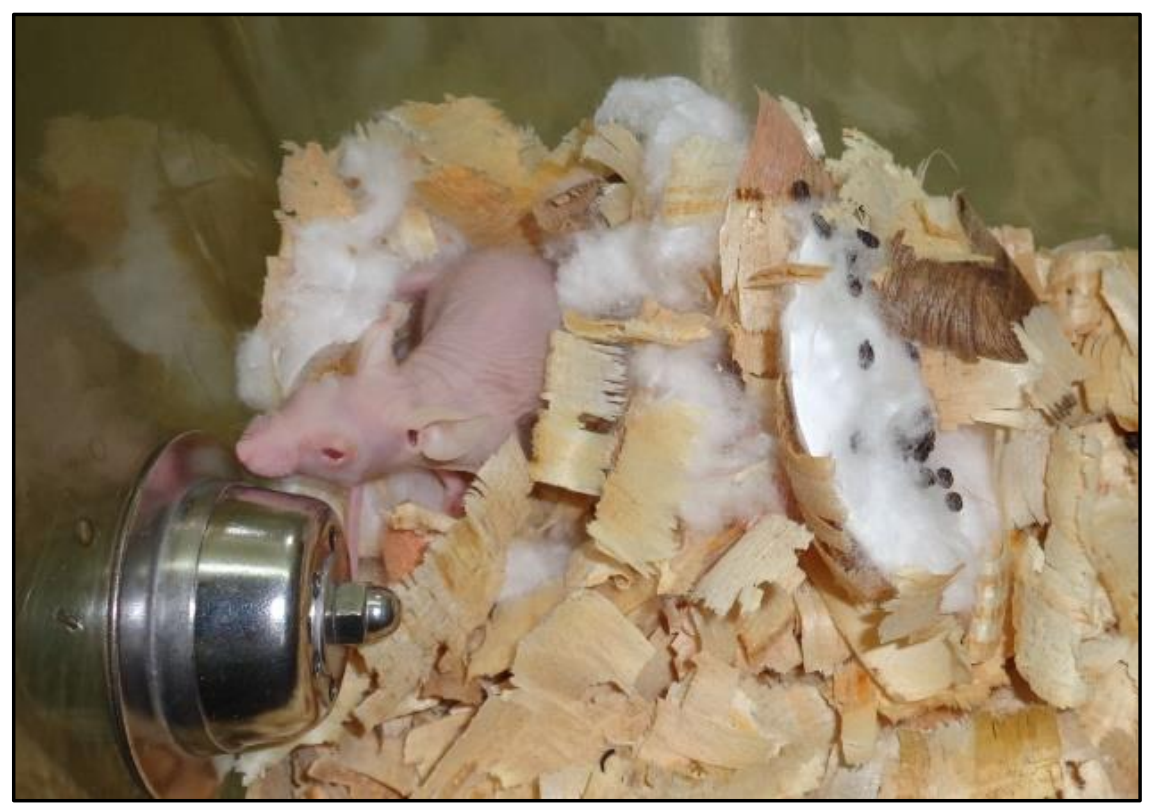

Imagen 4.4. Nido calidad 4. Más del 50\% de la superficie de los discos de algodón modificada.

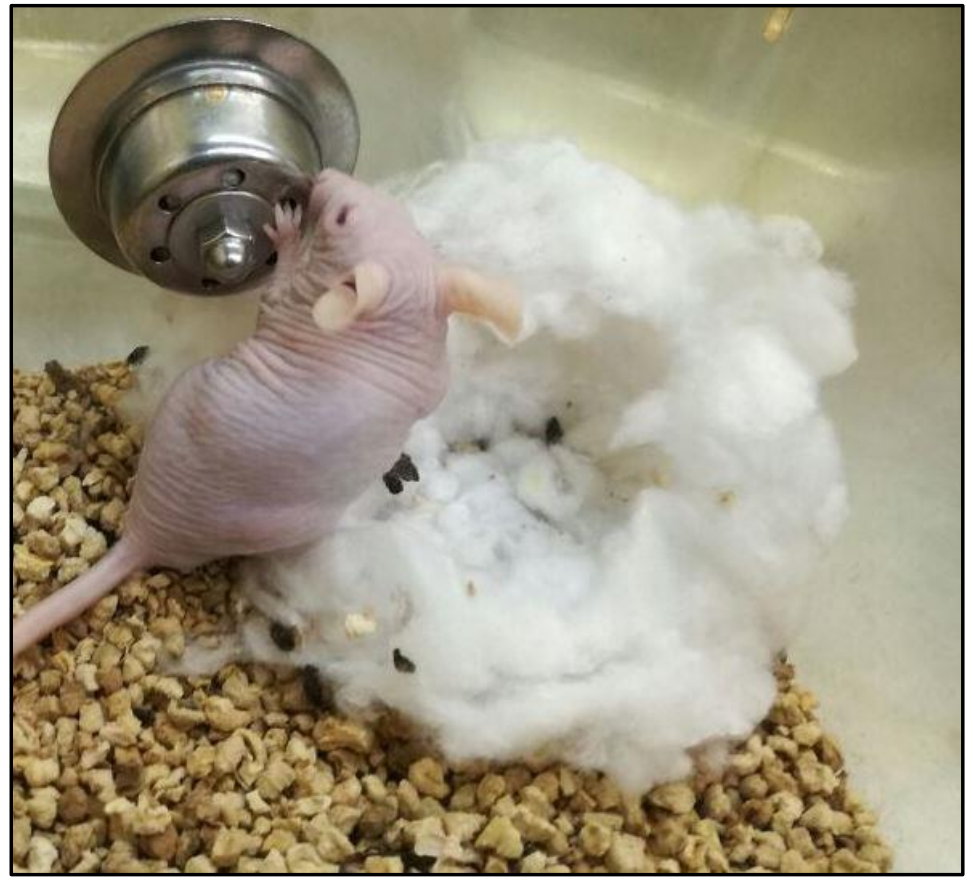

Imagen 4.5. Nido calidad 4. Más del 90\% de la superficie de los discos de algodón modificada. 


\section{Frecuencias comportamentales en la caja}

Para la determinación de las frecuencias comportamentales se utilizó la técnica de animal focal en la que se efectuó un registro continuo de todas pautas de comportamiento que realizaron en un período de 20 minutos. Las observaciones se realizaron inmediatamente después de colocar a cada ratón individualmente en una caja limpia con lecho de marlo de maíz, mediante la filmación de dicho período y posterior análisis de los videos obtenidos. Los comportamientos que se analizaron fueron:

Elevarse: el ratón lleva el peso de su cuerpo hacia los miembros posteriores, despega del piso los miembros anteriores y direcciona la cabeza hacia arriba.

Escavar: desplazamiento de la cama hacia atrás utilizando movimientos alternados de los miembros anteriores y posteriores.

Empujar: desplazamiento de la cama hacia adelante utilizando los miembros anteriores mientras se desplaza hacia adelante.

Saltos tipo "pochoclo": saltos espasmódicos con los cuatro miembros en el que los mismos se despegan del piso al mismo tiempo. Puede ir acompañado de movimientos laterolaterales de la cabeza y la porción anterior del tronco.

Acicalarse: el ratón lame su piel, o desplaza los miembros anteriores por sobre la superficie anterior del cuerpo antes o después de lamerse las manos y antebrazos, o se rasca con cualquiera de los miembros.

Sacudirse: movimiento latero-lateral de la cabeza que puede ir acompañado también de movimientos latero-laterales de la porción anterior del cuerpo. 
Defecar/orinar: Expulsión de pellets de materia fecal o de orina. Cuando orina, el animal permanece inmóvil mientras desciende la parte posterior del cuerpo.

\section{Test "Novelty Suppress Feeding Test" modificado}

Esta prueba utiliza el conflicto potencial entre dos motivaciones contrapuestas presentadas en un campo abierto: el hambre, generalmente inducido por un período de ayuno de máximo 18 horas, que estimula a que el ratón se acerque a la fuente alimenticia, y la ansiedad que le genera separarse de los bordes de la caja (lugar donde se sienten más confortables debido a la thigmotaxis, es decir, la preferencia por tener su superficie corporal en contacto con otros objetos) para aventurarse hacia el centro de la arena donde se coloca el alimento (Samuels y Hen, 2011).

Como consecuencia, se obtiene como dato comportamental principal el período de latencia desde que el animal es colocado en el campo abierto hasta que ingiere el alimento mientras se sienta sobre sus ancas y lo sujeta con sus miembros anteriores. Adicionalmente, se pueden recolectar otras variables de comportamiento que se producen en el tiempo mientras el animal está en la prueba, tales como como la frecuencia en que orina o defeca (Hall, 1934).

Con el objetivo de evitar el estado afectivo negativo que puede llegar a provocar la deprivación del alimento, se utilizó la versión modificada del test en el que se reemplaza la misma por un ítem palatable (almendras). La prueba tuvo una duración de 300 segundos. En ella se colocaron a los animales en una esquina de una arena que contenía el ítem 
palatable en el centro y se contabilizó la cantidad de segundos que demoraron en ingerir dicho alimento (Imagen 4.6)

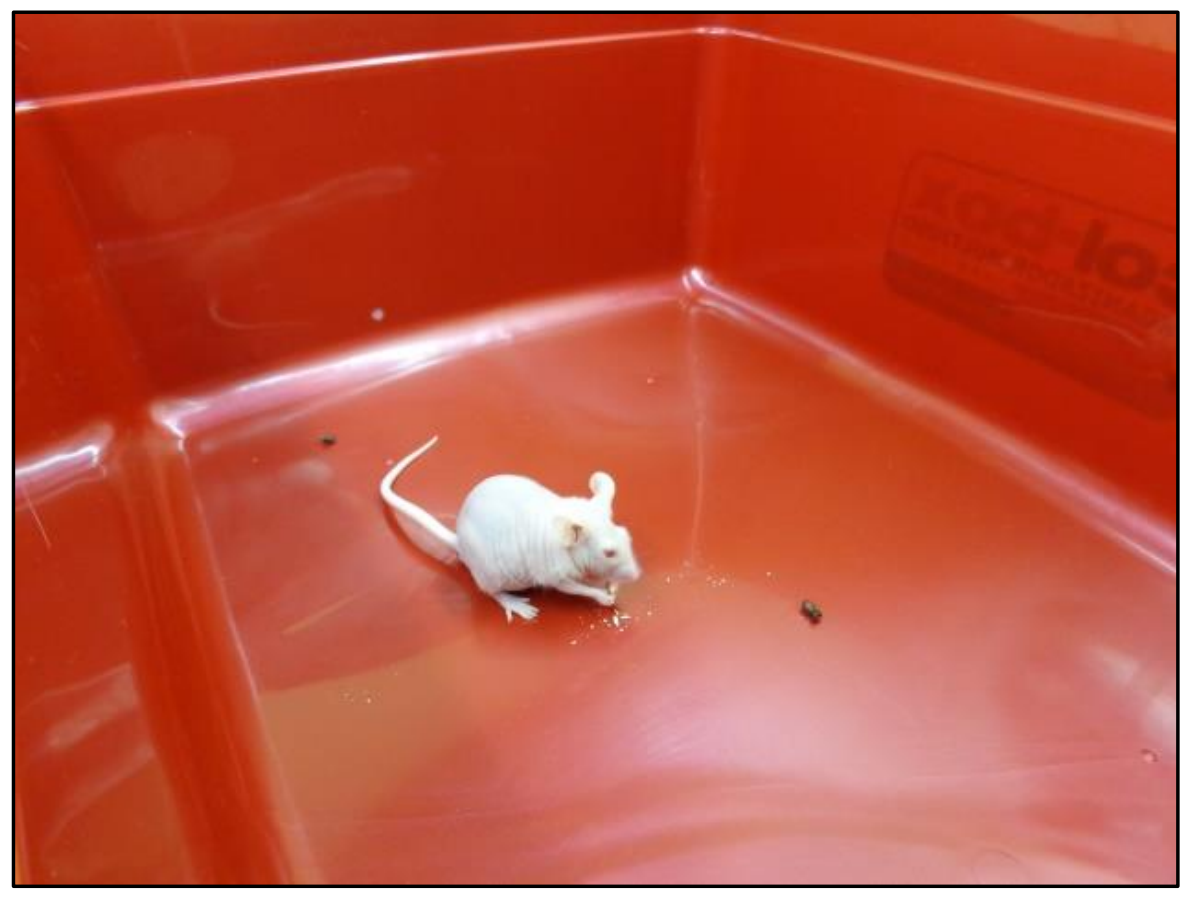

Imagen 4.6. Novelty-Suppressed Feeding Test

"Urine Sniffing (US) Test”

Los comportamientos que buscan estimular los circuitos de recompensa en el cerebro ("Reward-seeking behaviors") se definen como aquellos que generan un acercamiento hacia la fuente gratificante y pueden ser medidos por el mismo acercamiento, por los comportamientos consumatorios o por las reacciones afectivas que desencadenan (Malkesman y col., 2010). El "Urine Sniffing (US) Test" es un tipo de prueba para medir este tipo de comportamientos que no requiere un aprendizaje previo por parte del animal, sino que se basa en el interés que poseen los roedores por las feromonas presentes en la 
orina del sexo opuesto. Se utilizó una versión modificada del test propuesto por Malkesman (Malkesman y col., 2010), ya que no solo se implementó para evaluar el interés de los machos por la orina de la hembra en celo sino que también se empleó para evaluar el interés de las hembras por la orina del macho. Debido a que la orina de ambos sexos posee gran cantidad de información referente a la identidad de cada individuo (Beynon y Hurst, 2004), se infirió que la presencia de olores provenientes de un individuo desconocido motivarán el interés de ambos sexos por obtener nueva información del ambiente. Además, se ha descripto que una feromona presente en la orina de los ratones macho resulta atractiva para las hembras a partir de que éstas entran en la pubertad (Roberts y col., 2010).

Para la realización de esta prueba se depositaron $50 \mu \mathrm{l}$ de orina proveniente del sexo opuesto en un algodón que se colocó dentro en una celdilla para tomar muestras de necropsia. Esta celdilla se adhirió a la pared de una caja idéntica a la que utilizaron los ratones con lecho de marlo de maíz limpio. Posteriormente se colocaron los ratones de a uno en la caja y se contabilizaron los segundos que cada animal permaneció erguido con la cabeza dirigida hacia la fuente odorífera en un período de 180 segundos (Imagen 4.7). 


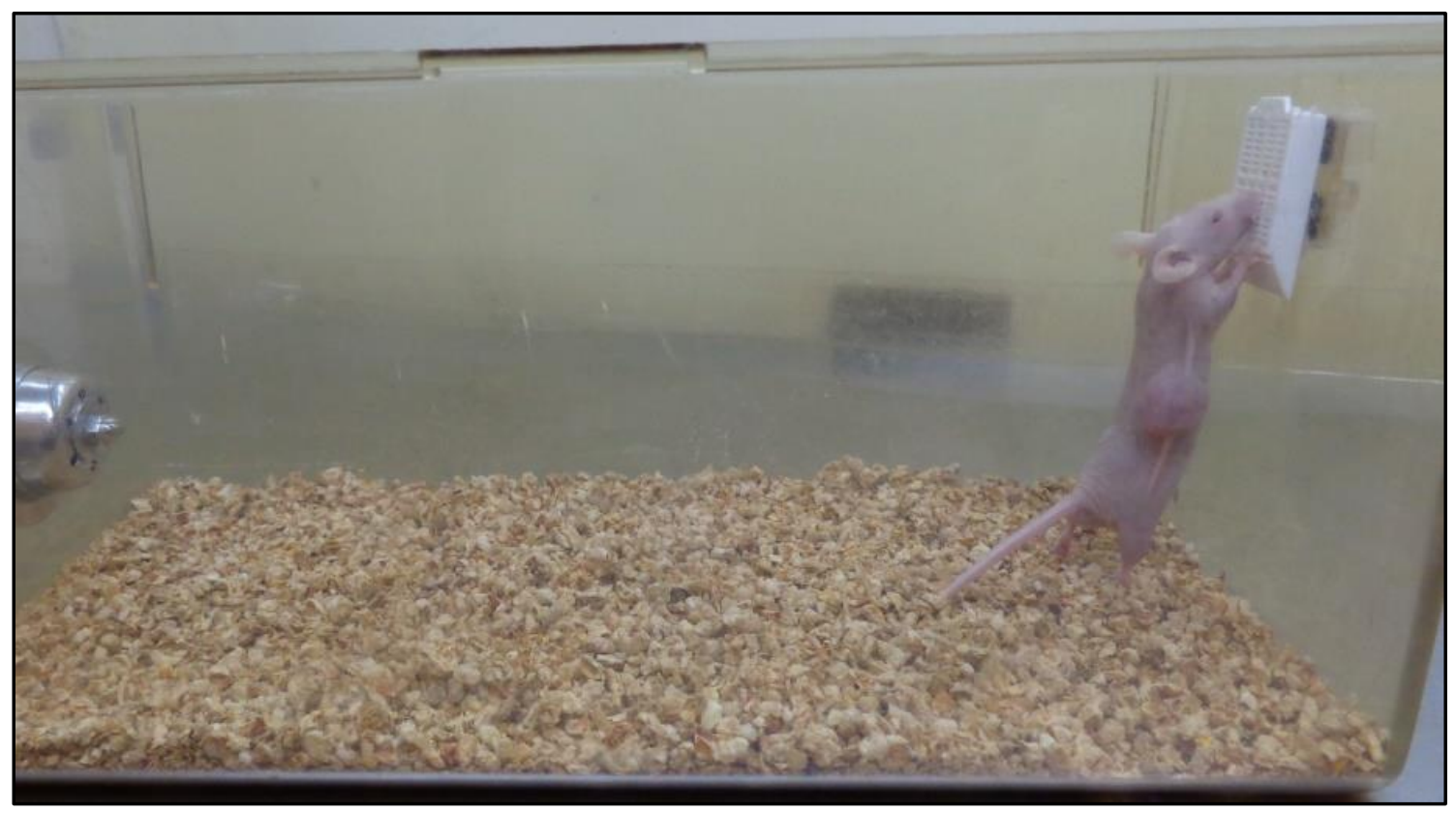

Imagen 4.7. Urine Seeking Test.

\section{Análisis estadístico}

Para evaluar el comportamiento espontáneo en la caja en las hembras se utilizaron modelos lineales mixtos con el objeto de analizar la respuesta de cada animal a lo largo de los días, utilizando el paquete estadístico de R lme4 (Bates y col., 2015). La relación entre la frecuencia de cada pauta comportamental según el grupo y el momento en que se realizó la filmación fue calculado como: $\operatorname{lmer}($ frecuencia $\sim$ grupo + día $+(1 \mid$ ID)). Se agregó a todos los modelos el intercepto para cada individuo (1|ID) como un efecto aleatorio y los valores de probabilidad se obtuvieron utilizando la razón de verosimilitud entre el modelo completo con cada uno de los efectos fijos. Para este fin en los ratones macho, se realizaron Análisis de la Varianza (ANOVA) o el test no paramétrico de Kruskall-Wallis según la normalidad de los datos. Para el caso del US test, las diferencias entre grupos se evaluaron mediante un ANOVA a dos vías, utilizando el grupo y el sexo como factores. Finalmente, la evaluación 
de la calidad de nido, del burrowing test y del NSF test se realizó mediante la prueba de Kruskal-Wallis.

\section{Resultados}

Frecuencias comportamentales en la caja

El análisis de las frecuencias comportamentales en la caja donde normalmente habitan los ratones se realizó mediante la filmación individual de cada ratón durante 20 minutos, y el análisis posterior de dichos videos. A continuación se resumen las frecuencias comportamentales obtenidas en ratones nude hembra, a los 15, 30 y 45 días postrasplante (Tablas 4.1-4.7):

\section{ELEVARSE}

\begin{tabular}{cccc}
\hline Días & Grupo & Media & D.E. \\
\hline \multirow{2}{*}{$\mathbf{1 5}$ días } & Control & 136,37 & 40,91 \\
& Tumor & 146,53 & 27,46 \\
\hline \multirow{2}{*}{ 30 días } & Control & 138,32 & 28,47 \\
& Tumor & 150,74 & 36,10 \\
\hline \multirow{2}{*}{ 45 días } & Control & 158,58 & 31,53 \\
& Tumor & 160,84 & 39,63 \\
\hline
\end{tabular}

Tabla 4.1. Frecuencia del comportamiento "ELEVARSE” a los 15, 30 y 45 días pos-trasplante 


\begin{tabular}{cccc}
\multicolumn{5}{c}{ CAVAR } \\
\hline Días & Grupo & Media & D.E. \\
\hline \multirow{2}{*}{ 15 días } & Control & 26,42 & 20,61 \\
& Tumor & 18,11 & 12,38 \\
\hline \multirow{2}{*}{ 30 días } & Control & 18,42 & 11,29 \\
& Tumor & 23,26 & 15,58 \\
\hline \multirow{2}{*}{ 45 días } & Control & 14,47 & 8,49 \\
& Tumor & 12,84 & 6,95 \\
\hline
\end{tabular}

Tabla 4.2. Frecuencia del comportamiento "CAVAR" a los 15, 30 y 45 días pos-trasplante

\section{EMPUJAR}

\begin{tabular}{cccc}
\hline Días & Grupo & Media & D.E. \\
\hline \multirow{2}{*}{$\mathbf{1 5}$ días } & Control & 9,74 & 10,35 \\
& Tumor & 14,42 & 8,59 \\
\hline \multirow{2}{*}{$\mathbf{3 0}$ días } & Control & 6,53 & 6,74 \\
& Tumor & 7,47 & 6,57 \\
\hline \multirow{2}{*}{ 45 días } & Control & 13,53 & 8,19 \\
& Tumor & 17,00 & 11,97 \\
\hline
\end{tabular}

Tabla 4.3. Frecuencia del comportamiento "EMPUJAR" a los 15, 30 y 45 días pos-trasplante

\section{Saltos tipo "POCHOCLO"}

\begin{tabular}{cccc}
\hline Días & Grupo & Media & D.E. \\
\hline \multirow{2}{*}{ 15 días } & Control & 20,26 & 18,55 \\
& Tumor & 21,11 & 22,30 \\
\hline \multirow{2}{*}{ 30 días } & Control & 7,26 & 9,84 \\
& Tumor & 8,11 & 9,00 \\
\hline \multirow{2}{*}{ 45 días } & Control & 2,32 & 2,54 \\
& Tumor & 5,26 & 10,60 \\
\hline
\end{tabular}

Tabla 4.4. Frecuencia del comportamiento "Saltos tipo POCHOCLO" a los 15, 30 y 45 días pos-trasplante 
ACICALARSE

\begin{tabular}{cccc}
\hline Días & Grupo & Media & D.E. \\
\hline \multirow{2}{*}{$\mathbf{1 5}$ días } & Control & 24,79 & 11,79 \\
& Tumor & 22,84 & 8,67 \\
\hline \multirow{2}{*}{ 30 días } & Control & 23,00 & 11,86 \\
& Tumor & 24,47 & 8,60 \\
\hline \multirow{2}{*}{ 45 días } & Control & 22,32 & 10,95 \\
& Tumor & 23,84 & 9,67 \\
\hline
\end{tabular}

Tabla 4.5. Frecuencia del comportamiento "ACICALARSE" a los 15, 30 y 45 días pos-trasplante

SACUDIRSE

\begin{tabular}{cccc}
\hline Días & Grupo & Media & D.E. \\
\hline \multirow{2}{*}{$\mathbf{1 5}$ días } & Control & 9,11 & 4,24 \\
& Tumor & 8,53 & 4,93 \\
\hline \multirow{2}{*}{ 30 días } & Control & 7,58 & 6,06 \\
& Tumor & 8,63 & 4,62 \\
\hline \multirow{2}{*}{ 45 días } & Control & 9,05 & 5,14 \\
& Tumor & 8,63 & 5,40 \\
\hline
\end{tabular}

Tabla 4.6. Frecuencia del comportamiento "SACUDIRSE” a los 15, 30 y 45 días pos-trasplante

DEFECAR/ORINAR

\begin{tabular}{cccc}
\hline Días & Grupo & Media & D.E. \\
\hline \multirow{2}{*}{$\mathbf{1 5}$ días } & Control & 2,05 & 1,87 \\
& Tumor & 2,89 & 1,88 \\
\hline \multirow{2}{*}{ 30 días } & Control & 2,47 & 2,14 \\
& Tumor & 1,58 & 1,57 \\
\hline \multirow{2}{*}{$\mathbf{4 5}$ días } & Control & 1,84 & 1,30 \\
& Tumor & 1,68 & 1,45
\end{tabular}

Tabla 4.7. Frecuencia del comportamiento "DEFECAR/ORINAR" a los 15, 30 y 45 días pos-trasplante 
A partir de los datos descriptos anteriormente, se realizaron los estadísticos correspondientes para evaluar las diferencias entre cada pauta según el grupo y el momento en que se realizaron las observaciones (Tabla 4.8):

\begin{tabular}{|c|c|c|c|c|c|}
\hline Comportamiento & $\begin{array}{l}\text { Estadístico } \\
\text { (grupos) }\end{array}$ & $\begin{array}{l}\text { p-valor } \\
\text { (grupos) }\end{array}$ & $\begin{array}{c}\text { Estadístico } \\
\text { (días) }\end{array}$ & $\begin{array}{l}\text { p-valor } \\
\text { (días) }\end{array}$ & $\begin{array}{c}\text { Comparaciones } \\
\text { (días) }\end{array}$ \\
\hline ELEVARSE & $X^{2}(1)=1,229$ & 0,267 & $\begin{array}{c}X^{2}(2)= \\
3,013\end{array}$ & 0,226 & - \\
\hline CAVAR & $\begin{array}{c}X^{2}(1)= \\
1,119\end{array}$ & 0,29 & $\begin{array}{c}X^{2}(2)= \\
5,244\end{array}$ & 0,072 & $\begin{array}{l}\text { 15-30días: } 0,847 \\
\text { 30-45 días: } 0,215 \\
\text { 15-45 días: } 0,067\end{array}$ \\
\hline EMPUJAR & $X^{2}(1)=3,387$ & 0,065 & $\begin{array}{c}X^{2}(2)= \\
10,27\end{array}$ & 0,005 & $\begin{array}{l}\text { 15-30días: } 0,004 \\
\text { 15-45 días: } 0,055 \\
\text { 30-45 días: } 0,661\end{array}$ \\
\hline $\begin{array}{l}\text { SALTOS TIPO } \\
\text { "POCHOCLO" }\end{array}$ & $X^{2}(1)=0,292$ & 0,588 & $\begin{array}{l}X^{2}(2)= \\
22,564\end{array}$ & $<, 001$ & $\begin{array}{c}\text { 15-30días: } 0,002 \\
\text { 15-45 días: }<0,001 \\
\text { 30-45 días: } 0,262\end{array}$ \\
\hline ACICALARSE & $X^{2}(1)=0,054$ & 0,814 & $\begin{array}{c}X^{2}(2)= \\
0,162\end{array}$ & 0,921 & $\ln _{1}$ \\
\hline SACUDIRSE & $X^{2}(1)=0,007$ & 0,929 & $\begin{array}{l}X^{2}(2)= \\
4,315\end{array}$ & 0,115 & - \\
\hline DEFECAR & $X^{2}(1)=0,086$ & 0,769 & $\begin{array}{l}X^{2}(2)= \\
11,437\end{array}$ & 0,003 & $\begin{array}{l}\text { 15-30días: } 0,001 \\
\text { 15-45 días: } 0,098 \\
\text { 30-45 días: } 0,348\end{array}$ \\
\hline
\end{tabular}

Tabla 4.8. Análisis estadístico de las distintas variables analizadas, incluyendo las diferencias entre los días. 
La observación de los comportamientos espontáneos en la caja en ratones nude macho se realizó únicamente a los 45 días pos-trasplante. A continuación se resumen las frecuencias comportamentales obtenidas junto con el análisis estadístico correspondiente (Tabla 4.9):

\begin{tabular}{cccccc} 
Pauta conductual & Grupo & Media & D.E. & Estadístico & p-valor \\
\hline \multirow{2}{*}{ ELEVARSE } & Control & 249,20 & 37,18 & $\mathrm{~F}_{(1,19)}=$ & 0,672 \\
& Tumor & 242,00 & 36,42 & 0,18 & \\
\hline \multirow{2}{*}{ CAVAR } & Control & 22,40 & 18,67 & $\mathrm{H}=$ & 0,40 \\
& Tumor & 21,80 & 8,38 & 0,69 & \\
\hline \multirow{2}{*}{ EMPUJAR } & Control & 22,70 & 13,61 & $\mathrm{~F}_{(1,19)}=$ & 0,517 \\
& Tumor & 20,40 & 21,08 & 0,44 & \\
\hline SALTOS TIPO & Control & 2,60 & 1,84 & $\mathrm{~F}_{(1,19)}=$ & \multirow{2}{*}{0,155} \\
“POCHOCLO" & Tumor & 1,50 & 1,90 & 2,20 & \\
\hline \multirow{2}{*}{ ACICALARSE } & Control & 30,40 & 14,09 & $\mathrm{~F}_{(1,19)}=$ & 0,392 \\
& Tumor & 40,90 & 32,42 & 0,77 & \\
\hline \multirow{2}{*}{ SACUDIRSE } & Control & 14,10 & 6,37 & $\mathrm{~F}_{(1,19)}=$ & \multirow{2}{*}{0,092} \\
& Tumor & 9,50 & 4,65 & 3,17 & 0,414 \\
\hline \multirow{2}{*}{ DEFECAR } & Control & 3,70 & 2,58 & $\mathrm{~F}_{(1,19)}=$ & \\
\hline & Tumor & 4,30 & 1,77 & 0,70 & \\
\hline
\end{tabular}

Tabla 4.9. Frecuencia de los comportamientos descriptos en el etograma en machos nude 45 días postrasplante

Prueba de inhibición de la alimentación por la novedad "Novelty Suppress Feeding (NSF) Test” modificado

Se evaluó el comportamiento asociado a estados de ansiedad colocando al animal en un campo abierto, y cuantificando cuánto tiempo demoraba en ingerir una almendra colocada 
en el centro de dicho lugar. El tiempo y el estadístico con su correspondiente valor de probabilidad de presentan en la tabla 4.10.

\begin{tabular}{cccccc} 
Sexo & Sexo & Media (seg) & D.E. & Estadístico & p-valor \\
\hline \multirow{2}{*}{ Hembras } & Control & 154,71 & 97,99 & $\mathrm{H}=0,01$ & 0,902 \\
& Tumor & 149,00 & 83,07 & & \\
\hline \multirow{2}{*}{ Machos } & Control & 204,20 & 92,76 & \multirow{H}{*}{$\mathrm{H}=0,85$} & 0,338 \\
& Tumor & 231,70 & 95,60 & & \\
\hline
\end{tabular}

Tabla 4.10. Segundos que demoraron en comer la almendra en la prueba NSF modificado

“Urine Sniffing (US)” Test

Con el objetivo de evaluar si la presencia del trasplante tumoral subcutáneo modificó el interés por un estímulo con un alto valor hedónico (tal como la orina del sexo opuesto, un fluido que le provee a los ratones una gran cantidad de información) se realizó el US test en ambos sexos a los 45 días de realizado el trasplante tumoral (Tabla 4.11).

\begin{tabular}{|c|c|c|c|c|c|}
\hline Grupo & Sexo & Media (seg) & D.E. & Estadístico & p-valor \\
\hline \multirow{2}{*}{ Control } & Hembras & 17,00 & 7,18 & \multirow{4}{*}{$\begin{array}{c}\mathrm{F}_{(1,92)}= \\
16,63\end{array}$} & \multirow{4}{*}{$>0,001$} \\
\hline & Machos & 19,55 & 8,04 & & \\
\hline \multirow{2}{*}{ Tumor } & Hembras & 13,10 & 7,31 & & \\
\hline & Machos & 11,89 & 7,48 & & \\
\hline
\end{tabular}

Tabla 4.11. Segundos que permanecieron oliendo el casete de necropsia en la prueba "UST" 
"Burrowing Test"

El análisis sobre la motivación de los ratones por realizar las pautas conductuales asociadas a la construcción de la madriguera fue realizada en tres puntos de tiempo en ratones hembra (15, 30 y 45 días) y únicamente a los 45 días en ratones macho. A continuación se muestran dichos valores en las tablas 4.12 y 4.13 .

\begin{tabular}{|c|c|c|c|c|c|}
\hline Días & Grupo & Media (gr) & D.E. & Estadístico & p-valor \\
\hline \multirow{2}{*}{15 Días } & Control & 110,03 & 67,34 & \multirow{2}{*}{$\mathrm{H}=0,04$} & \multirow{2}{*}{0,839} \\
\hline & Tumor & 107,93 & 70,82 & & \\
\hline \multirow{2}{*}{30 Días } & Control & 132,55 & 68,60 & \multirow{2}{*}{$\mathrm{H}=0,09$} & \multirow{2}{*}{0,761} \\
\hline & Tumor & 126,48 & 75,56 & & \\
\hline \multirow{2}{*}{45 Días } & Control & 144,79 & 64,85 & \multirow{2}{*}{$\mathrm{H}=0,84$} & \multirow{2}{*}{0,358} \\
\hline & Tumor & 122.97 & 79.94 & & \\
\hline
\end{tabular}

Tabla 4.12. Gramos de pellets removidos del tubo en la prueba "Burrowing test" en ratones nude hembra a los 15,30 y 45 días pos-trasplante.

\begin{tabular}{ccccc} 
Grupo & Media (gr) & D.E. & Estadístico & p-valor \\
\hline Control & 47,70 & 68,67 & $\mathrm{H}=0,19$ & 0,663 \\
Tumor & 45,10 & 60,20 & & \\
\hline
\end{tabular}

Tabla 4.13. Gramos de pellets removidos del tubo en la prueba "Burrowing test" en ratones nude macho a los 45 días pos-trasplante

\section{"Nesting”}

Debido a que la disrupción de los grupos en ratones macho más allá de la pubertad genera peleas intensas entre los mismos, la evaluación de la calidad del nido se realizó únicamente 
en las hembras a $\operatorname{los} 15,30$ y 45 días pos-trasplante. La frecuencia de las distintas categorías y el análisis estadístico posterior se presentan en la tabla 4.14.

\section{CALIDAD DEL NIDO}

\begin{tabular}{cccccccc} 
& & $\mathbf{1}$ & $\mathbf{2}$ & $\mathbf{3}$ & $\mathbf{4}$ & Estadístico & P-valor \\
\hline $\begin{array}{cccccc}\text { 15 días pos- } \\
\text { trasplante }\end{array}$ & Control & 1 & 17 & 9 & 2 & $\mathrm{H}=0,29$ & 0,551 \\
\hline 30 días pos- & Control & 2 & 13 & 13 & 1 & $\mathrm{H}=0,28$ & 0,565 \\
trasplante & Tumor & 2 & 12 & 11 & 4 & & \\
\hline 45 días pos- & Control & 2 & 11 & 9 & 7 & $\mathrm{H}=0,20$ & 0,638 \\
trasplante & Tumor & 3 & 9 & 14 & 3 & & \\
\hline
\end{tabular}

Tabla 4.14. Frecuencias de la calidad de nido obtenidas en hembras a lo largo del tiempo luego de una noche.

\section{Discusión}

El objetivo de este capítulo fue exponer las posibles diferencias en el comportamiento entre los ratones con y sin trasplante tumoral subcutáneo que podrían llegar a ser indicativas de un bienestar deficitario en este modelo animal. Para lograrlo se analizó: (i) el comportamiento espontáneo que se generó luego de colocar individualmente a cada ratón en una caja con las mismas características a aquella en la que normalmente habitaba, (ii) el comportamiento cuando se los expuso a una situación desconocida (NSF test), (iii) la performance en dos pruebas comportamentales que explotan dos necesidades comportamentales en esta especie (Burrowing test y calidad del nido) y (iv) el interés por la orina del sexo opuesto. 
Con respecto a los comportamientos espontáneos observados en la caja donde normalmente habitaban los animales, se detectaron diferencias estadísticamente significativas únicamente en la comparación entre los días. La ausencia de diferencias entre tratamientos nos permitiría inferir que la presencia del tumor no les indujo alteraciones en la movilidad y tampoco en la motivación para realizar comportamientos asociados a la exploración del ambiente (elevarse, cavar), al autocuidado (acicalamiento) y al juego (saltos tipo "pochoclo"). Se observó únicamente una tendencia en la pauta empujar, en la que los ratones con tumor tendieron a realizarla más que los ratones sin tumor. Este comportamiento lo expresan, además de para confeccionar el nido, para cubrir objetos que naturalmente les generan ansiedad, tal como en el "Marble Burying Test" (De Boer y Koolhaas, 2003). Por este motivo, y porque se ha demostrado que drogas ansiolíticas lo disminuyen (De Boer y Koolhaas, 2003), podría asociarse con un aumento leve de la ansiedad al grupo con tumor. Con respecto a las otras variables comportamentales que podrían asociarse con un aumento de la ansiedad, esto es la frecuencia de defecación y de acicalamiento, no se observaron diferencias estadísticamente significativas. La ansiedad es la respuesta de un individuo a una amenaza potencial, por lo tanto si bien es imprescindible para la supervivencia, su reducción es deseable para mejorar el bienestar. Las experiencias negativas provocan que el animal sea más cauto en situaciones novedosas futuras, lo que se manifestaría como una respuesta de ansiedad mayor (Cameron y Schoenfeld, 2018).

Se utilizaron dos pruebas que evalúan comportamientos altamente motivados en esta especie: la calidad del nido y el "Burrowing test". Para este caso no se detectaron diferencias estadísticamente significativas en ninguna de ellas, lo que podría esperarse 
cuando las alteraciones sobre el bienestar son inexistentes o lo suficientemente sutiles para no contrarrestar la motivación para realizar dichas pautas conductuales. Para el caso de la inhibición de la alimentación por la novedad (NSF test), se podrían inferir dos mecanismos mediante los cuales pudieron haber existido diferencias entre ambos grupos: mediante la alteración en la percepción del medio que los rodea que genere que el animal desarrolle un comportamiento más ansioso frente a una situación desconocida y mediante diferencias en el apetito que pudieron haberse generado con el desarrollo tumoral. Sin embargo, se obtuvo un resultado contradictorio cuando se lo comparó con la frecuencia del comportamiento "cavar" ya que para el "NSF test" no se observaron diferencias significativas entre los grupos con y sin trasplante tumoral. Esto podría deberse a que esta prueba pudo no haber sido ideal en detectar diferencias sutiles en la ansiedad entre ambos grupos, posiblemente debido a la elevada preferencia de esta especie por la recompensa alimenticia utilizada.

Finalmente resulta sumamente interesante resaltar la presencia de diferencias significativamente distintas en el interés por la orina del sexo opuesto. Al respecto existe evidencia empírica en la que se observó una correlación positiva entre el bienestar y la actividad exploratoria: los animales con un estado afectivo positivo tienden a explorar más que los animales en estados afectivos negativos (Franks, 2018). La exposición repetida o constante a lo largo del tiempo a una situación estresante genera en el animal un estado en el cual la respuesta emocional ante otros eventos se ve afectada. De esta forma, se produce un fenómeno denominado anhedonia en el cual disminuye la motivación ante eventos previamente ponderados como positivos por el animal (Veissier y col., 2012). Además según la teoría de asignación de recursos (Rauw y col., 1998), debido a que los elementos 
consumidos para realizar una función en particular no pueden utilizarse para otra, podría esperarse una modificación en el balance de dicha asignación ante el desarrollo tumoral. A partir de esta reasignación se espera que la motivación para realizar comportamientos que no son imprescindibles para la supervivencia (en este caso la reproducción) se vean disminuidos.

\section{Conclusiones}

En síntesis, sólo se manifestaron cambios comportamentales sutiles entre ambos grupos. Éstos se vieron reflejados sobre el interés que tuvieron en la orina del sexo opuesto, lo que podría ser un indicador temprano de la performance reproductiva y por lo tanto una actividad que no es esencial para la supervivencia. 


\section{Sesgo cognitivo en investigación oncológica}

Las emociones son respuestas afectivas que se desencadenan ante un determinado evento, en donde dicha respuesta es relativamente intensa y de corta duración (Dantzer, 1988). Éstas muy probablemente evolucionaron como mecanismos básicos adaptativos que le permitieron al animal evitar situaciones dañinas o perjudiciales, así como obtener recursos valiosos (Panksepp, 1994). Las emociones se manifiestan a partir de elementos comportamentales, fisiológicos, neurales y, al menos en humanos, a partir del componente subjetivo. Para evitar hablar del componente subjetivo, muchos investigadores hacen referencia a las emociones animales como estados afectivos, y los clasifican en términos de la respuesta comportamental y fisiológica que puede variar en relación a la valencia (placentero/aversivo) y la intensidad de su activación (Paul y col., 2005).

Por lo tanto, para estudiar las emociones animales se pueden tomar cada uno de estos componentes individualmente o en combinación. Así por ejemplo, las determinaciones fisiológicas en general se corresponden con aquellas usadas para estudiar la respuesta de estrés, principalmente porque ésta es vista generalmente ante situaciones que muy probablemente posean estados afectivos negativos. Sin embargo deben analizarse con precaución, ya que en situaciones en donde muy probablemente se desencadenen estados afectivos opuestos, la respuesta fisiológica generada puede llegar a ser la misma. De la misma forma, analizar el comportamiento espontáneo o el desencadenado ante distintas pruebas comportamentales puede utilizarse para demostrar las tendencias de acción que 
acompañan estados emocionales particulares. Tal como fue descripto para el análisis del bienestar animal, se puede obtener una gran cantidad de información cuando se utilizan varios métodos para evaluar las emociones animales. No obstante, existen limitaciones cuando se desean realizar interpretaciones sobre las mismas de forma aislada (Paul y col., 2005). Además, resulta interesante resaltar que muchas de las técnicas utilizadas carecen de una hipótesis a priori de cómo deberían cambiar de acuerdo con el estado afectivo del animal (específicamente en relación a su valencia), lo que enfatiza tanto la dificultad de su interpretación como de su significación cuando se extrapolan a otras especies (Mendl y col., 2009). De la misma forma, también existe una ausencia llamativa en la falta de indicadores para evaluar estados afectivos positivos (Boissy y col., 2007)

En este marco surgió la técnica de sesgo cognitivo, desarrollada por primera vez por Harding y col. en 2004 (Harding y col., 2004) para evaluar los estados afectivos de ratas alojadas en condiciones de estrés imprevisible. Esta está basada en la psicología humana, en la que se describe que cuando las personas experimentan un cambio en su estado emocional o en su humor, se desencadenan modificaciones concomitantes en la forma que perciben el mundo que lo rodea, esto es, en la apreciación cognitiva que ejercen sobre el mismo (Paul y col., 2005). Al respecto Shettleworth definió a la cognición como aquellos mecanismos por los cuales los animales adquieren, procesan, almacenan y actúan en base a la información que obtienen del medio ambiente que los rodea (Shettleworth, 2001). Los cambios en el procesamiento cognitivo pueden desencadenarse por reacciones instantáneas hacia determinados objetos o situaciones y también debido a estados emocionales de largo plazo asociados a estados de humor o desordenes clínicos del estado afectivo. Estos 
cambios se han demostrado en numerosas tareas que involucran la atención, la percepción, la memoria, las expectativas y el análisis de riesgos (Paul y col., 2005), y se manifiestan en forma de sesgos irracionales influenciados por los estados afectivos de procesos cognitivos tales como la atención, la memoria y el juicio (Mendl y col., 2009).

Este sesgo en el juicio fue el que se utilizó Harding en un primer momento para desarrollar esta prueba de comportamiento con el objetivo de evaluar cómo fue el estado emocional en ratas expuestas a estrés crónico imprevisible. Actualmente, numerosos autores han descripto una variedad de metodologías distintas para muchas especies diferentes. Sin embargo todas comparten el mismo principio básico: se entrena a los animales para que aprendan que un estímulo predice un evento positivo y otro estímulo (de la misma modalidad sensorial) predice un evento negativo (o menos positivo que el anterior). Luego se les presenta un estímulo intermedio a aquellos dos que el animal aprendió y se evalúa cómo se comportó: la hipótesis radica en que los animales que se encuentran en estados afectivos negativos van a juzgar el estímulo ambiguo como si éste predijese el evento negativo ("respuesta pesimista"), comparándolos con aquellos animales en estados afectivos positivos (Roelofs y col., 2016).

Las señales típicamente se asociaron con refuerzos positivos (principalmente alimentos preferidos) y con refuerzos negativos tales como alimento no palatable o ruido en tareas de ir/no ir hacia el estímulo (Mendl y col., 2009). Debido a que los refuerzos negativos podrían llegar a alterar el estado emocional de los animales, los protocolos más recientes lo reemplazaron por una recompensa menos deseada o por un refuerzo neutro (Novak y col., 2016). 
A pesar de que se han desarrollado múltiples protocolos para evaluar el sesgo cognitivo desde que esta técnica fue descripta por primera vez (Harding y col., 2004), solo alguno de ellos han sido específicamente desarrollados para ratones de laboratorio (Boleij y col., 2012; Kloke y col., 2014; Novak y col., 2015, 2016; Graulich y col., 2016; Jones y col., 2017). La intención de este capítulo es desarrollar un protocolo de sesgo cognitivo que se adapte a nuestra colonia de ratones nude, que poseen ciertas particularidades que no permiten que se utilice alguno de los protocolos previamente validados. Por un lado, poseen un fondo genético Swiss, un stock al que se le han atribuido problemas visuales (Clapcote y col., 2005) por otro lado, debido a que carecen de pelo, no poseen bigotes para permitirles ubicarse en el espacio o discernir estímulos táctiles (Ahl, 1986).

Para validar este protocolo se realizaron dos experimentos. En el primero de ellos se evaluó si los ratones fueron capaces de aprender la prueba propuesta y además, se correlacionó la respuesta al estímulo ambiguo con una prueba clásica para evaluar la ansiedad (Mogg y Bradley, 2005; Burman y col., 2009; Mendl y col., 2010). En el segundo experimento se evaluó si los ratones con un trasplante tumoral subcutáneo respondían al estímulo ambiguo de forma más pesimista que los ratones que no lo poseían, de forma de poder contrastar si su bienestar se encontraba comprometido. 


\section{Materiales y métodos}

Animales

Se utilizaron 29 ratones machos y 29 hembras, las condiciones de alojamiento y la técnica de trasplante tumoral ya fueron descriptas previamente.

Diseño experimental

Experimento 1: se utilizaron diez machos y siete hembras de 8 semanas de edad. El objetivo de este experimento fue evaluar si nuestra colonia de ratones nude con fondo genético Swiss fueron capaces de aprender la tarea y observar su comportamiento cuando estuvieron expuestos al estímulo ambiguo. Luego, ésta respuesta fue correlacionada con el comportamiento en una prueba clásica para evaluar la ansiedad: la prueba de la inhibición de la alimentación por la novedad ("Novelty-Suppressed Feeding (NSF) Test")

Experimento 2: El objetivo de esta prueba fue evaluar si los animales con el tumor subcutáneo juzgaban los estímulos ambiguos de forma más pesimista que los ratones que no lo poseían. Para esto se utilizaron 19 machos y 22 hembras de 4 semanas de edad, la mitad de ellos recibieron el trasplante tumoral y la otra mitad el tratamiento "sham". Debido a que como ya fue descripto, la línea A549 se desarrolla lentamente, se permitió que los tumores crezcan durante 4 semanas antes de comenzar el entrenamiento. 


\section{Trasplante tumoral}

La técnica de trasplante tumoral ya fue descripta en capítulos anteriores, ésta se realizó a las 4 semanas de edad de los ratones para el experimento 2 .

Pruebas comportamentales

"Novelty-Suppressed Feeding (NSF) Test" modificado:

La prueba de la supresión de la alimentación ya fue descripta en capítulos anteriores. La misma fue realizada al día siguiente de haberle presentado al animal el estímulo ambiguo.

\section{Sesgo cognitivo:}

El dispositivo que se utilizó consistió de una arena rectangular $(15 \mathrm{~cm}$ de ancho x $47 \mathrm{~cm}$ de largo x $14 \mathrm{~cm}$ de alto) dividida en tres secciones: un compartimiento de inicio en donde los animales fueron colocados utilizando ambas manos "en copa" y dos brazos $(7,5 \mathrm{~cm}$ de ancho x $27 \mathrm{~cm}$ de largo). Al final de cada brazo se posicionó un cuenco de $5 \mathrm{~cm}$ de diámetro que fue relleno con viruta de álamo. La entrada de los brazos no poseía compuertas de acceso pero una celdilla de necropsia rellena de algodón $(7 \mathrm{~cm}$ de ancho x 3 cm de largo x 0,5 cm de ancho) se adhirió a la entrada de cada uno de ellos (Figura 5.1).

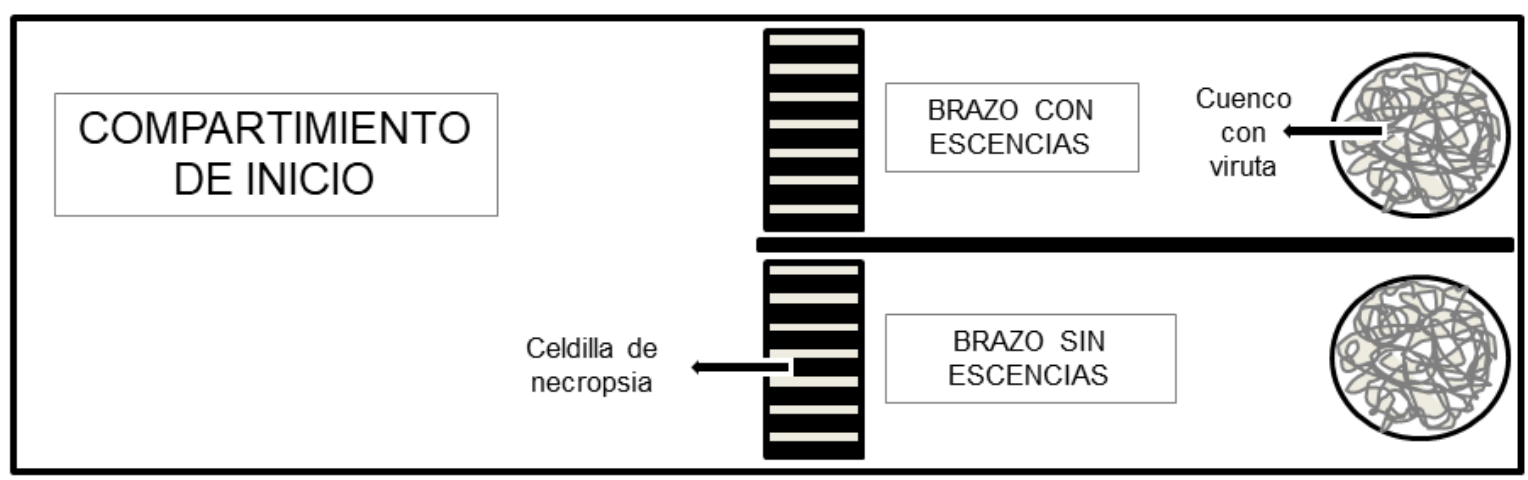

Figura 5.1. Dispositivo utilizado para la prueba de sesgo cognitivo. 
Los animales tuvieron que aprender mediante condicionamiento clásico que en el brazo que contenía las esencias, una de ellas predeciría una recompensa de alto valor para el ratón (una almendra) mientras que otra esencia predeciría la ausencia completa del premio. En el brazo adyacente siempre se presentó una recompensa de bajo valor para el animal (un copo de maíz), asociada únicamente a agua destilada como señal odorífera. Por lo tanto, los animales tuvieron que elegir entre ir a buscar la almendra o el copo de maíz según qué tipo de olor se encuentre presente en cada entrenamiento. La preferencia por las recompensas alimenticias se estableció en base a la experiencia previa con esta cepa de ratones y a otros experimentos previos (Novak y col., 2016). Para este protocolo se utilizaron esencias de vainilla y menta, diluidas en agua destilada en una proporción de 1:4. Se utilizaron olores como estímulo no condicionado debido a que ha sido demostrado que los ratones pueden utilizarlos para guiarse en comportamientos apetitivos (Matzel y col., 2006) y, como consecuencia, también han sido usados en otros ensayos de sesgo cognitivo en esta especie (Boleij y col., 2012).

Para facilitar el aprendizaje y por lo tanto para reducir el número de sesiones de entrenamiento (Brydges y Hall, 2017), las esencias se coloraron tanto en el algodón presente dentro de las celdillas de necropsia como en la viruta que se situaba dentro de los cuencos. Además, no se intercambiaron las señales odoríferas entre los brazos, que permanecieron constantes: en uno de ellos solo se colocó agua destilada para predecir la presencia del copo de maíz, y en el brazo contrario las esencias $(0,1 \mathrm{ml}$ en cada sitio) fueron rotando para predecir a la recompensa de alto valor o a la ausencia de la misma según qué fase del entrenamiento se trate. Los entrenamientos que predijeron la presencia de la almendra se denominaron "Entrenamientos Positivos", mientras que aquellos que 
anticiparon la ausencia de la recompensa se denominaron como "Entrenamientos Negativos".

La prueba fue dividida en 3 fases: habituación, entrenamiento y evaluación. Cada fase consistió en varias sesiones ( 1 sesión por día) con dos ensayos cada una. Se utilizó etanol al $70 \%$ para suprimir los olores entre animales y tanto la viruta como las celdillas de necropsia se cambiaron entre cajas.

La habituación consistió de 4 sesiones con ambos ensayos positivos, que tuvieron una duración de 5 minutos cada una. Las recompensas se colocaron al principio por encima de la viruta y posteriormente se fueron enterrando hasta permanecer completamente cubiertas al final de la fase de habituación. Se recolectó información de qué recompensa el ratón decidió comer primero (almendra o copo de maíz) y el tiempo en que demoró en comenzar a ingerirla.

El entrenamiento consistió en 12 sesiones de 3 minutos cada una. El primer entrenamiento de cada sesión fue positivo y el segundo fue negativo. Las recompensas, cuando fueron usadas, se enterraron completamente y se consideró que el animal tomó una decisión cuando comenzó a escavar en el sustrato. Se recolectó información del lugar que el animal decidió escavar primero y el tiempo en que demoró en tomar la decisión de empezar a escavar.

La fase de evaluación se solapó con los últimos tres días de la fase de entrenamiento: al finalizar la décima y onceava sesión se le presentó una señal sin la recompensa. En la décima sesión se le presentó la esencia asociada al refuerzo positivo y en la onceava sesión se le presentó la esencia asociada al refuerzo neutro, al tiempo que se los filmó durante 1 
minuto. Se contabilizó el tiempo que los ratones permanecieron en el brazo con cada esencia y éste se utilizó como criterio de aprendizaje: los animales se utilizaron en el análisis posterior sólo si permanecieron más tiempo en el brazo con la esencia que predijo la presencia de la almendra que en el brazo con la esencia que predijo la ausencia de la misma.

Al finalizar la doceava sesión de entrenamiento, se le presentó al animal el estímulo ambiguo que consistió en adicionar $0,05 \mathrm{ml}$ de ambas esencias (vainilla y menta) tanto en el algodón como en la viruta. Los animales se colocaron nuevamente en la arena y se los filmó durante 1 minuto: el tiempo que los animales permanecieron en el brazo que contenía ambas esencias fue contabilizado para comparar cómo los animales de cada grupo reaccionaron al estímulo ambiguo.

\section{Metodología estadística}

Los animales fueron asignados a cada tratamiento al azar cuando llegaron a la sala experimental utilizando una secuencia de números al azar generada en Microsoft Excel. Los análisis estadísticos se realizaron utilizando los software R 3.3.0 y R studio (2016). Se evaluó la normalidad de los datos utilizando el test de Shapiro-Wilks modificado y la homogeneidad de las varianzas con el test de Bartlett. De ser necesario, se realizó la transformación logarítmica de los datos para satisfacer los requerimientos de los tests estadísticos. Los resultados se muestran como las medias \pm E.E. Se consideró una probabilidad por debajo de 0,05 como significativa y una probabilidad entre 0,05 y 0,1 como una tendencia. 
Para el experimento 1, se utilizaron modelos lineales mixtos para analizar la respuesta de cada animal a lo largo de los días, utilizando el paquete estadístico de R lme4(Bates y col. 2015). Para la habituación, el tiempo en que el animal demoró en comer la almendra y el copo fue promediado por día. La relación entre el tiempo y el tipo de recompensa que eligieron comer según el día fue calculado como: lmer(segundos para empezar a comer tipo de comida ingerida + día + (1|ID)). Para la fase de entrenamiento primero se realizó un índice de discriminación para cada día de forma de poder calcular la relación entre el tiempo en que demoraron en tomar la decisión en el entrenamiento positivo y en el negativo como: $\left(\right.$ Tiempo $_{\text {positivo }}-$ Tiempo $\left._{\text {negativo }}\right) /\left(\right.$ Tiempo $_{\text {positivo }}+$ Tiempo $\left._{\text {negativo }}\right)$. La relación entre el índice de discriminación, el día y el sexo fue calculado de la siguiente forma: lmer(índice de discriminación $\sim$ día + sexo + (1|ID)). Para la fase de evaluación, la relación entre el tiempo que permanecieron en el brazo con las esencias y el tipo de esencia que se utilizó se calculó como: lmer(segundos en el brazo con las esencias esencia + sexo $+(1 \mid$ ID)).

Se agregó a todos los modelos el intercepto para cada individuo (1|ID) como un efecto aleatorio y los valores de probabilidad se obtuvieron utilizando la razón de verosimilitud entre el modelo completo con cada uno de los efectos fijos. En caso de ser necesario, se utilizó la prueba post-hoc de Tukey para comparar las diferencias entre grupos. Las diferencias en la prueba NSF modificada en machos y hembras fueron analizadas utilizando el test de Mann-Whitney. Para evaluar si hubo una asociación entre el tiempo que los animales permanecieron en el brazo con el estímulo ambiguo y el comportamiento en la prueba de ansiedad, se utilizó la correlación de Pearson.

Las diferencias entre los volúmenes tumorales se evaluaron con el test de Kruskal-Wallis. Se consideró la posibilidad de que el tiempo en que demoraron en comer la almendra pudo 
haberse visto modificado debido a algún proceso diferente al estado afectivo (tal como una pérdida del apetito o alteraciones en su locomoción). Para este fin se realizó otro análisis linear mixto para evaluar la relación entre el tiempo que demoraron en comer la almendra en las sesiones de entrenamiento y la respuesta de los animales de cada grupo a lo largo de los 12 días de la siguiente forma: $\operatorname{lmer}($ segundos para comer la almendra $\sim$ grupo + día + sexo + (1|ID)). Para evaluar el comportamiento hacia el estímulo ambiguo en los ratones con o sin tumores, se realizó un Análisis de la Varianza de 2 vías, utilizando el tratamiento y el sexo como factores. Finalmente, se utilizó la correlación de Spearman para evaluar si existió una asociación entre el tamaño tumoral y la respuesta al estímulo ambiguo.

\section{Resultados}

Para la habituación en el experimento 1 (Figura 5.3), se confirmó la preferencia de los ratones para comer la almendra por sobre el copo de maíz, con diferencias estadísticamente significativas $\quad\left(\mathrm{X}^{2}(1)=110,91 ; \quad \mathrm{P}<0,001\right)$. También $\quad$ se encontraron diferencias estadísticamente significativas en el comportamiento de los ratones a lo largo de los días $\left(X^{2}(3)=40,20 ; P<0,001\right)$; específicamente, una tendencia fue observada entre los días 1 y 2 $(\mathrm{P}=0,06), \mathrm{y}$ diferencias estadísticamente significativas entre el día 1 con los días 3 $(\mathrm{P}<0,001)$ y $4(\mathrm{P}<0,001)$. También se observó una tendencia entre los días 2 y $3(\mathrm{P}=0,056)$. No hubo diferencias entre los días 3 y 4 ( $\mathrm{P}=0,48)$. 


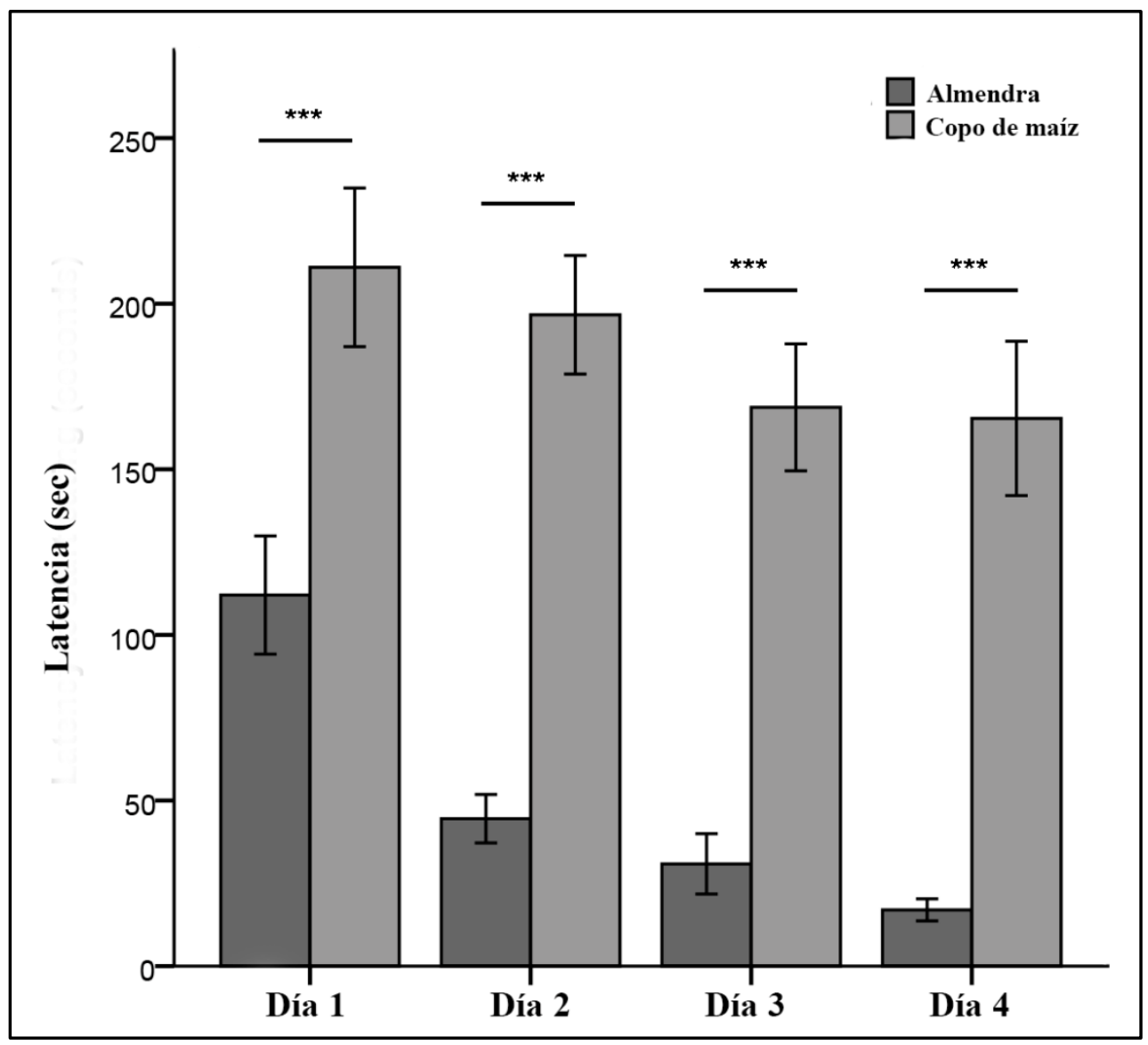

Figura 5.3. Promedio de tiempo por día en que los ratones demoraron en comer la almendra y el copo durante la fase de habituación. Modelo lineal mixto, ${ }^{* * *} \mathrm{P}<0.001$.

El índice de discriminación para la latencia en el tiempo que demoraron en cavar en el cuenco durante los entrenamientos positivos y negativos a lo largo de los 12 días de la fase de entrenamiento puede verse en la figura 5.4. Los valores más cercanos a (-1) indican una mejor discriminación entre el tiempo que demoraron en cavar en el cuenco que contenía la almendra con el cuenco que no contenía ninguna recompensa en el entrenamiento negativo. Esto es, con valores más cercanos a la discriminación perfecta (-1), los ratones demoraron menos tiempo en cavar en el cuenco cuando la almendra estaba presente. Se encontraron diferencias estadísticamente significativas en el índice de discriminación entre los días 
$\left(X^{2}(11)=83,54 ; \quad P<0,01\right) \quad$ pero no entre los $\operatorname{sexos} \quad\left(X^{2}(1)=1,407 ; \quad P=0,23\right)$. Más particularmente, las diferencias fueron encontradas cuando los primeros cuatro días de entrenamiento fueron comparados con los cuatro últimos.

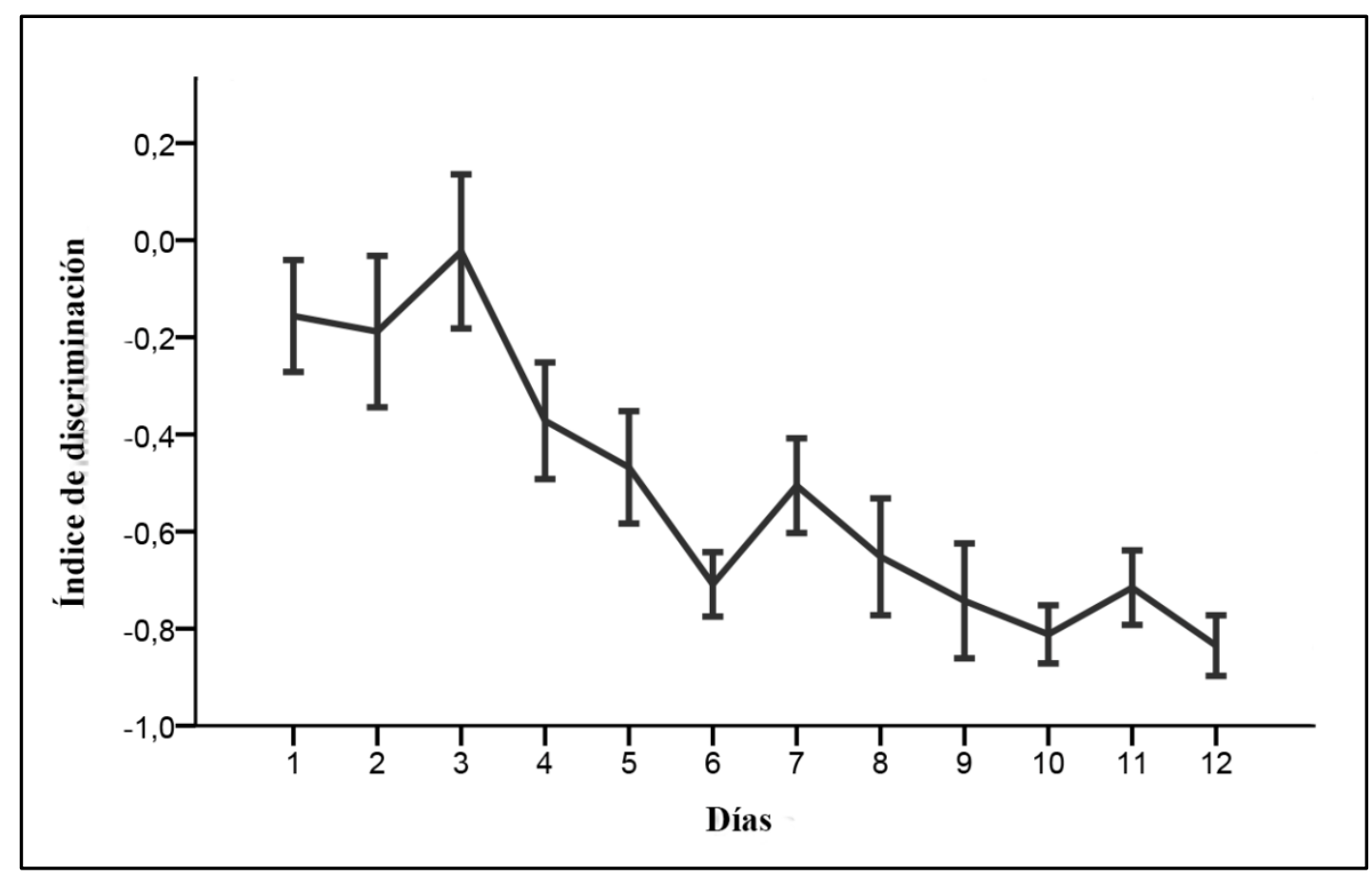

Figura 5.4. Índice de discriminación para la fase de entrenamiento en el experimento 1, que fue calculada como $\left(\right.$ Tiempo $_{\text {positivo }}-$ Tiempo $\left._{\text {negativo }}\right) /\left(\right.$ Tiempo $_{\text {positivo }}+$ Tiempo $\left._{\text {negativo }}\right)$. Valores más cercanos a (-1) indican una discriminación mejor entre el tiempo que demoraron en cavar en el ensayo positivo con el negativo.

Para la fase de evaluación en el experimento 1 (Figura 5.5), diferencias estadísticamente significativas se encontraron en el tiempo en que permanecieron en el brazo con la esencia en los entrenamientos positivos y negativos $\left(\mathrm{X}^{2}(2)=27,42 ; \mathrm{P}<0,01\right)$ pero no se encontraron diferencias entre los sexos $\left(\mathrm{X}^{2}(1)=0,137 ; \mathrm{P}=0,71\right)$. Específicamente, el tiempo en el que permanecieron en el brazo con la esencia durante la fase de evaluación del paradigma positivo fue significativamente más largo que en los paradigmas negativo y ambiguo. 


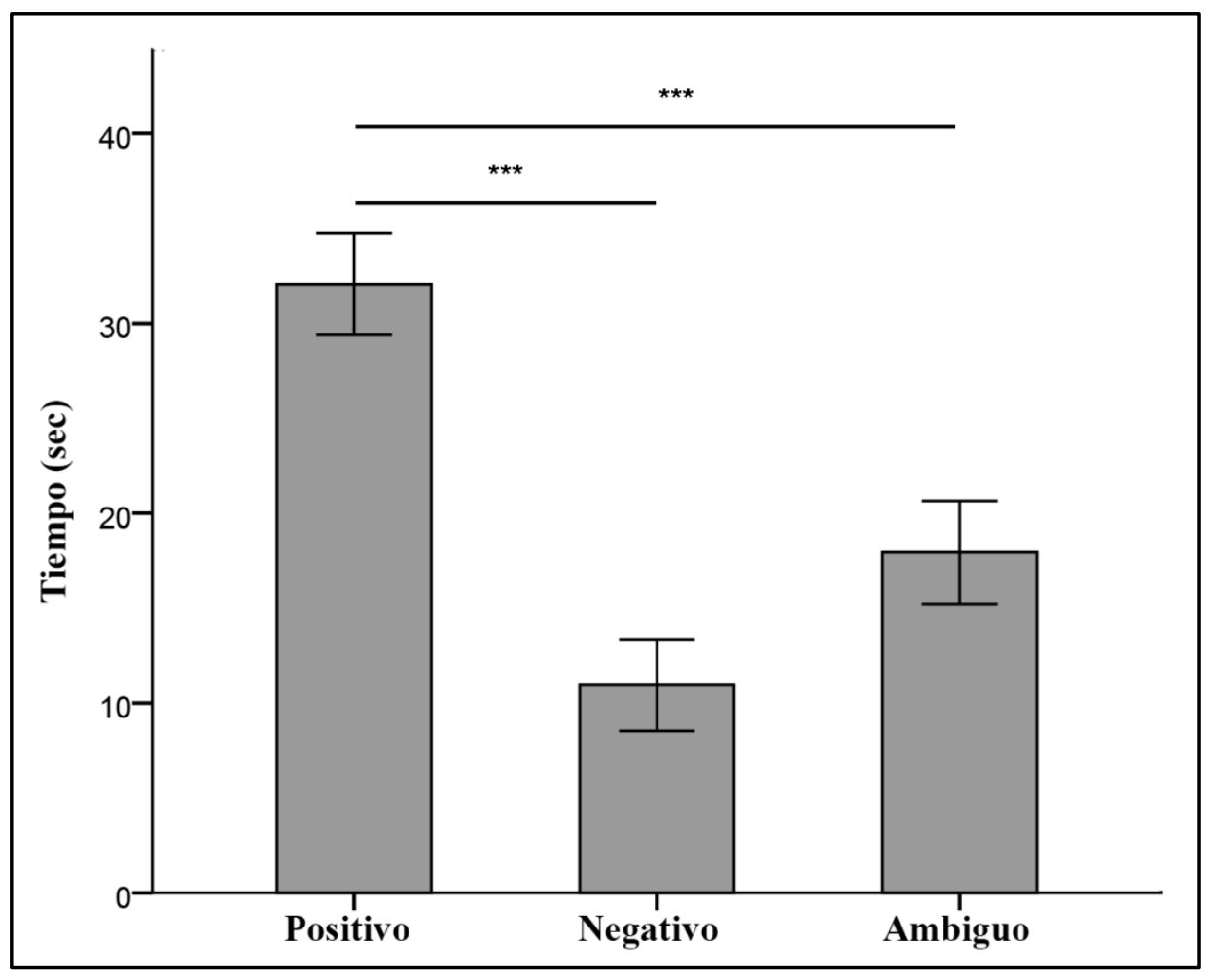

Figura 5.5. Tiempo en que los ratones permanecieron con los estímulos positivo, negativo y ambíguo en la fase de evaluación para el experimento 1 . Modelo lineal mixto, ${ }^{* *} \mathrm{P}<0.01 * * * \mathrm{P}<0.001$.

El tiempo que demoraron en comer la almendra en la prueba de la supresión de la alimentación modificada (modified-NSF test) fue 99,68 \pm 31,52 segundos para los machos y $50 \pm 7,5$ segundos para las hembras; estas diferencias no fueron significativas $(\mathrm{W}=46,00$; $\mathrm{P}=0,102)$. Se obtuvo una correlación negativa entre el tiempo que permanecieron en el brazo con el estímulo ambiguo y la respuesta en el NSF test $(R=-0,502 ; p<0,05)$, esto es, los animales que permanecieron menos tiempo en el brazo con el estímulo ambiguo demoraron más tiempo en comer la almendra.

Para el experimento 2, dos hembras no cumplieron el criterio de aprendizaje (el tiempo en el que permanecieron en el brazo con la esencia durante la fase de evaluación del 
paradigma positivo fue menor que en el paradigma negativo) por lo que no fueron incluidas en el análisis posterior. Los volúmenes tumorales al finalizar la experiencia fueron $0,95 \pm$ $0,30 \mathrm{~cm}^{3}$ para las hembras y $0,92 \pm 0,27 \mathrm{~cm}^{3}$ para los machos; estas diferencias no fueron significativas $(\mathrm{H}=0,11 ; \mathrm{P}=0,99)$. La presencia del tumor no modificó el tiempo en que demoraron en comer la almendra a lo largo de los días del entrenamiento $\left(X^{2}(1)=0,282\right.$; $\mathrm{P}=0,594$ ). Cuando se les presentó el estímulo ambiguo (Figura 5.6) se observó una tendencia a ser más "pesimista" en aquellos ratones que llevaban los tumores subcutáneos comparados con aquellos que no los llevaban $\left(\mathrm{F}_{1,35}=3,60 ; \mathrm{P}=0,065\right)$. También se observaron diferencias en la respuesta al estímulo ambiguo según el sexo, siendo las hembras las que se comportaron de forma más "pesimista" $\left(\mathrm{F}_{1,35}=4,84 ; \mathrm{P}<0,05\right)$. No se observó una correlación entre el volumen tumoral y la respuesta al estímulo ambiguo $(\mathrm{P}=0,44$ en las hembras y $\mathrm{P}=0,82$ en los machos). 


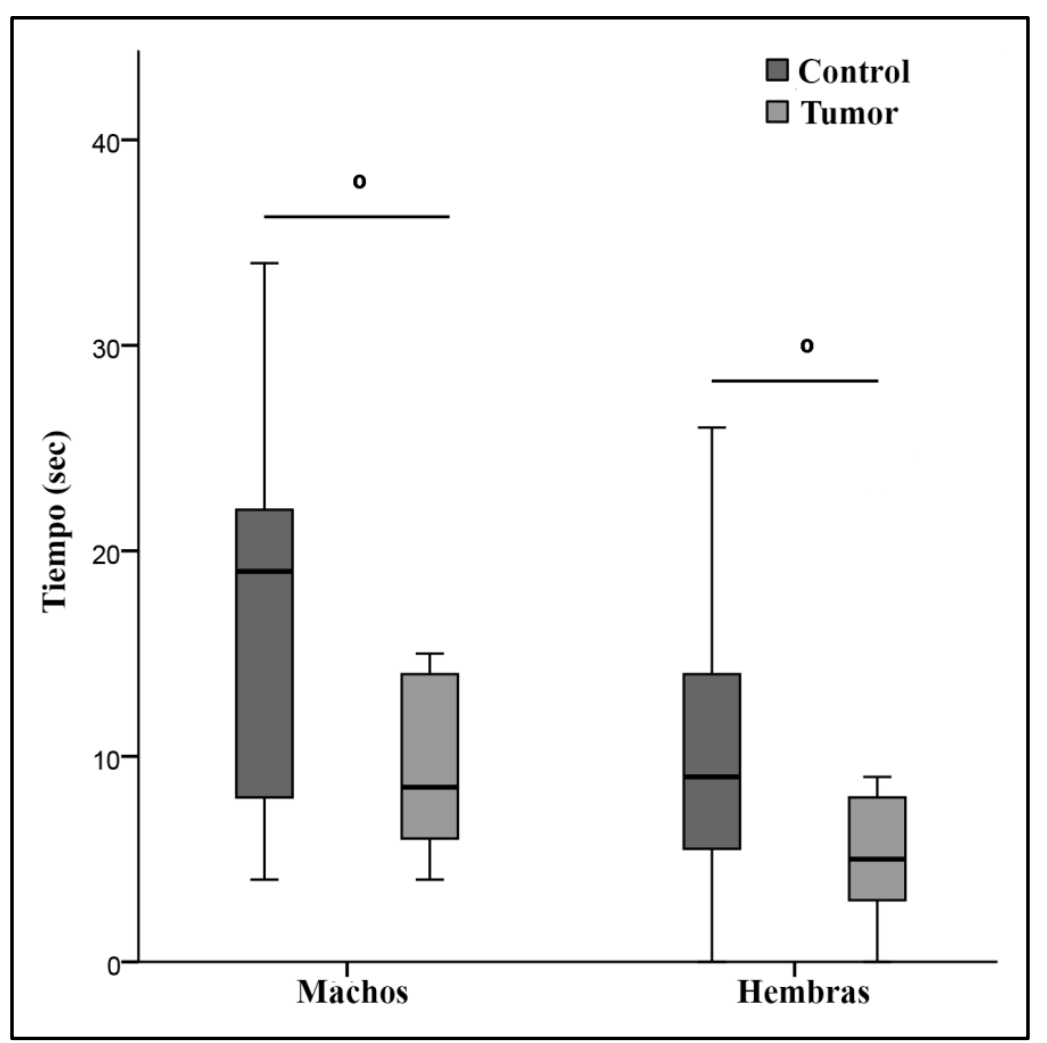

Figura 5.6. Fase de evaluación en el experimento 2. Tiempo en que los ratones macho y hembra con y sin trasplante tumoral permanecieron en el brazo con el estímulo ambiguo. Prueba de Kruskal-Wallis, ${ }^{\circ}=\mathrm{P}<0.01>0.05$.

\section{Discusión}

El objetivo de este capítulo fue introducir un nuevo método para evaluar sesgo cognitivo en ratones nude y utilizarlo para evaluar el impacto del desarrollo tumoral sobre el bienestar de este modelo animal. A partir de los resultados obtenidos, se pudo inferir que los ratones efectivamente pudieron distinguir entre ambos estímulos odoríferos y por lo tanto, presentaron una respuesta comportamental distinta dependiendo si la esencia estuvo asociada con la recompensa o si consistió en la esencia que predecía la ausencia de la misma. Además, encontramos una asociación entre el tiempo que permanecieron en el brazo durante el paradigma ambiguo y la respuesta a una prueba clásica para evaluar la 
ansiedad, lo que es importante ya que la ansiedad está frecuentemente asociada a sesgos pesimistas (Burman y col., 2009). Esto es significativo ya que para validar nuevas pruebas de sesgo cognitivo es necesario compararlas con otras pruebas para evaluar estados emocionales (Roelofs y col., 2016).

La tendencia pesimista en el experimento 1 para el estímulo ambiguo era de esperarse para ratones criados en condiciones de alojamiento estándar, en donde su bienestar está claramente comprometido (Balcombe, 2010). En ensayos anteriores de sesgo cognitivo también han descripto respuestas similares entre las respuestas a los estímulos negativos y ambiguos en esta especie (Boleij y col., 2012).

Sin embargo, en los ensayos previos de sesgo cognitivo en los que se han utilizado ratones, el enfoque estuvo puesto principalmente en cómo el alojamiento y la manipulación modifican la respuesta de los animales al estímulo ambiguo; por lo tanto su aplicación durante un ensayo biomédico no ha sido utilizado en tanta profundidad. Las observaciones clínicas veterinarias se realizaron continuamente y en ningún momento se detectaron signos que pudieran indicar una disminución del bienestar de aquellos ratones que poseían los trasplantes tumorales (Workman y col., 2010). De la misma forma, en ensayos previos que evaluaron el dolor en ratones de este modelo animal no detectaron alteraciones en el peso o en el comportamiento (Miller y col., 2016). Sin embargo resulta interesante resaltar que en otra experiencia en la cual se utilizaron otras líneas celulares (Jacobsen y col., 2013), el desarrollo tumoral sí disminuyó los indicadores de bienestar. En este experimento no se pesaron los ratones debido a la influencia que el peso del tumor podría tener en esta variable, pero sin embargo no detectamos alteraciones en la condición corporal. Por lo 
tanto, se podría concluir que las diferencias en la manifestación de la enfermedad podrían llegar a estar influenciadas por la línea celular que se utilice.

De la misma forma, tampoco se detectó una asociación entre el tamaño tumoral y la respuesta al estímulo ambiguo, pero esto podría deberse a que todos los animales acarrearon los tumores por la misma cantidad de tiempo. Por estos motivos se consideró que la evaluación del sesgo cognitivo en ratones en distintos estadios de desarrollo tumoral y con otras líneas celulares podría conllevar variaciones en el resultado.

A pesar de que se deberían realizar nuevos ensayos para descubrir la razón exacta por la cual el bienestar de los ratones de este modelo pareciera verse disminuido, además de examinar si estos ratones poseen una sensibilidad al dolor diferente que los utilizados anteriormente, estos resultados parecieran indicar que estos animales presentan un bienestar disminuido a pesar de que no se detectaron signos clínicos de sufrimiento. En este sentido, las nuevas ediciones de las guías de recomendaciones en el bienestar de los ratones en investigación oncológica deberían considerar que el bienestar evaluado mediante indicadores clásicos no siempre resulta adecuado, y la discusión ética debería realizarse para redefinir los estándares de bienestar basados en estas nuevas técnicas.

La relación entre el sexo y el sesgo cognitivo no fue estudiado en su totalidad. Un trabajo reciente describió una asociación entre ratas hembra y una respuesta más "pesimista" en la prueba de sesgo cognitivo (Barker y col., 2017), pero no tenemos conocimiento de que una relación similar haya sido descripta en ratones. En este trabajo en particular, no se observaron diferencias en la respuesta al estímulo ambiguo entre machos y hembra en el experimento 1 pero si se hallaron en el experimento 2. El aumento de respuestas fisiológicas y comportamentales debidas al estrés era de esperarse en este último, en donde 
la mayor tendencia de las hembras comparadas con los machos de sufrir ansiedad (Bale 2006) pudo haber desencadenado una respuesta más pesimista. Por este motivo, se necesitarían realizar más ensayos en esta temática ya que si el sexo podría desencadenar una respuesta global más pesimista, podría llegar a enmascarar alteraciones sutiles en el bienestar cuando se utiliza la prueba de sesgo cognitivo como indicador de bienestar animal.

\section{Conclusiones}

En este capítulo se diseñó una técnica de sesgo cognitivo para ratones nude en la que se emplearon estímulos olfativos que predijeron la presencia o ausencia de una recompensa. Dicha técnica posteriormente se utilizó en ratones nude inoculados con tumores subcutáneos, y se detectaron evidencias de que existió una disminución del bienestar de estos animales aunque no hayan existido signos clínicos de sufrimiento. Por lo tanto, este estudio plantea la problemática de que puedan existir alteraciones en el bienestar de estos animales, aún en ausencia de signos clínicos. Además, y en concordancia con lo que fue descripto por otros autores, las hembras parecieran ser más susceptibles al estrés que los machos, lo que puede incrementar las respuestas fisiológicas deletéreas y como consecuencia, modificar las variables experimentales. En el futuro, indicadores modernos de bienestar tales como la técnica de sesgo cognitivo, en la que se considera el punto de vista del animal, pueden llegar a mejorar el refinamiento de estudios biomédicos. 


\section{Refinamiento en investigación oncológica}

El uso de los animales de experimentación es un privilegio que se les otorga a los científicos a partir del consentimiento explícito de que las experiencias que se realicen proveerán nueva información relevante para el avance del área evitando todo el sufrimiento innecesario (Bailoo y col., 2014). Por este motivo resulta llamativo (y preocupante) la baja tasa de éxito que existe en la reproducibilidad de los resultados cuando se los desea trasladar los conocimientos adquiridos de los modelos animales hacia la especie humana (Kola y Landis, 2004). Al respecto, resulta imperativo mejorar la calidad de la investigación biomédica, mediante un refinamiento apropiado de las técnicas (Macleod, 2011). En especial para mejorar la validez de los modelos animales, más que de adherir a métodos o normativas específicas, se deben generar nuevos avances en investigación acerca del constructo que está siendo modelado (Bailoo y col., 2014). El bienestar de los animales utilizados en investigación corresponde una parte fundamental para mejorar la validez de estos modelos (Bailoo y col., 2014), y la estandarización de las condiciones ambientales (con el objetivo de disminuir por ejemplo las infecciones con patógenos en las distintas colonias) fue planteado en los inicios de la Ciencia de Animales de Laboratorio como una forma de mejorar el bienestar de estos individuos. Sin embargo, muchos autores están empezando a cuestionar la validez de dichos modelos, aludiendo cambios irreversibles en la fisiología de los organismos que generan que ya no sean comparables con el objeto de estudio (Garner, 2005, 2014; Martin y col.; 2010). 
El refinamiento en esta área de estudio se ha centrado principalmente en la determinación de los puntos finales humanitarios y de signos clínicos asociados a estados severos en los cuales el bienestar de los ratones con trasplantes de tumores se encuentra claramente comprometido (UKCCCR, 1998; Wallace, 2000; Workman y col., 2010). Al respecto en los capítulos anteriores se evaluó el efecto sobre el bienestar principalmente a través de indicadores comportamentales más sutiles para determinar el impacto real del desarrollo tumoral. El presente capítulo se centrará en el refinamiento del manejo de ratones utilizados en este tipo de modelos, en particular sobre la forma en la cual se obtienen las mediciones de los tumores in vivo y sobre la forma en que se alojan a los ratones, de forma de ponderar el efecto real que el enriquecimiento ambiental, en condiciones de manejo relativamente estándar, sobre el desarrollo tumoral.

\section{MÉTODO FOTOGRÁFICO DE MEDICIÓN DE TUMORES NO AVERSIVO}

La medición de los tumores subcutáneos a lo largo del tiempo es un procedimiento fundamental cuando se desea evaluar la efectividad de nuevos agentes terapéuticos. La metodología estándar de medición es mediante el uso de calibres externos, analógicos o digitales, a través de los cuales se toman distintos tipos de medidas en dos o tres dimensiones que luego se utilizan para determinar el volumen total del tumor (Tomayko y Reynolds, 1989). Las fórmulas que determinan el volumen de un elipsoide incluyendo la altura del tumor $(1 / 2 \mathrm{x}$ largo $\mathrm{x}$ ancho $\mathrm{x}$ altura) son las mejores para determinar la masa del tumor (con coeficiente de correlación de Pearson correspondiente a 0,93), sin embargo aquí

se estimó el volumen del elipsoide mediante la fórmula $\left(1 / 2 \times\right.$ largo $\mathrm{x}$ ancho $\left.{ }^{2}\right)$ debido a que 
es difícil obtener una medida consistente de la altura con el calibre y además, con esta última fórmula aún se mantienen excelentes coeficientes de correlación $(r=0,82)$ (Tomayko y Reynolds, 1989). La medición con calibre es económica, rápida y fácil de realizar, sin embargo posee una gran variación inter-observador que va desde el 7\% para tumores grandes hasta el 27\% para tumores chicos (Euhus y col., 1986). Para disminuir la variación inter-observador se han desarrollado otros métodos a partir de técnicas de imágenes tales como el ultrasonido, la tomografía computada y la resonancia magnética, pero éstas son más trabajosas, costosas, y dependen de la inmovilización física o química (a través de drogas tranquilizantes o anestésicas) del animal (Jensen y col., 2008; Ayers y col., 2010; Kersemans y col., 2013; Delgado San Martin y col., 2015).

Tal como fue descripto previamente, los ratones perciben la inmovilización física como sumamente aversiva, lo que puede alterar su comportamiento y fisiología (Gouveia y Hurst, 2013) y, por lo tanto, afectar los resultados experimentales. A pesar de que el efecto del estrés sobre el desarrollo tumoral no ha sido dilucidado en su totalidad, se ha descripto que la manipulación aumenta el volumen tumoral (Aarstad y Seljelid, 2006; Thaker y col., 2006) y las metástasis (Brenner y col., 1990). Además, contrariamente a lo que se podría esperar este último trabajo, los autores también describieron un aumento de las células natural killer $(\mathrm{NK})$ in situ, un tipo celular involucrado en la respuesta antitumoral. Un aumento de las células NK también se ha descripto en animales criados en ambientes enriquecidos, que es considerado un tipo de estrés positivo o eustrés, junto con una disminución en el volumen tumoral (Benaroya-Milshtein y col., 2011). Por lo tanto, el efecto del estrés sobre la inmunidad y, por consiguiente, sobre el desarrollo tumoral, 
pareciera que está afectado por la controlabilidad y la intensidad del estresor (Sklar y Anisman, 1979). Por este motivo consideramos que controlar las fuentes de estrés provenientes de situaciones sumamente desagradables para el animal contribuirá a refinar los procedimientos de investigación oncológica y, en última instancia, a mejorar los porcentajes de éxito cuando se desea trasladar los resultados a la especie humana.

Basados en la thigmothaxis, que es la preferencia natural de los ratones por tener su superficie corporal y en particular sus vibrisas, en contacto con otra superficie (Latham y Mason, 2004), se desarrolló un método de medición de tumores subcutáneos a partir de fotografías. Debido a esta propiedad, el uso de túneles para manipular a esta especie disminuye las respuestas de ansiedad sobre todo cuando se habitúan al procedimiento (Gouveia y Hurst, 2013). Esta habituación no se produce cuando los ratones se manipulan por la cola, en donde la repetición de los procedimientos no disminuye las respuestas de ansiedad (Gouveia y Hurst, 2013). Así, el objetivo de este apartado consistió en desarrollar un nuevo método para determinar el tamaño tumoral que se denominó método de medición fotográfica no aversiva (MFnoA). Para el mismo se utilizó un túnel transparente dentro del cual se colocó una hoja milimetrada como escala, y se tomaron fotografías a medida que los ratones ingresaron en dicho objeto que fueron utilizadas luego para medir los tumores. El objetivo consistió en evaluar si éste nuevo método de medición es válido para determinar el volumen tumoral, y en determinar si los ratones lo perciben menos desagradable que la medición clásica utilizando un calibre externo. 


\section{Materiales y métodos}

Animales y trasplante tumoral

Se utilizaron 56 ratones machos y hembras nude. Salvo que el procedimiento lo impidiera, para evitar los efectos de confusión que pudieron haberse producido por la sujeción por la base de la cola, los ratones siempre se manipularon con ambas manos "en copa", tal como fue descripto en el trabajo de Gouveia y Hurst (Gouveia y Hurst, 2017).

\section{Diseño experimental}

Experimento 1. El objetivo de este experimento fue evaluar si este nuevo método de medición fue válido para medir los tumores subcutáneos. Para alcanzar dicho objetivo se evaluó la variación intra-observador entre las mediciones con calibre y el MFnoA y la validez de dichos métodos comparándolos con un método de referencia (volumen de desplazamiento de agua y peso). Asimismo, se registró el tiempo que fue necesario para realizar cada determinación así como también el efecto de cada método sobre indicadores comportamentales y bioquímicos para determinar el impacto sobre el bienestar.

Para alcanzar estos objetivos se utilizaron 20 hembras trasplantadas y alojadas en grupos de 5 durante 3 semanas para permitirles al tumor crecer. El primer día de las próximas dos semanas (esto es, las semanas 4 y 5), se obtuvieron las medidas de los tumores con el calibre en la mitad de los ratones y con el MFnoA en la otra mitad. Inmediatamente después de estas determinaciones, se tomaron muestras de sangre en la semana 4 y, en la semana 5, se realizó la prueba de inhibición de la alimentación por la novedad (NSF test). 
Durante la semana 6 se evaluó la variación intra-observador, midiendo los tumores de todos los animales con ambos métodos dos días consecutivos (días 1 y 2 de la semana 6). Inmediatamente después, los animales fueron sacrificados por dislocación cervical y los tumores se diseccionaron para determinar su peso y volumen mediante el desplazamiento de agua.

Experimento 2. Su objetivo fue evaluar si alguno de estos dos métodos indujo variaciones en el comportamiento hacia el experimentador a lo largo del tiempo, así como también en la concentración de corticosterona en materia fecal. Para alcanzar este objetivo, 20 hembras y 16 machos fueron alojados en grupos de 2 animales por caja durante 4 semanas. El tamaño del tumor se determinó con el calibre en la mitad de ellos y con el MFnoA en la otra mitad. Para la identificación de cada individuo, el trasplante tumoral se realizó en el flanco derecho o izquierdo. Cada semana, las determinaciones de volumen fueron realizadas en el primer y segundo día. Las observaciones comportamentales fueron realizadas inmediatamente después de haber realizado las mediciones de los tumores en el segundo día. Las cajas se limpiaron al finalizar la observación del comportamiento y, al día siguiente, todos los pellets de materia fecal se recolectaron de dichas cajas.

\section{Medición del volumen tumoral}

Los tumores se midieron con el calibre o con el MFnoA según la necesidad de cada experimento. El tiempo que demoró realizar cada determinación fue contabilizado con un cronómetro. Luego de la eutanasia, se registró el peso de los tumores y el volumen determinado por el desplazamiento de agua. Para esto último, se evaluó la diferencia en el 
volumen medido con una probeta llena de agua destilada a temperatura ambiente antes y después de introducir los tumores. Los valores se expresaron en $\mathrm{cm}^{3}$.

Para el MFnoA, se utilizó una tubo trasparente de acrílico de sección rectangular de $12 \mathrm{~cm}$ de largo, $4 \mathrm{~cm}$ de ancho y $5 \mathrm{~cm}$ de alto (Imagen 6.1.a). Para medir los tumores se empleó papel milimetrado a modo de escala, que fue colocado dentro del tubo ocupando la mitad de su largo. El papel milimetrado se sostuvo en su lugar (a la mitad del ancho del tubo) utilizando una figura en "L". Este dispositivo de medición se colocó en la misma caja donde se alojaban los ratones (experimento 2) o en otra caja idéntica a la que utilizaban normalmente (experimento 1). Para el experimento 1, los animales se colocaron de uno en uno en la caja sujetándolos con ambas manos "en copa". Dentro de las cajas, el tubo fue colocado sobre uno de sus esquineros, adyacente a la pared más larga de la caja (Imagen 6.1.a). Cada ratón se introdujo voluntariamente dentro del tubo, desde el lado opuesto a donde se encontraba el papel milimetrado. A medida que exploraron el nuevo objeto, la mayoría de las veces permanecieron con la cabeza y los miembros anteriores detrás del papel milimetrado (Imagen 6.1.b). De esta forma, cuando los ratones se encontraron con la porción anterior del cuerpo detrás del papel milimetrado, se tomaron imágenes con la función ráfaga de una cámara Nikon modelo NSLR D3100. La cámara se situó perpendicular al lado más largo de la caja, a una distancia de $15 \mathrm{~cm}$. Las imágenes luego se analizaron utilizando el software gratuito Image J (Imagen 6.1.c.). Cuando se calibró la escala en el programa, la distancia tomada de referencia en el papel estuvo situada a la misma altura en que se encontraba el tumor. Dicha escala fue calibrada para cada imagen 
individualmente. Dos mediciones se tomaron en cada foto: el diámetro mayor del tumor fue considerado el largo y el menor fue considerado el ancho (Imagen 6.1.d.).

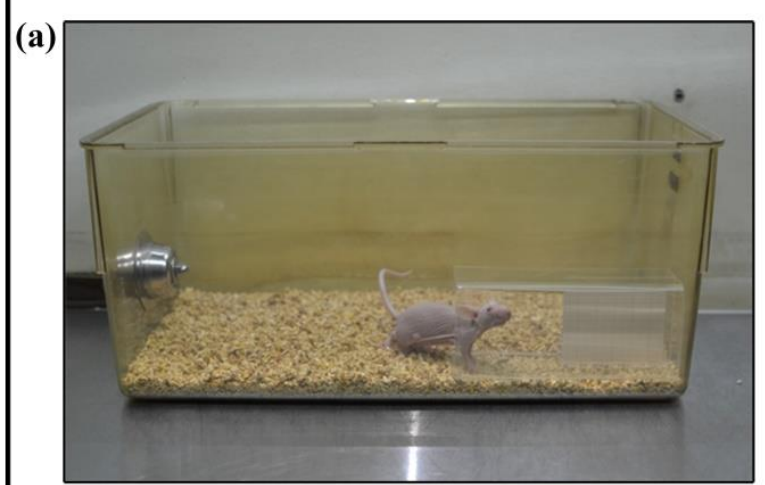

(b)

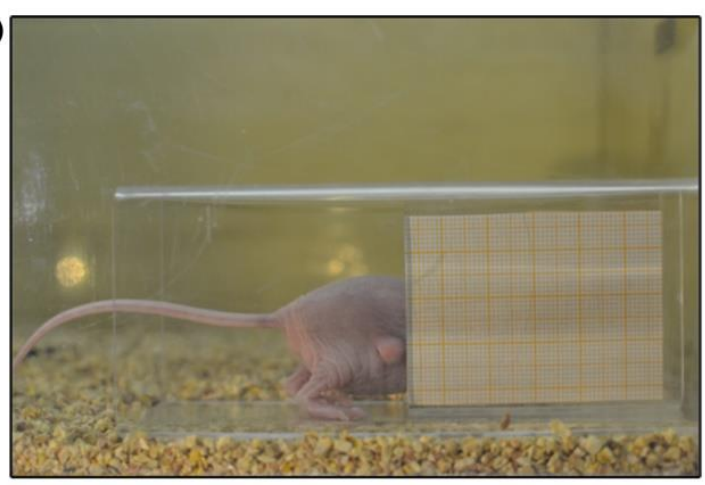

(c)

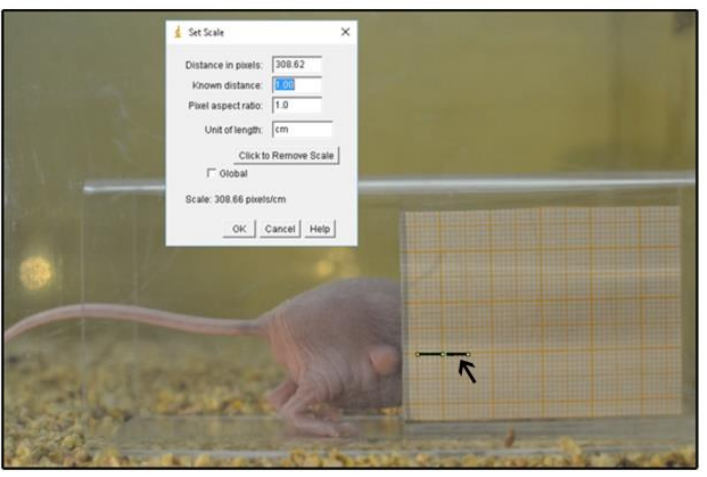

(d)

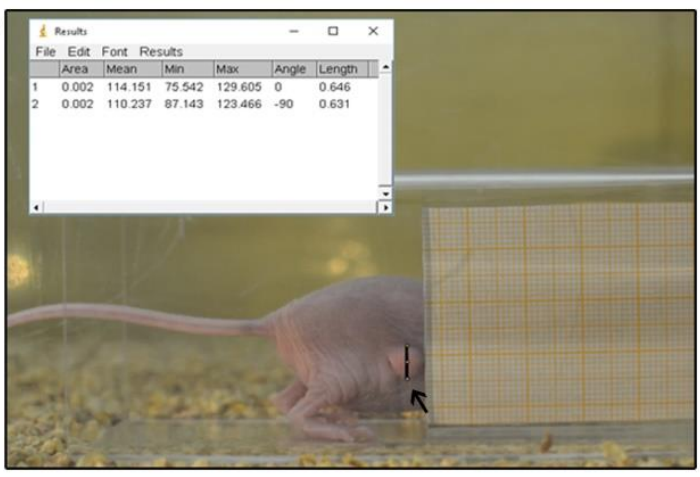

Imagen 6.1: Método de medición fotográfico de tumores no aversivo (MFnoA): (a) El dispositivo, que consistió de un tubo de acrílico trasparente con papel milimetrado en su interior, se colocó dentro de la caja donde normalmente habitaban los ratones o en una caja con las mismas características. (b) El ratón se introduce voluntariamente dentro del tubo y se toman fotografías cuando el tumor se sitúa al lado del papel milimetrado. (c) Se calibra la escala utilizando al papel milimetrado como referencia. (d) Se realiza la medición de los tumores utilizando los diámetros mayor y menor de los mismos.

\section{Glucemia}

Las muestras de sangre fueron tomadas 5 minutos después de la medición con cada método

a través de la vena submandibular utilizando una aguja $21 \mathrm{G}$ (Golde y col., 2005). Se extrajeron aproximadamente $100 \mu \mathrm{l}$ de sangre que se analizaron inmediatamente utilizando un glucómetro compacto (ContourTM ${ }^{\mathrm{TS}}$, Bayer). 
Determinación de los metabolitos de la corticosterona en materia fecal

Para realizar el muestreo de los metabolitos de la corticosterona en materia fecal en el experimento 2, se recolectaron todos los pellets de materia fecal 24 hs luego del procedimiento de medición de los tumores. El procesamiento de las muestras y el análisis mediante la técnica de EIA se describió en capítulos previos.

\section{Ensayos comportamentales}

Experimento 1. Se realizó el "NSF test", explicado en los capítulos previos, inmediatamente luego de realizar las mediciones de los tumores con cada método. La hipótesis radicó en que, al utilizar un método de medición menos aversivo, los ratones se comportarían menos ansiosos, y por lo tanto más dispuestos a aventurarse al centro del campo abierto para comer la recompensa, a la vez que realizaron menos comportamientos de ansiedad (acicalamiento y defecación).

Experimento 2. Se evaluó la frecuencia de los contactos voluntarios del ratón con la mano del investigador, inmediatamente después de realizar la segunda medición con cada método. Ambos ratones se condujeron gentilmente hacia uno de los lados de la caja utilizando una barrera de cartón. Debido al diseño de la caja, los animales se dirigieron hacia donde estaba situado el comedero y por lo tanto, resultó ser el sitio menos expuesto y por lo tanto más protegido para los mismos. Posteriormente, el investigador colocó su mano en el lado opuesto de la caja y retiró la barrera de cartón. Se registró el número de contactos con la cabeza o las patas en un período de tres minutos. La hipótesis radicó en que, al utilizar un método de medición menos aversivo, los animales se encontrarían menos 
ansiosos y por lo tanto, más dispuestos a abandonar la zona más protegida de la caja para aventurarse y explorar la mano del investigador.

\section{Metodología estadística}

Los animales se asignaron al azar a las diferentes cajas cuando llegaron a la sala de experimentación mediante una secuencia de números aleatorios generada en Microsoft Excel; además, las cajas se asignaron a cada tratamiento y seleccionadas para la recolección de información en los diferentes momentos de análisis con la misma modalidad. Los análisis estadísticos fueron realizados utilizando R3.3.0, Rstudio (2016) e Infostat (2015). La normalidad de los datos se evaluó mediante la prueba de Shapiro-Wilks. Los valores fueron expresados como media $\pm \mathrm{EE}$.

Para evaluar la validez intra-observador se utilizó el Coeficiente de Correlación Intraclase (CCI). Se consideró a los valores por encima de 0,75 como representativos de una excelente concordancia entre la primera y la segunda repetición. Para comparar entre métodos, el test no paramétrico de Friedman con el método de comparación post hoc de Dunn. La concentración de glucosa en sangre fue evaluada mediante Análisis de la Varianza (ANOVA)

Para el experimento 2, las diferencias en la concentración de corticosterona y de los contactos voluntarios con el investigador entre los dos métodos fueron evaluadas semanalmente utilizando un ANOVA a dos vías. Debido a que no se separó a los animales para evaluar el comportamiento y recolectar la materia fecal, la caja fue considerada la unidad experimental. Para cumplimentar con los presupuestos del método, se realizó la 
transformación logarítmica de la concentración de corticosterona y la transformación a raíz cuadrada de la frecuencia de contactos con el investigador. Los resultados estadísticamente significativos se sometieron al análisis post-hoc de Tukey.

\section{Resultados}

\section{Experimento 1}

Los volúmenes tumorales fueron determinados mediante la metodología clásica a través de la utilización de un calibre y del método propuesto de MFnoA. Los detalles de los volúmenes tumorales en la primera y segunda repetición así como los Coeficiente de Correlación Intraclase (CCI) pueden observarse en la Tabla 6.1. Todos los coeficientes demostraron una concordancia excelente entre repeticiones, ya que todos los valores fueron superiores 0,95. Se encontraron diferencias significativas entre los volúmenes de desplazamiento de agua y los obtenidos a partir de las mediciones con calibres y el MFnoA, pero no a partir de repeticiones entre cada método $(\mathrm{F}=9,81 ; \mathrm{P}<0,001)$. No hubo diferencias significativas entre el peso y el volumen de desplazamiento de agua.

\begin{tabular}{lcc}
\multicolumn{1}{c}{ Método y repetición } & Media $\pm \mathbf{E E}$ & CCI \\
\hline Volúmen & $0,398 \pm 0,10 \mathrm{~cm}^{3}$ & 0,994 \\
Peso & $0,391 \pm 0,10 \mathrm{gr}$ & \\
\hline Calibre 1 $^{\text {ra }}$ & $0,556 \pm 0,15 \mathrm{~cm}^{3}$ & 0,987 \\
Calibre 2 $^{\text {da }}$ & $0,553 \pm 0,15 \mathrm{~cm}^{3}$ & \\
\hline MFnoA 1 $^{\text {ra }}$ & $0,614 \pm 0,16 \mathrm{~cm}^{3}$ & 0,963 \\
MFnoA 2 $^{\text {da }}$ & $0,609 \pm 0,15 \mathrm{~cm}^{3}$ & \\
\hline
\end{tabular}

Tabla 6.1. Volúmenes tumorales para cada método con dos repeticiones expresados como media \pm EE, y los coeficientes de correlación intraclase para cada par de repeticiones. 
La latencia para ingerir la almendra en el NSF modificado fue significativamente más corta para los ratones del MFnoA que para los ratones cuyos tumores fueron medidos con los calibres (Figura 6.1.a). De la misma forma, la frecuencia de acicalamiento (Figura 6.1.b) y de defecación (Figura 6.1.c) fue significativamente menor en aquellos ratones que fueron expuestos al MFnoA. Los valores de $\mathrm{H}$ fueron 3,53 $(\mathrm{p}=0,049)$ para el NSF test; 8,17 $(\mathrm{P}=0,002)$ para la frecuencia de acicalamiento y 7,94 $(\mathrm{P}=0,002)$ para la frecuencia de defecación.

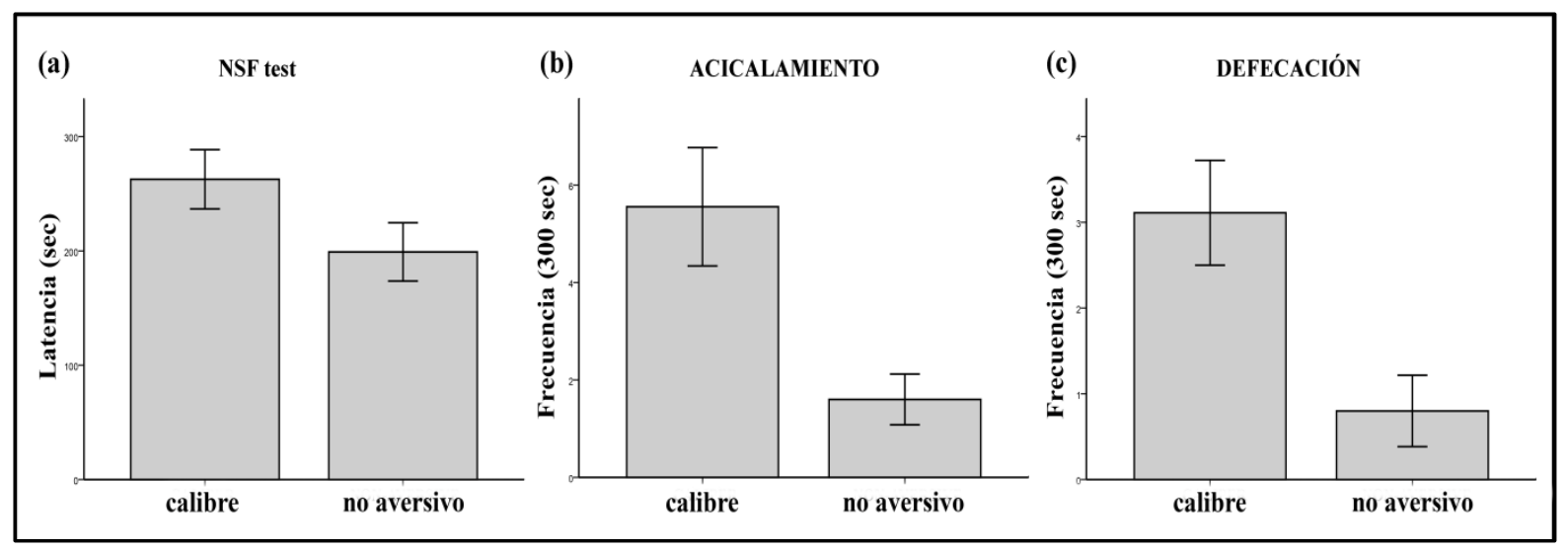

Figura 6.1. Comportamiento de los ratones inmediatamente después de la medición con el calibre y el método fotográfico no aversivo (MFnoA). (a) Latencia para comer la almendra en el NSF test y frecuencia de (b) grooming y (c) defecación durante los 300 segundos que duró la prueba.

La glucemia fue levemente superior en el grupo de los ratones medidos con el calibre $(142,33 \pm 6,09 \mathrm{mg} / \mathrm{dL})$ que con el MFnoA $(130,70 \pm 6,1 \mathrm{mg} / \mathrm{dL})$, pero estas diferencias no fueron estadísticamente significativas $\left(\mathrm{F}_{1,18}=1,81 ; \mathrm{P}>0,05\right)$. Finalmente, tal como era de esperarse, el MFnoA demandó más tiempo, dado que llevó 71,40 \pm 10,73 segundos comparado con la medición con el calibre que ocupó $20,22 \pm 1,62$ segundos por animal. Además, el MFnoA demandó un procesamiento posterior de las imágenes en el cual se 
calibró la escala, se midieron los tumores, se completó la base de datos y ocasionalmente, se incrementó el contraste de la imagen para delimitar mejor los tumores, que conllevó $98,10 \pm 5,17$ segundos por animal.

Experimento 2

La frecuencia de los contactos voluntarios con el investigador así como también la concentración de los metabolitos de la corticosterona en materia fecal obtenidos a los largo del tiempo (4 semanas) se muestra en la Figura 6.2. Para los contactos voluntarios con el investigador, se observaron diferencias significativas entre tratamientos $\left(F_{1,64}=17,53\right.$; $\mathrm{P}<0,001)$ y semanas $\left(\mathrm{F}_{3,64}=7,21 ; \mathrm{P}<0,001\right)$. Desde la semana 2 y hasta el final del estudio, los ratones que estuvieron expuestos al MFnoA fueron menos reacios a establecer contacto con el investigador que aquellos cuyos tumores fueron medidos con el calibre. Diferencias significativas en la concentración de los metabolitos de la corticosterona en materia fecal fueron observados entre semanas $\left(F_{3,64}=6,13 ; \mathrm{P}<0,001\right)$ pero no entre métodos $\left(\mathrm{F}_{1,64}=0,69\right.$; $\mathrm{P}=0,40)$. 


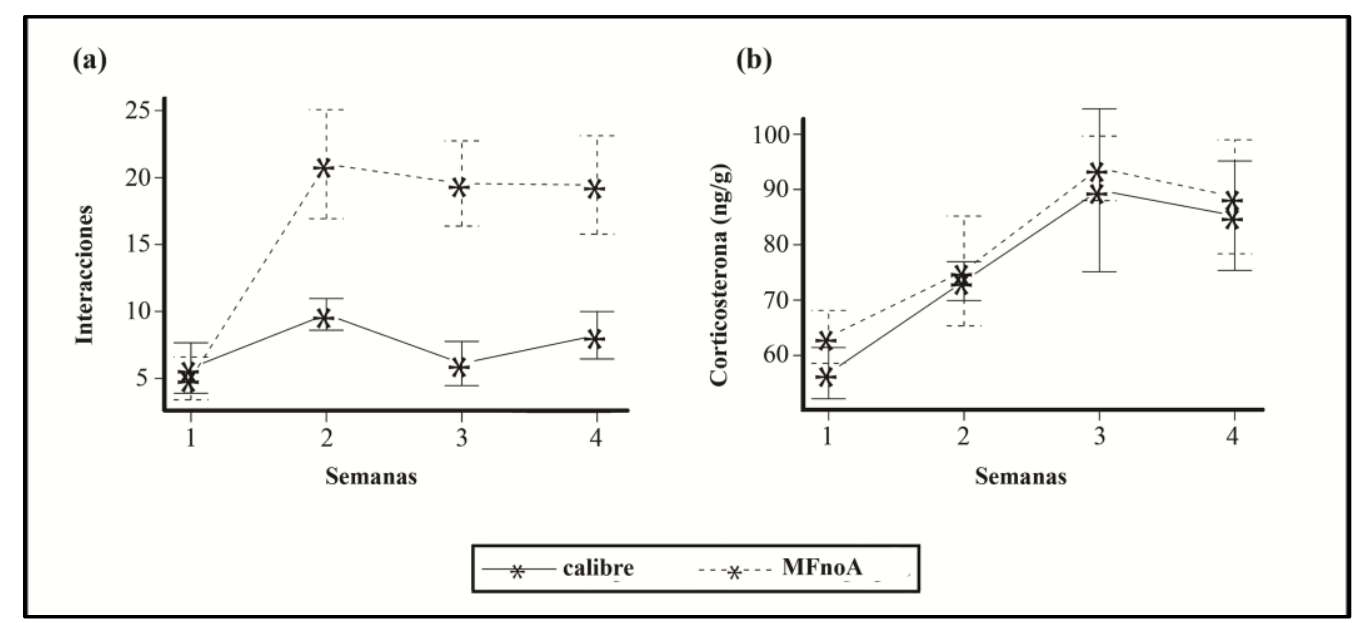

Figura 6.2. Parámetros comportamentales y fisiológicos a través del tiempo en ratones que estuvieron expuestos a ambos métodos de medición. (a) Secuencia temporal de las interacciones humano-animal expresadas como frecuencia de contactos en un período de 3 minutos (b) Concentración de los metabolitos de la corticosterona en heces (ng/g) a lo largo de 4 semanas.

\section{Discusión}

El método de MFnoA corresponde, según nuestro conocimiento, a la primera técnica para medir los tumores subcutáneos que no requiere la inmovilización del animal. La necesidad de un método con estas características fue descrita recientemente por Delgado San Martin y col. (Delgado San Martin y col., 2015). Esta técnica puede ser realizada en ratones alojados individualmente o en parejas, sin la necesidad de manipular a los animales para medir los tumores a través del tiempo. En este experimento identificamos a cada individuo según el lado sobre el que se realizó el trasplante tumoral (derecha o izquierda). La medición tumoral con el MFnoA en ratones alojados en grupos más grandes que dos individuos por caja también podría realizarse, siempre que los ratones se encuentren debidamente identificados. Además, aunque la medición en la caja no sea posible, se observó una 
reducción en la ansiedad medida en el NSF test, luego de que los ratones fueran trasladados a otra caja con las manos "en copa" y se midieran los tumores utilizando el MFnoA.

Tal como era de esperarse para tumores bien vascularizados y no calcificados, el peso de los tumores fue el valor más cercano al volumen de desplazamiento de agua (Euhus y col., 1986). Tanto el calibre como el MFnoA produjeron medidas estadísticamente diferentes a aquellas obtenidas usando el método de referencia, lo que pudo haberse debido principalmente a que éstos también incluyen la piel y el tejido subcutáneo (Kersemans y col., 2013). Aunque las mediciones con calibre se acercaron más a las medidas generadas a partir del método de referencia, hubo una buena consistencia entre las repeticiones para ambas técnicas, lo que significa que el MFnoA resulta aceptable para registrar el desarrollo tumoral a lo largo del tiempo. Debido a que el MFnoA tiende a sobreestimar el tamaño de los tumores, antes de implementarlo se recomienda realizar estudios piloto para determinar qué tamaño de tumor se considera aceptable para determinar el punto final humanitario. Para alcanzar dicho objetivo, esta nueva técnica se debería comparar con técnicas modernas de medición por imágenes para sobrellevar la problemática de incluir tejidos adicionales cuando se determina el tamaño de los tumores. Además, resulta interesante resaltar que las guías de recomendaciones internacionales en investigación oncológica no especifican sobre qué métodos se basan y por lo tanto, esto puede tener importantes implicancias para mejorar dichos documentos.

Además, se evaluó el impacto que ambos métodos (calibre vs MFnoA) tuvieron sobre el bienestar de los ratones, a través de indicadores fisiológicos y comportamentales. La interpretación global del bienestar basada en parámetros objetivos es complicada dada la 
subjetividad intrínseca del estado afectivo de un animal (Fraser 2008). Por lo tanto, evaluar el contexto y los datos comportamentales es importante para interpretar los datos fisiológicos.

Aunque no se observaron diferencias significativas en los metabolitos de la corticosterona en materia fecal ni en la glucemia entre los dos métodos, la respuesta comportamental que los animales realizaron en el MFnoA fue sumamente diferente a aquella respuesta posterior al uso de los calibres, ya que los ratones se comportaron de forma menos ansiosa en el NSF test. La corta duración de la respuesta de estrés producida luego de un solo evento de sujeción pudo no haber sido vista en los metabolitos de corticosterona, ya que los mismos consideraron un período de 24 hs (Cinelli y col., 2007). Sin embargo, la similitud entre ambos métodos en la concentración de glucosa en sangre podría llegar a predecir una respuesta en la concentración de corticosterona similar, ya que la glucemia se incrementa debido a la activación del sistema nervioso simpático (SNS) y éste anticipa la respuesta del eje hipotálamo-hipófisis-adrenal (HPA). A pesar de ello, centrándonos en los datos comportamentales, se podría intuir una mejora en el bienestar debido a una reducción en la ansiedad para el MFnoA, ya que los animales de este grupo comieron la almendra en significativamente menos tiempo, fueron menos reacios a establecer contacto con el investigador, y se acicalaron y defecaron menos que los ratones expuestos a la medición con el calibre. Tanto el acicalamiento como la defecación también son variables comportamentales extensamente utilizados como indicadores de ansiedad (Kauleff y Touhimaa, 2005; Kauleff y col., 2007; O’Leary y col., 2013). Además, inferimos que el tubo utilizado en el MFnoA no generó una respuesta aversiva ya que todos los animales 
decidieron entrar al tubo. Estos resultados concuerdan con lo que previamente describieron Hurst y West (Hurst y West, 2010), quienes describieron que sujetar a los ratones por la cola es sumamente aversivo para esta especie y les induce una elevada ansiedad, mientras que el uso de túneles aumenta el acercamiento voluntario al investigador, disminuye la ansiedad y conduce a la aceptación de la inmovilización física.

Por estos motivos podría predecirse que será más sencillo para los ratones adaptarse a esta nueva técnica y por consiguiente, se podría disminuir la variabilidad de los distintos parámetros de estudio debido a la exposición a estrés incontrolable. El MFnoA también es económico, ya que sólo requiere de un tubo de acrílico transparente y una cámara fotográfica. En esta experiencia se utilizó una cámara Nikon modelo DSLR D3100, pero cualquier equipo de buena resolución podría llegar a utilizarse. Además, aunque para aplicar esta técnica no se requiere de una cantidad de tiempo excesivo (aproximadamente 60 segundos), inferimos que a medida que los ratones se habitúan al procedimiento la cantidad de tiempo necesario para tomar las mediciones se irá reduciendo. El tiempo que necesario para realizar el análisis de cada foto también fue corto, ya que el mismo fue de aproximadamente 100 segundos para analizar cada imagen. Finalmente, esta técnica también se podría usar para medir tumores subcutáneos inoculados en ratones inmunodeficientes de cepas con pelo (por ejemplo ratones SCID), pero en ese caso el área que rodea el tumor debe der debidamente depilada. 


\section{Conclusiones}

En conclusión, las evidencias comportamentales demostraron una marcada disminución en la ansiedad cuando se utilizó el MFnoA, por lo que su implementación podría contribuir a mejorar el bienestar de los ratones utilizados en investigación oncológica. Sin embargo, la ausencia de un correlato fisiológico resalta la importancia de realizar nuevos experimentos para caracterizar el perfil fisiológico de los animales sometidos a los distintos métodos de medición. En particular, en relación a la concentración de corticosterona en sangre, nuestro diseño experimental solo nos permitió inferir una asociación similar con la glucemia, con una ausencia en el efecto de largo plazo en la liberación de esta hormona.

\section{ENRIQUECIMIENTO AMBIENTAL EN RATONES CON XENOTRASPLANTES SUBCUTÁNEOS}

Bajo los estándares actuales, el nivel de bienestar que se considera ideal va más allá de los estándares regulatorios: es la diferencia entre un estado bueno y uno óptimo de bienestar (Maple y Bloomsmith, 2017). Una forma posible de lograr este nivel óptimo de bienestar es estableciendo oportunidades para realizar comportamientos gratificantes, en particular aquellos asociados a la exploración, la alimentación y los comportamientos afiliativos (Mellor, 2015). En general, aquellos ambientes que promueven comportamientos activos, diversos y flexibles son preferibles a aquellos que generan comportamientos apáticos o estereotipados (Meehan y Mench, 2007). 
El enriquecimiento ambiental hace referencia a una combinación de estimulación inanimada compleja y social que mejora la estimulación sensorial, cognitiva, motora y social, comparado con las condiciones estándar de alojamiento. Sobre todo, el enriquecimiento ambiental provee a los animales de oportunidades para realizar comportamientos específicos de especie (Sztainberg y Chen, 2010). El uso de enriquecimiento ambiental, típicamente una herramienta aplicada en los zoológicos para atenuar las condiciones de encierro, tuvo un inicio controvertido en la Ciencia del Bienestar Animal, ya que se argumentaba que podría modificar los resultados y la variabilidad de los datos obtenidos. El aumento de la variabilidad de los datos representaría un problema ético, ya que se debería aumentar el número de animales utilizados para alcanzar la significación estadística (André y col., 2018). Al respecto, Ritcher y col. (Richter y col., 2009) describieron un enfoque distinto, en el que la heterogenización sistemática de las condiciones ambientales pueden aumentar la variación intra-experimento pero con menor variación inter-experimento, lo que mejoraría la validez externa de los mismos. Sin embargo, este enfoque no pudo ser completamente comprobado. La aplicación del enriquecimiento ambiental en distintos protocolos demostró que efectivamente puede modificar los resultados alcanzados en distintas variables experimentales (Van de Weerd y col., 2002). Sin embargo, en un trabajo reciente llegaron a la conclusión de que si bien el enriquecimiento ambiental modifica algunas de las variables experimentales, no afecta a la variabilidad de los resultados obtenidos (André y col., 2018). Por lo que aplicado de forma sistemática y con una correcta descripción de la metodología empleada, no debería afectar la calidad científica (Van de Weerd y col., 2002). 
En líneas generales, se han planteado dos tipos de experimentos para evaluar el impacto que tiene el enriquecimiento ambiental sobre el bienestar animal. Por un lado, se han desarrollado experimentos que miden el deseo que tienen los animales por determinados objetos, en los que se evalúa la preferencia de unos materiales por sobre otros y también en qué medida están dispuestos a trabajar para obtenerlos (tests de preferencia y fuerza de motivación). Por el otro lado, se ha evaluado los efectos del enriquecimiento ambiental sobre distintas variables comportamentales y fisiológicas (Hutchinson y col., 2005).

Para el caso particular del desarrollo tumoral se ha visto que los ratones alojados en cajas enriquecidas presentan una mayor actividad citotóxica de las células natural killer (NK), un tipo de linfocito programado para destruir ciertas células infectadas por virus y algunos tipos de células de tumores (Benaroya-Milshtein et al, 2004). Esto se torna de gran relevancia para la oncología humana, dado que las células de la línea A549 son sensibles al efecto citotóxico de las células NK (He et al, 2013). Además, se ha observado que el enriquecimiento ambiental disminuye el desarrollo tumoral en modelos de melanoma y cáncer de colon (Cao et al, 2010). El mecanismo que promueve esta acción parecería ser una retroalimentación positiva estimulada por el enriquecimiento ambiental y que promueve la liberación hipotalámica del factor neurotrófico derivado del cerebro (BDNF). Sin embargo, en este último trabajo no se diseccionaron los distintos componentes del enriquecimiento ambiental (social, cognitivo, sensorial, alimenticio, estructural). 


\section{Materiales y métodos}

Animales y diseño experimental

Se utilizaron 20 ratones macho y 20 ratones hembra, que se alojaron en grupos de a 5 animales por caja en alguna de las 4 condiciones ambientales. Los ratones llegaron a la sala de experimentación a las 3 semanas de edad y se mantuvieron en dichas condiciones durante 4 semanas. Se utilizó este período de tiempo debido a que se observó que las modificaciones ambientales durante menos de tres semanas previas al trasplante tumoral resultaron inefectivas para alterar la progresión tumoral (Garofalo y col., 2015). Transcurrido ese tiempo se realizó el trasplante tumoral. Se permitió que los tumores crezcan durante 4 semanas antes de sacrificar a los ratones por dislocación cervical para pesar a los ratones y diseccionar los tumores y los bazos.

\section{Enriquecimiento ambiental}

Los ratones se mantuvieron en alguna de las siguientes modificaciones ambientales:

A- Enriquecimiento simple: los ratones se mantuvieron en cajas "Super Mouse 750"TM" $\left(>483 \mathrm{~cm}^{2}\right)$, a las que se les adicionó papel como material de nido y semillas de girasol sin cáscara (Imagen 6.2).

B- Enriquecimiento complejo en caja de tamaño estándar (Imagen 6.3): los ratones se mantuvieron en cajas "Super Mouse $750^{\mathrm{TM} "}\left(>483 \mathrm{~cm}^{2}\right)$ a las que se les adicionó los siguientes materiales: 
- Tubo relleno: 1 rollo de cartón de $5 \mathrm{~cm}$ de diámetro y $10 \mathrm{~cm}$ de largo relleno con viruta de álamo prensada. Los extremos del mismo se sellaron utilizando la porción cóncava de una huevera de cartón

- Refugio: caja de cartón circular con tapa de $9 \mathrm{~cm}$ de diámetro y $5 \mathrm{~cm}$ de alto. En el interior se colocaron 4 hojas de papel tipo tissue

- Un barbijo colgado del techo de la caja

- Semillas de girasol con cáscara

- Un disco de algodón de $6 \mathrm{~cm}$ de diámetro

- $\quad$ Papel en tiras

- Un hilo de papel

C- Remoción EA post-trasplante tumoral: los animales se mantuvieron en el enriquecimiento ambiental complejo (B) hasta el procedimiento de trasplante tumoral, luego de lo cual se mantuvieron en la condición de enriquecimiento simple (A).

D- Enriquecimiento complejo en caja de tamaño superior (Imagen 6.4): los ratones se mantuvieron en cajas "Super Mouse $1800^{\mathrm{TM}}$ " $\left(>1160 \mathrm{~cm}^{2}\right)$ a las que se les adicionó los siguientes materiales:

- Tubo relleno: 1 rollo de cartón de $5 \mathrm{~cm}$ de diámetro y $10 \mathrm{~cm}$ de largo relleno con viruta de álamo prensada. Los extremos del mismo se sellaron utilizando la porción cóncava de una huevera de cartón

- Refugio: caja de cartón circular con tapa de $9 \mathrm{~cm}$ de diámetro y $5 \mathrm{~cm}$ de alto, en cuyo interior se colocaron 4 hojas de papel tipo tissue

- Un barbijo colgado del techo de la caja 
- $\quad$ Semillas de girasol con cáscara

- Un cuadrado de algodón de $10 \mathrm{~cm}$ de lado

- $\quad$ Papel en tiras

- Un hilo de papel

- Tubo de cartón de $15 \mathrm{~cm}$ de largo por $5 \mathrm{~cm}$ de diámetro

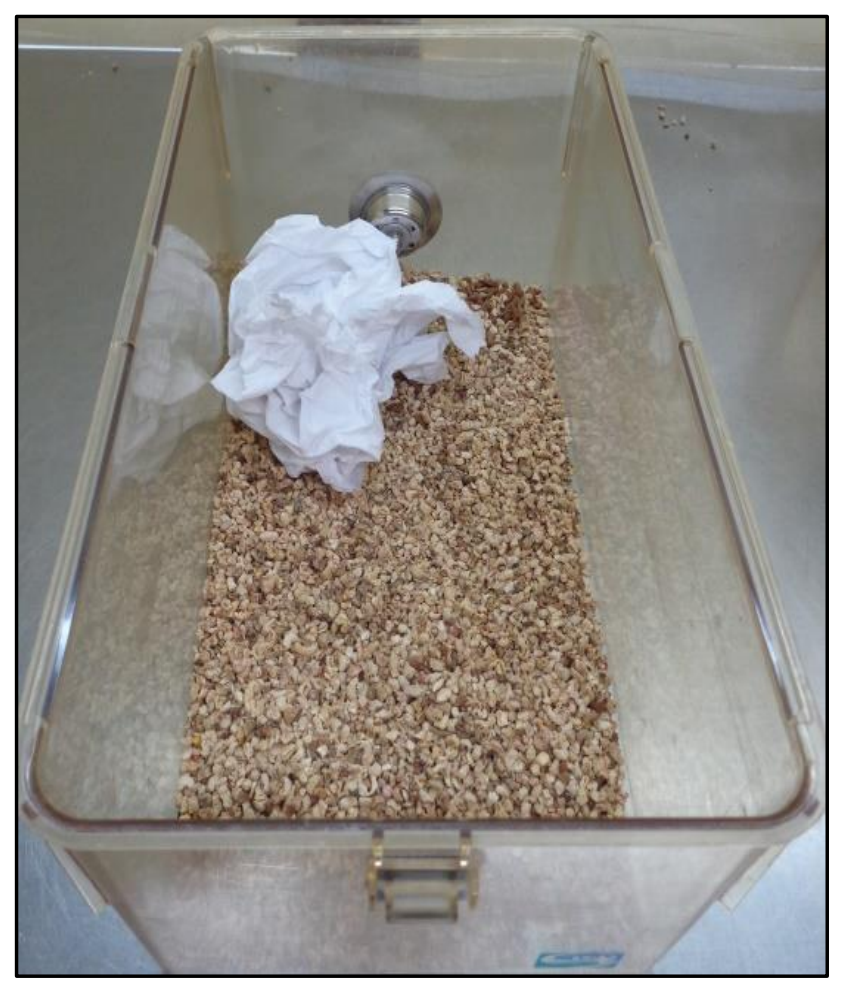

Imagen 6.2. Enriquecimiento simple. 


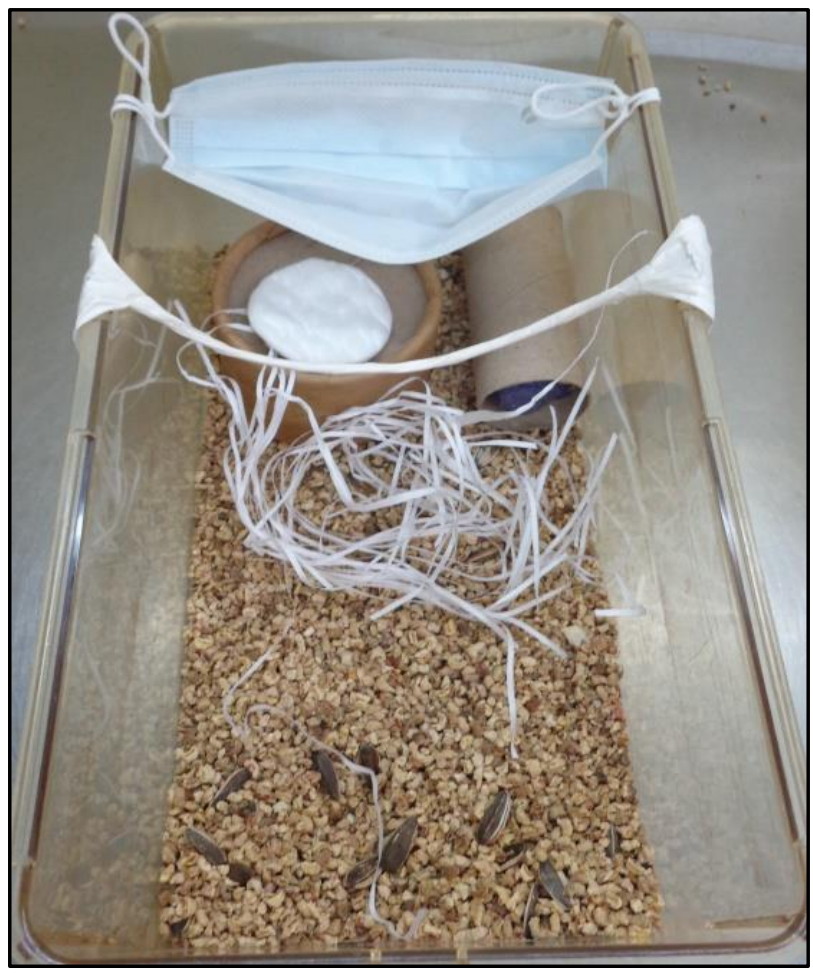

Imagen 6.4. Enriquecimiento complejo en caja estándar.

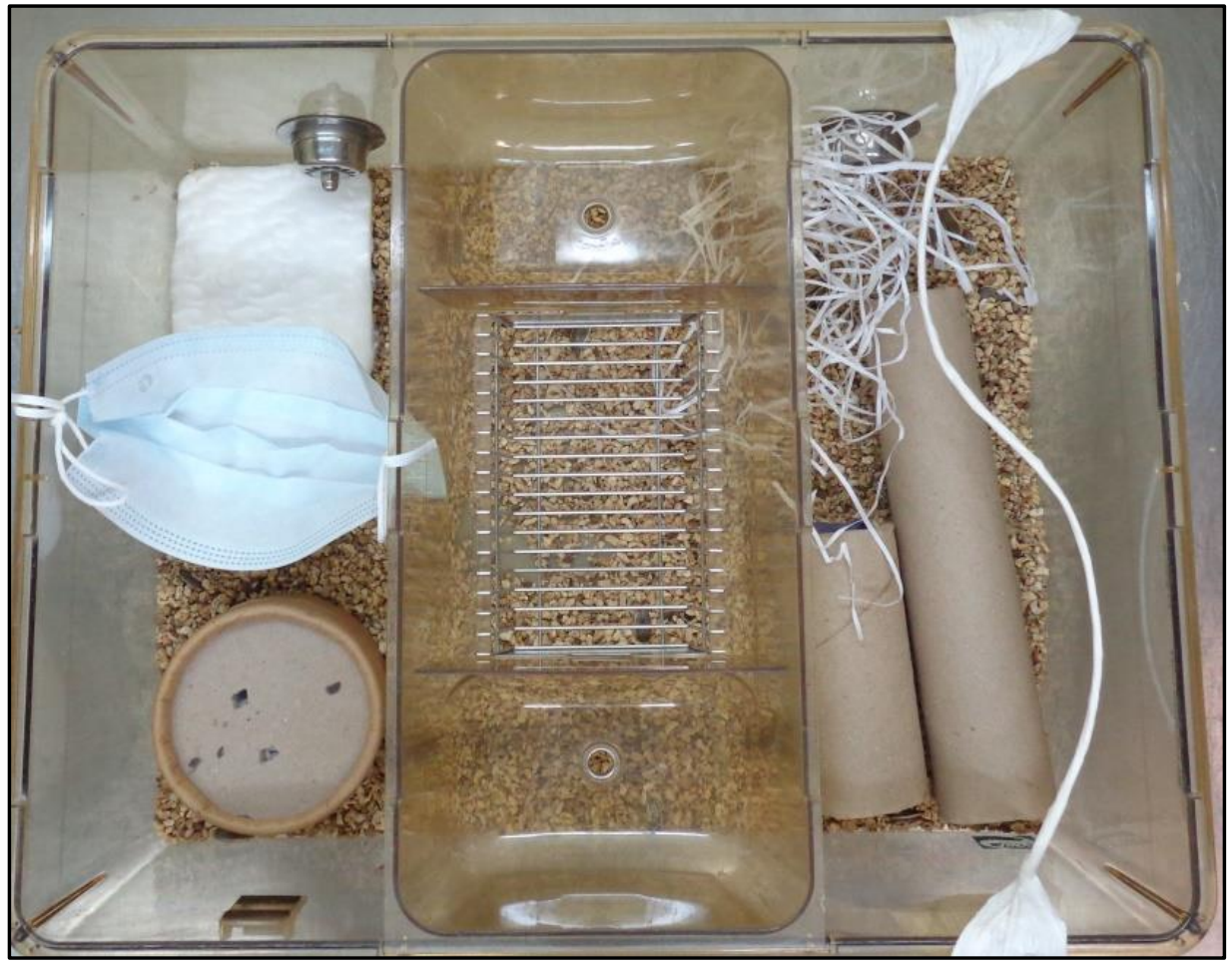

Imagen 6.5. Enriquecimiento complejo en caja "Super Mouse 1800"TM". 


\section{Tamaño tumoral}

Los tumores se midieron utilizando el MFnoA, una vez por semana entre los 15 y los 35 días. Al finalizar la experiencia se pesaron los tumores se diseccionaron para obtener los pesos de los tumores.

Prueba de inhibición de la alimentación por la novedad (NSF test)

Se realizó la prueba de inhibición de la alimentación por la novedad (NSF test) que fue descripta en capítulos anteriores pero se reemplazó la recompensa de almendras por semillas de girasol. Para esta experiencia en particular, además de registrar la latencia a la primera ingestión de alimento, el acicalamiento y la defecación se registró la frecuencia del comportamiento elevarse y de freezing. La primer pauta conductual fue descripta en el etograma del capítulo de análisis del bienestar de los ratones nude con tumores subcutáneos a través de indicadores comportamentales. En cuanto al freezing, se definió como un período de inmovilidad absoluta del ratón por un período de por lo menos un segundo.

\section{Análisis estadístico}

Para comparar las diferencias en el peso y en el volumen tumoral a lo largo del tiempo se realizaron modelos lineales mixtos que fueron calculados respectivamente como: lmer(peso $\sim$ grupo + día $+(1 \mid$ ID) $)$ y lmer(volumen $\sim$ grupo + día $+(1 \mid$ ID)). Se agregó a todos los modelos el intercepto para cada individuo (1|ID) como un efecto aleatorio y los valores de probabilidad se obtuvieron utilizando la razón de verosimilitud entre el modelo completo con cada uno de los efectos fijos. Para evaluar los parámetros comportamentales y postmortem, se realizaron Análisis de la Varianza (ANOVA) o el test no paramétrico de 
Kruskall-Wallis según la normalidad de los datos. En caso de existir diferencias estadísticamente significativas, se utilizó la prueba post-hoc de Tukey para detectar diferencias entre grupos.

\section{Resultados}

Se realizaron análisis lineales mixtos tanto en machos como en hembras para comparar las diferencias a lo largo del tiempo en el peso y en el volumen tumoral. En los machos se observaron diferencias estadísticamente significativas en el peso a lo largo del tiempo $\left(x^{2}(3)=11,03 ; p=0,011\right)$, específicamente entre el grupo control y el grupo al que se le removió el EA posterior al trasplante tumoral $(\mathrm{p}<0,001)$ (Figura 6.3). Además, se observaron diferencias estadísticamente significativas entre grupos en el tamaño tumoral $\left(x^{2}(3)=14,46 ; p=0,002\right)$. En particular se obtuvieron diferencias significativas entre el grupo control tanto con el grupo de EA en caja estándar $(\mathrm{p}=0,012)$ como con el grupo de EA en caja de tamaño superior $(\mathrm{p}=0,003)$. De la misma forma se observaron diferencias con el grupo al que se le removió el EA luego del trasplante tumoral con los dos grupos enriquecidos ( $\mathrm{p}=0,01$ para la caja estándar y $\mathrm{p}=0,003$ para la caja de $1160 \mathrm{~cm}^{2}$ ) (Figura 6.4). 


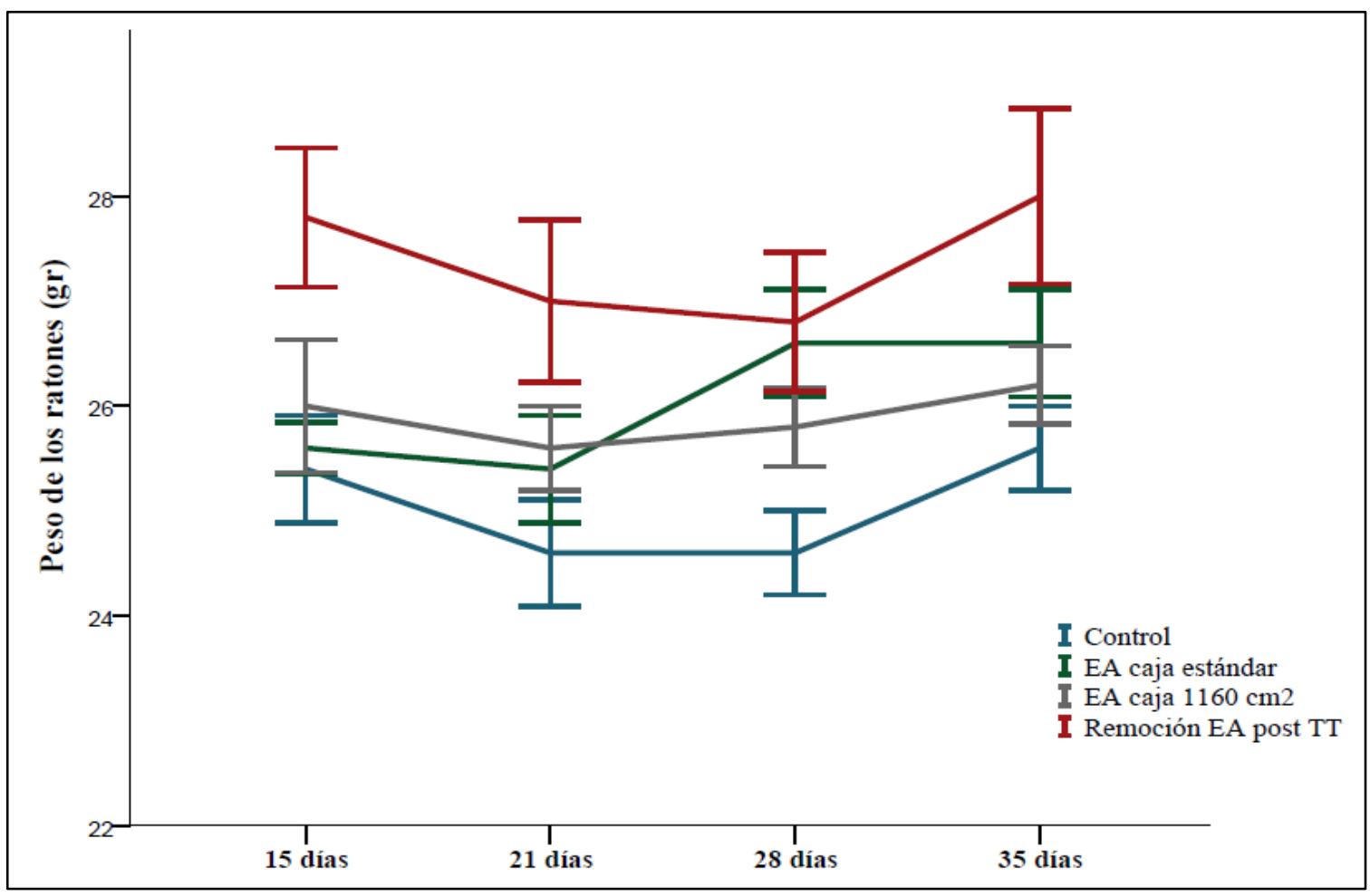

Figura 6.3. Línea temporal del peso en machos nude alojados bajo distintas condiciones ambientales.

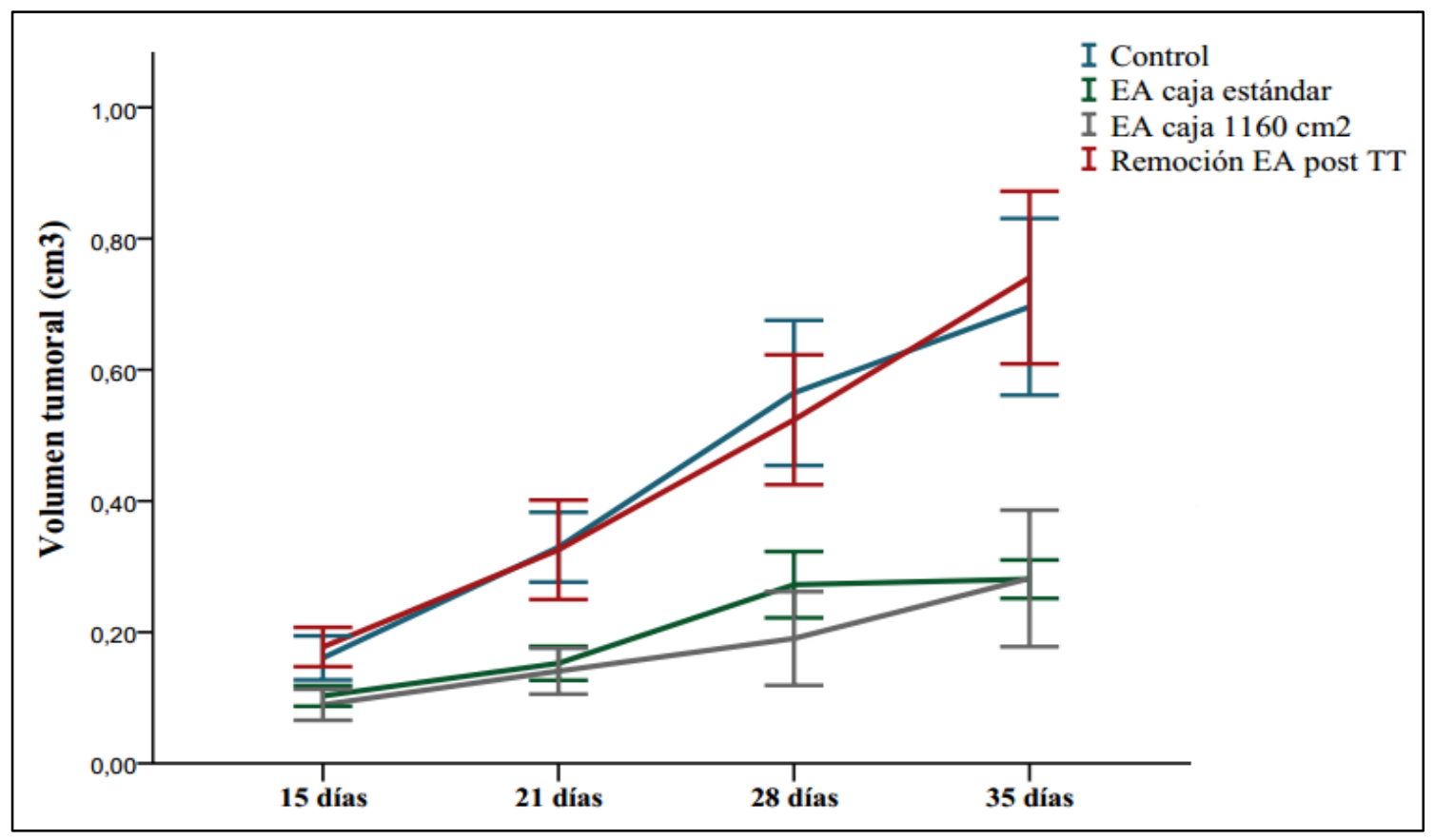

Figura 6.4. .Línea temporal del tamaño tumoral en machos nude alojados bajo distintas condiciones ambientales. 
Para el caso de las hembras (Figuras 6.5 y 6.6), no se detectaron diferencias significativas entre los grupos en el peso $\left(\mathrm{X}^{2}(3)=0,782 ; \mathrm{p}=0,853\right)$, como así tampoco en el volumen tumoral $\left(X^{2}(3)=2,58 ; p=0,459\right)$.

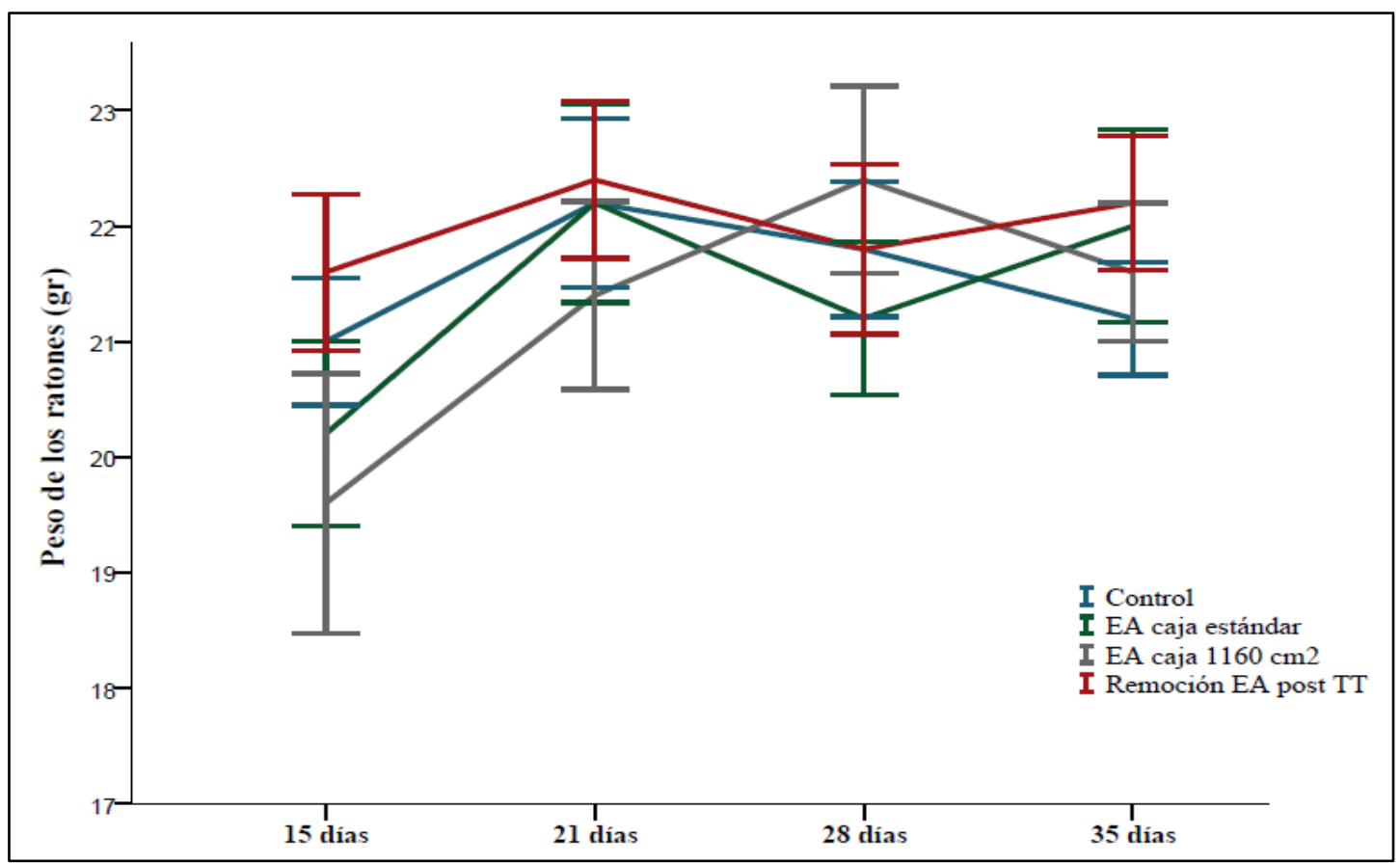

Figura 6.5. Línea temporal del peso en machos nude alojados bajo distintas condiciones ambientales. 


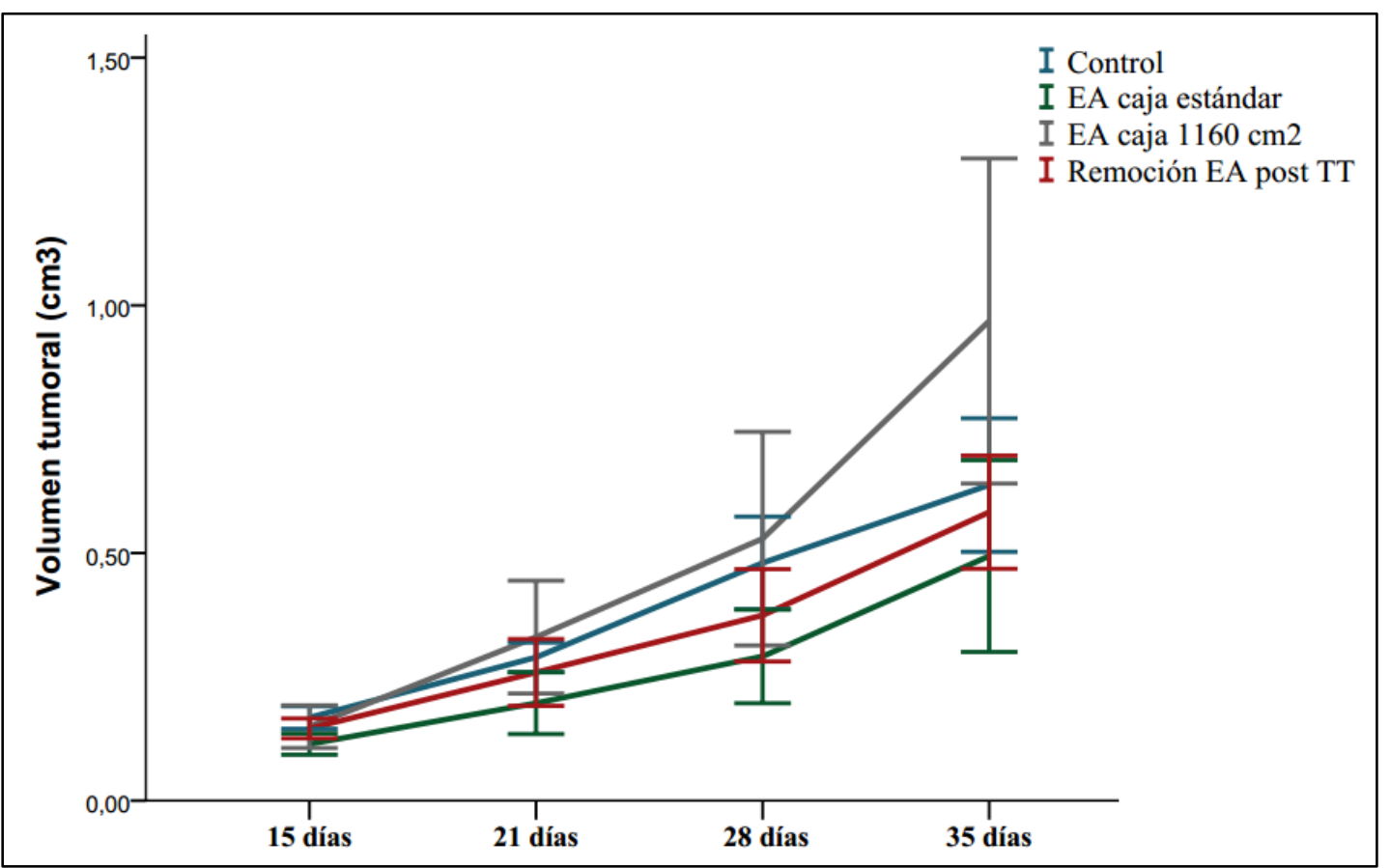

Figura 6.6. Línea temporal del tamaño tumoral en hembras nude alojadas bajo distintas condiciones ambientales.

PRUEBA DE INHIBICIÓN DE LA ALIMENTACIÓN POR LA NOVEDAD (NSF test)

Tiempo en que demoraron en comer la almendra

Debido a que únicamente tres de los 20 machos utilizados comieron las semillas de girasol en el período de tiempo pautado (cinco minutos), éstos no se utilizaron para el análisis. Con respecto a las hembras, no se obtuvieron diferencias significativas entre los grupos (Tabla $6.2)$. 


\begin{tabular}{cccccc} 
Sexo & Grupo & Media & D.E. & Estadístico & p-valor \\
\hline \multirow{4}{*}{ Hembras } & Control & 147,80 & 103,84 & & \\
& EA caja estándar & 67,40 & 35,37 & & \\
& EA caja 1160 cm & 167,40 & 74,71 & $\mathrm{H}=4,69$ & 0,195 \\
& Remoción EA post-TT & 90,20 & 28,39 & & \\
\hline
\end{tabular}

Tabla 6.2. Segundos que demoraron en comer la almendra en la prueba NSF modificado. Prueba no paramétrica de Kruskal-Wallis.

\section{Elevarse}

Se registró la frecuencia del comportamiento "elevarse" en el período que los ratones permanecieron en la arena durante el NSF test. Con respecto a esta variable, se obtuvieron resultados consistentes en machos y en hembras en el que su frecuencia fue significativamente mayor en el grupo con EA en la caja de $1160 \mathrm{~cm}^{2}$ (Tabla 6.3).

\begin{tabular}{ccccccc} 
Sexo & Grupo & Media & D.E. & Estadístico & p-valor & Grupos \\
\hline \multirow{4}{*}{ Hembras } & Control & 35,60 & 5,27 & & & $\mathrm{~A}$ \\
& EA caja estándar & 38,80 & 11,03 & $\mathrm{~F}_{(3,19)}=$ & & 0,005 \\
& EA caja 1160 $\mathrm{cm}^{2}$ & 59,40 & 14,98 & 6,15 & & $\mathrm{~A}$ \\
& Remoción EA post-TT & 34,40 & 8,50 & & & $\mathrm{~A}$ \\
\hline \multirow{4}{*}{ Machos } & Control & 60,40 & 14,22 & & & $\mathrm{~A}$ \\
& EA caja estándar & 55,80 & 7,98 & $\mathrm{~F}_{(3,19)}=$ & $<0,001$ & $\mathrm{~A}$ \\
& EA caja 1160 $\mathrm{cm}^{2}$ & 96,60 & 15,39 & 16,80 & & $\mathrm{~B}$ \\
& Remoción EA post-TT & 46,60 & 8,35 & & & $\mathrm{~A}$ \\
\hline
\end{tabular}

Tabla 6.3. Frecuencia del comportamiento "ELEVARSE" en la prueba NSF modificado. Análisis de la Varianza (ANOVA). 


\section{Acicalamiento}

La frecuencia de acicalamiento fue otra de las variables analizadas durante la prueba de inhibición de la alimentación por la novedad. Esta pauta conductual no presentó diferencias estadísticamente significativas en ninguno de los grupos analizados (Tabla 6.4.).

\begin{tabular}{|c|c|c|c|c|c|}
\hline Sexo & Grupo & Media & D.E. & Estadístico & p-valor \\
\hline \multirow{4}{*}{ Hembras } & Control & 1,60 & 0,89 & \multirow{4}{*}{$\mathrm{H}=1,68$} & \multirow{4}{*}{0,614} \\
\hline & EA caja estándar & 1,60 & 3,05 & & \\
\hline & EA caja $1160 \mathrm{~cm}^{2}$ & 1,20 & 1,10 & & \\
\hline & Remoción EA post-TT & 1,40 & 1,14 & & \\
\hline \multirow{4}{*}{ Machos } & Control & 1,20 & 1,64 & \multirow{4}{*}{$\mathrm{H}=2,52$} & \multirow{4}{*}{0,445} \\
\hline & EA caja estándar & 3,40 & 3,21 & & \\
\hline & EA caja $1160 \mathrm{~cm}^{2}$ & 2,40 & 2,07 & & \\
\hline & Remoción EA post-TT & 1,20 & 1,10 & & \\
\hline
\end{tabular}

Tabla 6.4. Frecuencia del comportamiento "ACICALARSE" en la prueba NSF modificado. Prueba no paramétrica de Kruskal-Wallis.

Defecación

Se registró la frecuencia de defecación durante el período que los ratones permanecieron en el campo abierto. La misma presentó diferencias estadísticamente significativas únicamente en los ratones macho, en el que el grupo que se alojó en la caja de tamaño estándar con EA defecó con una frecuencia significativamente mayor que el resto de los grupos (Tabla 6.5). 


\begin{tabular}{ccccccc} 
Sexo & Grupo & Media & D.E. & Estadístico & p-valor & Grupo \\
\hline \multirow{4}{*}{ Hembras } & Control & 0,20 & 0,45 & & & \\
& EA caja estándar & 0,20 & 0,45 & & & \\
& EA caja $1160 \mathrm{~cm}^{2}$ & 0,80 & 1,10 & $\mathrm{H}=0,97$ & 0,686 & - \\
& Remoción EA post-TT & 0,80 & 1,30 & & & $\mathrm{~A}$ \\
\multirow{3}{*}{ Machos } & Control & 0,00 & 0,00 & & & $\mathrm{~B}$ \\
& EA caja estándar & 2,20 & 0,84 & & \multirow{2}{*}{$\mathrm{H}=9,003$} & $\mathrm{~A}$ \\
& EA caja 1160 cm & 0,40 & 0,89 & & & $\mathrm{~A}$ \\
\hline
\end{tabular}

Tabla 6.5. Frecuencia del comportamiento "DEFECAR" en la prueba NSF modificado. Prueba no paramétrica de Kruskal-Wallis.

Freezing

Finalmente, también se analizó la frecuencia de "freezing" durante esta prueba comportamental. Para este parámetro se registraron diferencias estadísticamente significativas en las hembras, en las que el grupo control permaneció inmóvil durante un período de tiempo significativamente mayor que el grupo que se alojó en las cajas estándar con EA (Tabla 6.6). 


\begin{tabular}{ccccccc} 
Sexo & Grupo & Media & D.E. & Estadístico & p-valor & Grupo \\
\hline \multirow{4}{*}{ Hembras } & Control & 5,20 & 6,69 & & & $\mathrm{~A}$ \\
& EA caja estándar & 0,60 & 1,34 & & & $\mathrm{~B}$ \\
& EA caja $1160 \mathrm{~cm}^{2}$ & 0,80 & 0,84 & & & \\
& Remoción EA post-TT & 3,40 & 3,65 & & & $\mathrm{AB}$ \\
\multirow{4}{*}{ Machos } & Control caja estándar & 1,00 & 1,73 & & & \\
& EA caja 1160 cm & 1,00 & 1,41 & & & \\
& Remoción EA post-TT & 5,60 & 4,83 & & & \\
& Rem & 1,20 & 1,10 & & & \\
\hline
\end{tabular}

Tabla 6.6. Frecuencia del comportamiento "FREEZING" en la prueba NSF modificado. Prueba no paramétrica de Kruskal-Wallis.

\section{PESAJE POST-MORTEM}

Al finalizar la prueba de inhibición de la alimentación por la novedad (NSF test) los ratones se sacrificaron mediante dislocación cervical e inmediatamente se pesaron y posteriormente se diseccionaron los tumores y los bazos.

\section{Peso ratones}

No existieron diferencias significativas en el peso final en las hembras pero sí entre los distintos grupos en los ratones macho. En particular, el peso obtenido en la caja estándar a la que se le removió el EA luego de realizar el trasplante tumoral fue significativamente mayor que el peso obtenido en los ratones del grupo control y en los que poseían EA en la caja de igual tamaño (Tabla 6.7). 


\begin{tabular}{ccccccc} 
Sexo & Grupo & Media & D.E. & Estadístico & p-valor & Grupo \\
\hline \multirow{4}{*}{ Hembras } & Control & 21,48 & 0,51 & & & \\
& EA caja estándar & 21,59 & 1,74 & $\mathrm{~F}_{(3,19)}=$ & \multirow{2}{*}{0,572} & - \\
& EA caja 1160 cm $\mathrm{cm}^{2}$ & 22,48 & 1,59 & 0,69 & & \\
& Remoción EA post-TT & 22,25 & 1,09 & & & $\mathrm{~A}$ \\
\multirow{2}{*}{ Machos } & Control & 25,07 & 0,95 & & & $\mathrm{~A}$ \\
& EA caja estándar & 24,79 & 1,65 & $\mathrm{~F}_{(3,19)}=$ & \multirow{2}{*}{0,017} & $\mathrm{AB}$ \\
& EA caja 1160 cm & 26,19 & 0,54 & 4,51 & & $\mathrm{~B}$ \\
\hline
\end{tabular}

Tabla 6.7. Peso de los ratones macho y hembra obtenidos inmediatamente después del sacrificio. Análisis de la Varianza (ANOVA).

Peso tumoral

De la misma forma que para la variable anterior, no existieron diferencias significativas en el peso de los tumores en ratones hembra pero sí en los machos (Imagen 6.6). Específicamente los tumores del grupo control fueron más grandes que los tumores de los ratones criados en ambos tamaños de cajas enriquecidas. Igualmente, los tumores de los ratones provenientes de las cajas en las que se les removió el enriquecimiento luego del trasplante tumoral fueron significativamente más grandes que los tumores de los ratones alojados en la caja de tamaño estándar con EA (Tabla 6.8). 


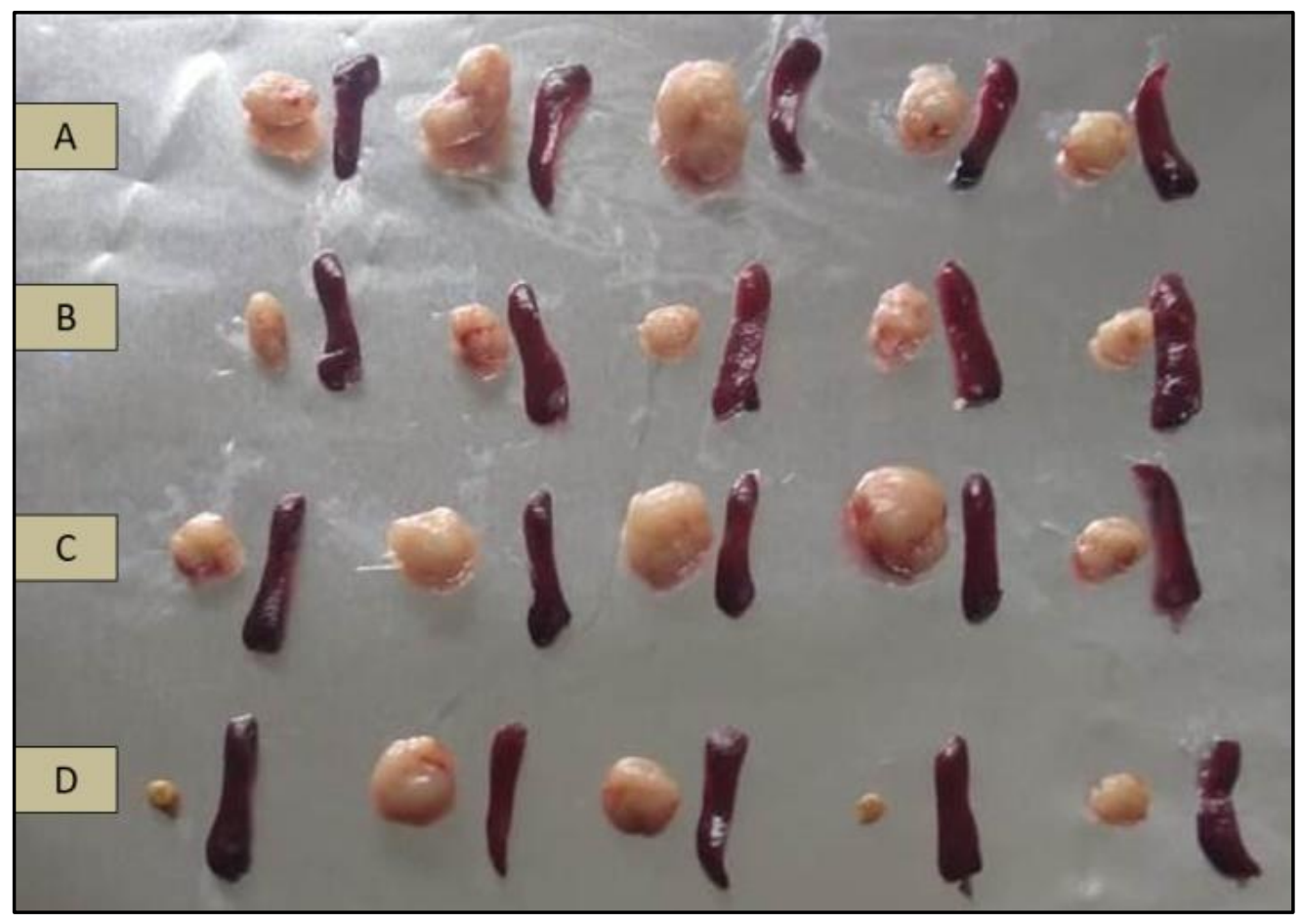

Imagen 6.6. Tamaño de los bazos y los tumores en machos alojados en las distintas condiciones ambientales. (A) Grupo control; (B) Enriquecimiento ambiental en caja estándar; (C) Remoción EA post-trasplante tumoral; (D) Enriquecimiento ambiental en caja $1160 \mathrm{~cm}^{2}$.

\begin{tabular}{|c|c|c|c|c|c|c|}
\hline Sexo & Grupo & Media & D.E. & Estadístico & p-valor & Grupos \\
\hline \multirow{4}{*}{ Hembras } & Control & 0,35 & 0,21 & \multirow{4}{*}{$\mathrm{H}=0,79$} & \multirow{4}{*}{0,825} & \multirow{4}{*}{-} \\
\hline & EA caja estándar & 0,35 & 0,32 & & & \\
\hline & EA caja $1160 \mathrm{~cm}^{2}$ & 0,57 & 0,56 & & & \\
\hline & Remoción EA post-TT & 0,38 & 0,24 & & & \\
\hline \multirow{4}{*}{ Machos } & Control & 0,50 & 0,35 & \multirow{4}{*}{$\mathrm{H}=8,56$} & \multirow{4}{*}{0,035} & $\mathrm{~A}$ \\
\hline & EA caja estándar & 0,14 & 0,04 & & & $\mathrm{~B}$ \\
\hline & EA caja $1160 \mathrm{~cm}^{2}$ & 0,16 & 0,17 & & & $\mathrm{BC}$ \\
\hline & Remoción EA post-TT & 0,47 & 0,31 & & & $\mathrm{AC}$ \\
\hline
\end{tabular}

Tabla 6.8. Peso de los tumores en ratones macho y hembra obtenidos inmediatamente después del sacrificio. Prueba no paramétrica de Kruskal-Wallis. 
Peso bazo

En cuanto a la última de las variables analizadas post-mortem, esto es el peso de los bazos, no se observaron diferencias estadísticamente significativas en ninguno de los sexos con los cuatro tipos de tratamiento (Tabla 6.9).

\begin{tabular}{cccccc} 
Sexo & Grupo & Media & D.E. & Estadístico & p-valor \\
\hline \multirow{3}{*}{ Hembras } & Control & 0,17 & 0,01 & & \\
& EA caja estándar & 0,15 & 0,01 & $\mathrm{~F}_{(3,19)}=$ & 0,141 \\
& EA caja 1160 $\mathrm{cm}^{2}$ & 0,17 & 0,02 & 2,09 & \\
\hline \multirow{3}{*}{ Machos } & Remoción EA post-TT & 0,16 & 0,02 & & \\
& EA caja estándar & 0,17 & 0,03 & $\mathrm{~F}_{(3,19)}=$ & 0,130 \\
& EA caja 1160 cm & & & \\
& Remoción EA post-TT & 0,17 & 0,01 & & \\
\hline
\end{tabular}

Tabla 6.9. Peso de los bazos de ratones macho y hembra obtenidos inmediatamente después del sacrificio. Prueba no paramétrica de Kruskal-Wallis, $\mathrm{n}=40$.

\section{Discusión}

En esta sección se determinó cómo las condiciones ambientales modificaron el desarrollo tumoral. Además, se observó el comportamiento ante un ambiente novedoso, que pone en evidencia la percepción que tienen los ratones del medio que los rodea. Desafortunadamente los ratones macho fallaron en realizar la prueba por lo que el dato principal, esto es el tiempo que demoraron en comer las semillas de girasol, no pudo ser utilizado como referencia. De todas formas ésta si se pudo analizar en las hembras y en las mismas no se observaron diferencias estadísticamente significativas entre los distintos 
tratamientos. Con respecto a las determinaciones accesorias a la prueba, se obtuvieron resultados consistentes entre machos y hembras únicamente en la variable elevarse, en la que los ratones de la caja enriquecida de mayor tamaño la realizaron con una frecuencia mayor que el resto de los tratamientos. Este resultado es de esperarse dadas las características de la caja, en el que una mayor superficie podría promover este tipo de comportamiento. Los otros dos valores que generaron datos con diferencias estadísticamente significativas fueron el freezing (únicamente en hembras) y la defecación (en machos). Estas dos variables suelen ser utilizadas como un indicador de ansiedad (Prut y Belzung 2003), por lo que resulta llamativo que hayan alcanzado resultados contrapuestos. De esta forma hubo diferencias estadísticamente significativas entre el grupo control y la caja enriquecida de tamaño estándar para ambas variables y sexos, con los machos del grupo control defecando menos y las hembras del mismo grupo realizando el comportamiento de freezing más que los ratones de la caja enriquecida de tamaño estándar. Es esperable que los ratones provenientes de las cajas estándar se comporten de forma más ansiosa que aquellos provenientes de cajas enriquecidas (Rogers y col. 2017), lo cual es comprobado en las hembras (el género principalmente afectado por dicho trastorno (Palanza 2001). Para el caso de los machos podría deberse a un aumento en la tensión social generada por el acaparamiento de los recursos (Van Loo y col., 2002) o posiblemente porque la ausencia de espacios libres en la caja debidos a los objetos presentes en la misma hayan generado una sensibilización de los mismos hacia el campo abierto.

El refinamiento de las condiciones de alojamiento de los ratones que se utilizan para este modelo animal es importante por un lado para garantizar la reproducibilidad de los 
resultados y por otro, para buscar nuevas alternativas terapéuticas en oncología. Al respecto se han generado una serie de trabajos que buscaron reproducir los resultados obtenidos en el primer experimento de este estilo publicado por Cao (Cao y col., 2010), en el que se observó un fenotipo resistente al desarrollo tumoral en aquellos ratones alojados en cajas enriquecidas y de mayor tamaño. Sin embargo, no todos los trabajos posteriores lograron reproducir dichos resultados: Nachat-Kappes (Nachat-Kappes y col., 2012) describió que en un tumor mamario subcutáneo presentó diferencias en el tamaño cuando se los crió en ambientes enriquecidos sólo hasta el día 10, mientras que Westwood (Westwood y col., 2013) no observó ninguna diferencia en el desarrollo tumoral en ratones con EA.

En este experimento, se observaron diferencias en el desarrollo tumoral a lo largo del tiempo únicamente en ratones macho. Específicamente, las diferencias fueron estadísticamente significativas entre ambos grupos enriquecidos con ambos grupos sin enriquecer, siendo el tamaño tumoral menor en los primeros. Pareciera entonces que la progresión tumoral no se relaciona con el EA previo sino que tiene que ver con las condiciones del momento en particular. Conjuntamente con los resultados descriptos por Garofalo (Garofalo y col., 2015), podría esperarse entonces cambios en el tamaño tumoral únicamente luego de una pre-exposición al ambiente enriquecido durante al menos tres semanas y manteniendo dichas condiciones durante todo el experimento. También en los machos se observaron diferencias en el peso únicamente entre el grupo control y el grupo al que se le removió el enriquecimiento luego del trasplante tumoral, pero estas diferencias se podrían atribuir a un artefacto en la división de los grupos, ya que dichos animales tuvieron un tamaño mayor desde la primera medición. 
Para el caso de las hembras, no se observaron diferencias estadísticamente significativas en ninguna de estas dos variables (peso y tamaño tumoral). Al respecto resulta llamativo resaltar que en todos los trabajos en los que se utilizó EA para evaluar el impacto sobre el desarrollo tumoral, únicamente se emplearon ratones machos. En un único trabajo se utilizaron hembras (Nachat-Kappes y col., 2012), y en éste las diferencias observadas entre los grupos fueron estadísticamente significativas sólo hasta el día diez. Además, no en todos los trabajos en los que evaluaron el desarrollo tumoral en un ambiente enriquecido con ratones machos detectaron diferencias significativas (Benaroya-Milshtein y col., 2007; Westwood y col., 2013). Por consiguiente, analizar los resultados de los distintos trabajos en profundidad desde una perspectiva etológica podría esclarecer posibles motivos para dichas diferencias.

En primer lugar, todos los experimentos que se realizaron utilizaron cajas de mayor tamaño y ruedas de ejercicio, por lo que el aumento de la actividad física per se podría ser un factor de confusión cuando se compara el efecto de una mayor estimulación sensorial con el desarrollo tumoral. Esto es debido a que existen evidencias de que el ejercicio es un elemento preponderante en la disminución de la incidencia de múltiples tipos de patologías oncológicas (Paceli y col., 2012; Betof y col., 2013; Idorn y Hojman, 2016). En el trabajo de Cao y colaboradores (2010), se incluyó este factor en el análisis y concluyeron que el ejercicio por si solo fue incapaz de generar diferencias significativas en el desarrollo tumoral. Sin embargo, la diferencia en la percepción del ejercicio que tuvieron los ratones entre correr en una rueda de ejercicios y un ambiente amplio pudo haber influenciado este resultado, ya que en humanos se describió como más placentero correr en el exterior que 
sobre una cinta de ejercicios (Harte y Eifert, 1995; LaCaille y col., 2004). En los resultados correspondientes a este experimento, se observó una disminución del desarrollo tumoral en los machos inclusive en la caja enriquecida de tamaño chico, lo que permitiría descartar el ejercicio como un factor importante que afectaría el desarrollo tumoral.

El mantenimiento de los ratones a temperaturas sub-óptimas (a aproximadamente $22^{\circ} \mathrm{C}$ ) por debajo de la temperatura confort que se ubica por encima de $\operatorname{los} 26^{\circ} \mathrm{C}$ (Gaskill y col., 2009), se ha descripto como un factor de estrés crónico que inclusive puede llegar a modificar el curso del desarrollo tumoral (Hylander y Repasky, 2016), debido a que por ejemplo compromete la respuesta inmune (Kokolus y col., 2013). En todos los trabajos citados en los que se buscó evaluar el desarrollo tumoral asociado al EA, la temperatura no se especifica en lo absoluto o se describe que los ratones se mantuvieron bajo temperaturas estándar. De la misma forma el material de nido, que se ha descripto como una metodología sencilla y económica para permitirle al ratón regular su temperatura (Gaskill y col., 2013), no se introdujo en ninguno de los grupos control. En este sentido, la diferencia observada pudo haberse producido porque, si bien el EA provisto en los distintos trabajos no fue estandarizado, la presencia en ellos de distintas estructuras y de elementos que pudieron haberles servido para construir el nido pudo haber funcionado para promover una mejor respuesta inmune y por lo tanto disminuir el desarrollo tumoral. En este diseño experimental los ratones se mantuvieron bajo las temperaturas estándar de alojamiento $\left(22^{\circ} \mathrm{C}\right.$ ), pero se les proveyó a todas las cajas (lo que incluyó al grupo control y al que se le removió el enriquecimiento ambiental) papel tipo tissue para que los ratones puedan construir el nido y por lo tanto, mantener una temperatura corporal adecuada. Por lo tanto 
para este protocolo se descarta el estrés crónico inducido por una temperatura sub-óptima como un factor relevante para definir la causalidad de los tamaños tumorales mayores en los grupos que carecían de enriquecimiento.

Una posible hipótesis es que el EA haya aumentado el estrés crónico debido a la competencia por los recursos altamente valorados tales como los tubos de cartón o los refugios. Dicho aumento en la agresión en ratones macho en cajas enriquecidas ya ha sido descripto previamente (ver por ejemplo (Marashi y col., 2003)) y genera dudas con respecto a la efectividad en la adición del EA para mejorar el bienestar animal. Al respecto en este experimento se observaron lesiones leves en algunos de los ratones provenientes de las cajas enriquecidas, a partir de la tercera semana luego del trasplante tumoral. Dichas lesiones fueron evidentes debido a que se trataban de ratones nude, y por lo tanto pudieron haber pasado desapercibidas en ratones con cubierta pilosa. Resulta llamativo que no ha sido descripto en ninguno de los experimentos citados previamente un aumento en la agresión intra-específica a partir del aumento de la complejidad ambiental. Con respecto a los ratones hembra, y tal como podría esperarse de este grupo, no se observaron este tipo de lesiones en ninguno de los grupos.

La relación entre el estrés y el desarrollo tumoral ha sido profundizada en mayor medida en distintos trabajos. De esta forma, se ha observado que tanto el estrés agudo como el estrés crónico promueven el crecimiento de los trasplantes (Hasegawa y Saiki, 2002; Ben-eliyahu, 2003; Lamkin y col., 2012). El EA también es considerado un tipo de estrés beneficioso, muchas veces denominado eustrés (Crofton y col., 2015). Sin embargo, la activación de los sistemas generada por este último debería producir un nivel de activación diferencial de los 
distintos componentes o bien ser concebida a partir de un mecanismo distinto que permita manifestar las diferencias entre ambos eventos (estrés asociado a eventos placenteros vs no placenteros). Debido a que el efecto diferencial se observó únicamente en los machos, tendría sentido que este tipo de interacciones agonísticas sean para ellos de alguna forma agradables, o que elijan realizar estos comportamientos por sobre un estado apático o estereotipado. Los mecanismos por los cuales pudieron haberse exhibido estas diferencias excedieron a este protocolo experimental.

\section{Conclusiones}

En este apartado en el que se estudió el refinamiento de las condiciones de alojamiento para un modelo animal de cáncer heterotópico, se observaron diferencias en el comportamiento y el desarrollo tumoral entre machos y hembras que se manifestaron cuando se modificaron las condiciones de alojamiento. En particular se observó una disminución del desarrollo tumoral en machos en ambientes enriquecidos, posiblemente debido a que el aumento de estructuras que el animal dominante del grupo pueda acaparar haya aumentado los comportamientos agonísticos entre ellos. Sin embargo, se observó que la adición de material de nido, un elemento de EA utilizado frecuentemente en esta especie, pareciera no interferir con el desarrollo tumoral. Para confirmar esta última conclusión, se deberían realizar nuevos experimentos en los que se compare el desarrollo tumoral con y sin material de nido, pero se infiere que dicho protocolo podría reducir el bienestar de los ratones ya que los mismos podrían estar expuestos a estrés térmico, a un aumento de las peleas 
(especialmente en machos) y a frustración por no poder realizar un comportamiento que están intrínsecamente motivados a realizar. 


\section{Consideraciones finales}

El objetivo principal de esta tesis doctoral consistió en determinar el impacto de la línea tumoral humana A549 en el bienestar de ratones del stock NLAE:NIH(S)-FoxI ${ }^{n u}$ (ratones inmunodeficientes nude) trasplantados con la misma y en evaluar el efecto del EA sobre el desarrollo tumoral. Para ponderar el bienestar animal, se emplearon distintos enfoques de forma de evitar los sesgos en la interpretación del estado de los animales en relación al medio que los rodea. De esta forma, se evaluaron:

1) La fisiología de los ratones a través de la concentración de los metabolitos de la corticosterona en materia fecal, de cambios en la condición corporal y del análisis de parámetros sanguíneos.

2) Las frecuencias de comportamientos espontáneos que realizaron en la caja donde habitaban normalmente y la performance en distintas pruebas de comportamiento (burrowing/urine sniffing/novelty suppressed feeding/nesting/sesgo cognitivo). En particular estas pruebas de comportamiento explotaron por un lado comportamientos altamente motivados en esta especie (la construcción de la madriguera, del nido y la reproducción) y por el otro permitieron evaluar estados afectivos (la ansiedad ante un campo abierto y la forma en que se comportaron ante un estímulo ambiguo).

Además, para poder alcanzar dichos objetivos se pusieron a punto dos nuevas técnicas: 
1) Se desarrolló una técnica de medición de los tumores subcutáneos, que permite determinar los volúmenes tumorales sin la restricción de movimiento que es necesaria para las otras metodologías (entre ellas la medición con calibre). Dicha inmovilización es considerada desagradable para esta especie por lo que permitió refinar el experimento de EA al minimizar las fuentes de estrés ajenas a la modificación ambiental.

2) Se implementó una nueva metodología para evaluar el sesgo en el juicio ante un estímulo ambiguo. Dicha técnica explota las habilidades de percepción olfativa y posee la ventaja de que no utiliza refuerzos negativos, de forma que se evitan estados afectivos negativos asociados a eventos aversivos.

En líneas generales, no se evidenciaron alteraciones significativas en los parámetros de fisiología y de comportamiento que indicarían una alteración severa en el bienestar de los ratones. Sin embargo, sí se manifestaron algunas modificaciones sutiles que convalidan la interpretación de que el trasplante tumoral no es un procedimiento inocuo para estos animales. En particular, resulta interesante observar que las variaciones se pusieron en evidencia en aquellas pruebas que se podrían interpretar como las más sensibles para detectar diferencias. Por un lado para el caso del Urine Sniffing Test (US), se utilizan las señales olfativas que estimulan el comportamiento reproductivo; por el otro, el sesgo cognitivo analiza el proceso de toma de decisiones, que direcciona el comportamiento propiamente dicho y es afectado por los estados emocionales. Resultaría interesante, en un estudio posterior, analizar la asociación entre estos dos test para evaluar si el US Test, dada su sencillez y rapidez, podría utilizarse como prueba "tamiz" para estudiar aquellos 
procesos que generen estados afectivos negativos (aunque ésta no posibilitaría analizar estados afectivos positivos, como si puede hacerlo la prueba de sesgo cognitivo).

Con respecto al EA, resultó llamativa la diferencia en el desarrollo tumoral entre machos y hembras cuando se adicionaron materiales nuevos en la caja. Por lo tanto, sería interesante en trabajos posteriores comprobar cuál fue el factor causal que inhibió el desarrollo tumoral. Según los resultados que se presentaron en el capítulo anterior, se plantea la hipótesis de que la inhibición del desarrollo tumoral se debió al estrés asociado al aumento de los comportamientos agonistas en la caja como consecuencia del EA y no por dicha modificación ambiental.

\section{Aplicaciones prácticas}

Las aplicaciones prácticas descriptas a continuación se desprenden de los resultados obtenidos, y tienen como finalidad mejorar el refinamiento de los procedimientos experimentales tanto para los ratones inmunodeficientes con trasplantes tumorales subcutáneos como para otros modelos animales en los que se puedan extrapolar las técnicas de análisis que se utilizaron. De esta forma se recomienda emplear los siguientes criterios cuando se diseña un protocolo experimental:

- Los signos clínicos que pueden manifestarse en este modelo animal se presentarían en estados avanzados de deterioro físico y deberían ser utilizados más como un criterio de punto final humanitario que como un indicador de bienestar animal. 
- Las pruebas de comportamiento en las que se manifiestan las necesidades comportamentales imprescindibles para la supervivencia en estado silvestre, tales como la construcción del nido o de la madriguera, podrían utilizarse como un indicador de la necesidad de aplicar correcciones terapéuticas (por ejemplo el uso de analgésicos). Sin embargo, este enfoque no pudo ser corroborado en esta tesis doctoral dada las sutilezas de las alteraciones fisiológicas y de comportamiento manifestadas en este modelo animal.

- Las pruebas comportamentales que explotan aquellos comportamientos asociados a conductas "de lujo" como la reproducción, que en este caso se evaluó mediante el interés que presentaron por la orina del sexo opuesto, podrían emplearse como pruebas tamiz para evaluar una posible disminución en el bienestar animal. Esto sería de utilidad especialmente en las pruebas piloto, dada su facilidad y rapidez.

- La prueba de sesgo cognitivo podría emplearse para experimentos específicos de bienestar animal, tanto en ratones inmunodeficientes como de otras cepas, para evaluar cambios en los estados emocionales. En particular se recomienda para implementar estrategias que busquen mejorar el bienestar de los ratones de experimentación (generando estados emocionales positivos), ya que las herramientas experimentales que se disponen para realizar estas determinaciones son mucho más escasas que para analizar estados emocionales negativos.

- Tal como fue descripto en numerosos trabajos, la adición del EA en ratones machos debe hacerse más cuidadosamente que en las hembras por la posibilidad de generar conflictos sociales. En particular en esta tesis doctoral se observó que interfirió con el desarrollo tumoral, pudiendo por lo tanto anular experimentos completos cuando 
se lo implementa sin haber realizado previamente una prueba piloto. Este efecto no se observó en las hembras, por lo que en este sexo aparentemente sería seguro adicionar nuevas estructuras a la caja.

- Si bien no se analizó específicamente este aspecto, el material de nido pareciera no haber inhibido el desarrollo tumoral en ninguno de los sexos, como se observó en las diferencias con el grupo de machos enriquecidos. Al respecto, también se ha descripto que el material de nido disminuye la agresión y facilita la termorregulación, por lo que se espera que la calidad de los experimentos mejore cuando se emplea dicho elemento y por lo tanto, siempre se recomienda su adición para este modelo animal.

- Finalmente, al haberse observado una preferencia de los ratones por la medición con fotografías, se recomienda este nuevo método de medición como una herramienta para reducir las variaciones experimentales indeseadas asociadas a factores de estrés. 


\section{Glosario}

Agonismo: comportamiento dirigido hacia individuos de la misma especie que culminan con el alejamiento o la sumisión de uno de los animales involucrados en dicha interacción.

Animal de Laboratorio/Experimentación: cualquier tipo de ser vivo, con independencia de su categoría filogenética, o taxonómica, incluyendo tanto invertebrados como vertebrados, utilizados en experimentación animal y otros fines científicos.

Ansiedad: respuesta de un individuo a una amenaza potencial.

Bienestar Animal: el estado de un animal en sus intentos por enfrentarse con el medio ambiente.

Calidad de vida: estado de bienestar que se extiende en un período de tiempo determinado.

Cognición: mecanismos por los cuales los animales adquieren, procesan, almacenan y actúan sobre información procedente del ambiente.

Diestrés: un estado en el que un animal no puede escapar o adaptarse a los estresores internos o externos, lo que resulta en efectos negativos sobre su bienestar.

Emoción: estados afectivos que están ligados a un objeto/situación y que implican modificaciones comportamentales, fisiológicas, neurológicas y cognitivas. 
Estado afectivo: respuestas comportamentales y fisiológicas que varían en términos de valencia (placentero/ no placentero) e intensidad. Algunos autores lo usan como sinónimo de emociones.

Estereotipias: Forma invariable de un comportamiento que son producidas casi idénticamente entre cada repetición. Aparentemente carecen de función y pueden reforzarse en el tiempo.

Estrés: respuesta biológica establecida por un individuo cuando percibe una amenaza a su homeostasis.

Estresor: cualquier elemento que desencadena una respuesta de estrés por parte del individuo.

Eustrés: exposición a desafíos intermedios, que llevan a una respuesta de estrés más adaptativa y por consiguiente, pueden amortizar las reacciones subsecuentes a estresores externos.

Homeostasis: proceso por el cual se mantienen las variables fisiológicas dentro de un rango estrecho.

Material de nido: cualquier elemento suministrado cuyo objetivo es promover el comportamiento de nidificación.

Modelo animal: objeto animado de imitación (del hombre u otras especies), utilizado para investigar circunstancias fisiológicas o patológicas, que se crea y se utiliza en la investigación de la causa, naturaleza y tratamiento de los fenómenos funcionales y de las enfermedades humanas y animales. 
Necesidad comportamental: necesidad para realizar un patrón específico de comportamiento, independientemente del tipo de ambiente en el cual se encuentre el animal y si las necesidades fisiológicas se encuentran satisfechas o no.

Punto final humanitario: criterios que sirven para finalizar un procedimiento más temprano para terminar o evitar el dolor y sufrimiento asociados al punto final tradicional, pero aún pudiendo cumplir con las expectativas del estudio en curso.

Thigmotaxis: preferencia por tener su superficie corporal en contacto con otros objetos.

Xenotrasplante: trasplante de células, tejidos u órganos de una especie a otra.

Xenotrasplante heterotópico: aquel xenotrasplante que se realiza en una localización distinta a la que dicho tejido se situaría habitualmente en el organismo.

Xenotrasplante ortotópico: xenotrasplante ubicado en la localización habitual del tejido utilizado.

Valencia: apreciación cualitativa del estado emocional, es decir, si la misma es positiva o negativa. 


\section{Bibliografía}

1. Aarstad H, Seljelid R. Effects of stress on the growth of a fibrosarcoma in nu/nu and conventional mice. Scand J Immunol. 1992; 35(2):209-15.

2. Ahl AS. The role of vibrissae in behaviour: a status review. Vet Res Commun. 1986; 10: 245-68.

3. André V, Gau C, Scheideler A, Aguilar-pimentel JA, Amarie O V, Becker L, Garrett L, Hans W, Hölter SM, Janik D, Moreth K, Neff F, Manuela O, Racz I, Rathkolb B, Rozman J, Bekeredjian R, Graw J, Klingenspor M, Klopstock T, Ollert M, Schmidt-Weber C, Wolf W, Galius-Durner V, Brielmeier M, Fuchs H and Hrabe de Angelis M. Laboratory mouse housing conditions can be improved using common environmental enrichment without compromising data. PLoS Biology. 2018: 1-24.

4. ANMAT. Régimen de Buenas Prácticas de Investigación en Estudios de Farmacología Clínica. Disposición 5330/ 97. Ciudad Autónoma de Buenos Aires, 1997.

5. Atkinson HC, Waddell BJ. Circadian Variation in Basal Plasma Corticosterone and Adrenocorticotropin in the Rat: Sexual Dimorphism and Changes across the Estrous Cycle. Endocrinology. 1997; 138(9): 3842-8.

6. Ayers GD, McKinley ET, Zhao P, Fritz JM, Metry RE, Deal BC, Adlerz KM, Coffey RJ, Manning HC. Volume of preclinical xenograft tumors is more accurately assessed by ultrasound imaging than manual caliper measurements. J Ultrasound Med. 2010; 29(6): 891-901.

7. Bailoo JD, Reichlin TS, Würbel H. Refinement of Experimental Design and Conduct in Laboratory Animal Research. ILAR J. 2014; 55(3): 383-91.

8. Balcombe J. Laboratory rodent welfare: Thinking outside the cage. J Appl Anim Welf Sci. 2010; 13(1): 77-88. 
9. Balcombe JP, Barnard ND, Sandusky C. Laboratory routines cause animal stress. Contemp Top Lab Anim Sci. 2004; 43(6): 42-51.

10. Bale TL. Stress sensitivity and the development of affective disorders. Horm Behav. 2006; 50(4): 529-33.

11. Barker TH, Bobrovskaya L, Howarth GS, Whittaker AL. Female rats display fewer optimistic responses in a judgment bias test in the absence of a physiological stress response. Physiol Behav. 2017; 173: 124-31.

12. Bates D, Mächler M, Bolker B, Walker S. Fitting Linear Mixed-Effects Models Using lme4. J Stat Soft. 2015; 67: 1-48.

13. Ben-Eliyahu S. The promotion of tumor metastasis by surgery and stress: Immunological basis and implications for psychoneuroimmunology. Brain Behav Immun. 2003; 17(1): 27-36.

14. Benaroya-Milshtein N, Apter A, Yaniv I, Kukulansky T, Raz N, Haberman Y, Halpert H, Pick CG, Hollander N. Environmental enrichment augments the efficacy of idiotype vaccination for B-cell lymphoma. J Immunother. 2007; 30(5): 517-22.

15. Benaroya-Milshtein N, Hollander N, Apter A, Yaniv I, Pick CG. Stress conditioning in mice: alterations in immunity and tumor growth. Stress. 2011; 14(3): 301-11.

16. Bentham J. An Introduction to the Principles of Morals and Legislation. Oxford, Clarendon Press, 1789.

17. Betof AS, Dewhirst MW, Jones LW. Effects and potential mechanisms of exercise training on cancer progression: A translational perspective. Brain Behav Immun. 2013; 30: S75-S87.

18. Beynon RJ, Hurst JL. Urinary proteins and the modulation of chemical scents in mice and rats. Peptides. 2004; 25(9): 1553-63.

19. Birch J. Animal sentience and the precautionary principle. Anim Sentience 2017, 2(16): 1-15.

20. De Boer SF, Koolhaas JM. Defensive burying in rodents: Ethology, neurobiology and psychopharmacology. Eur J Pharmacol. 2003; 463(1-3): 145-61. 
21. Boissy A, Manteuffel G, Jensen MB, Moe RO, Spruijt B, Keeling LJ, Winckler C, Forkman B, Dimitrov I, Langbein J, Bakken M, Veissier I, Aubert A. Assessment of positive emotions in animals to improve their welfare. Physiol Behav. 2007; 92(3): 375-97.

22. Boleij H, van't Klooster J, Lavrijsen M, Kirchhoff S, Arndt SS, Ohl F. A test to identify judgement bias in mice. Behav Brain Res. 2012; 233(1): 45-54.

23. Boletín Oficial. Ley Nacional-14346: Malos tratos o actos de crueldad contra animales. Ciudad Autónoma de Buenos Aires 1954.

24. Brenner GJ, Cohen N, Ader R, Moynihan JA. Increased pulmonary metastases and natural killer cell activity in mice following handling. Life Sci. 1990; 47(20): 18139.

25. Broom DM. Animal welfare: concepts and measurement. J Anim Sci. 1991; 69(10): $4167-75$.

26. Broom DM. Behaviour and welfare in relation to pathology. Appl Anim Behav Sci. 2006; 97(1): 73-83.

27. Broom DM. Sentience and Animal Welfare, First Edition. Oxfordshire, Reino Unido, CABI, 2014.

28. Brydges NM, Hall L. A shortened protocol for assessing cognitive bias in rats. $\underline{\mathrm{J}}$ Neurosci Methods. 2017; 286: 1-5.

29. Burman OHP, Parker RMA, Paul ES, Mendl MT. Anxiety-induced cognitive bias in non-human animals. Physiol Behav. 2009; 98(3): 345-50.

30. Cameron HA, Schoenfeld TJ. Behavioral and structural adaptations to stress. Front Neuroendocrinol. 2018; 49: 106-13.

31. Cao L, Liu X, Lin EJD, Wang C, Choi EY, Riban V, Lin B, During MJ. Environmental and Genetic Activation of a Brain-Adipocyte BDNF/Leptin Axis Causes Cancer Remission and Inhibition. Cell. 2010; 142(1): 52-64.

32. Cardon AD, Bailey MR, Bennett BT. The Animal Welfare Act: from enactment to enforcement. J Am Assoc Lab Anim Sci. 2012; 51(3): 301-5. 
33. Cavigelli SA, Monfort SL, Whitney TK, Mechref YS, Novotny M, Mcclintock MK. Frequent serial fecal corticoid measures from rats reflect circadian and ovarian corticosterone rhythms. J Endocrinol. 2005; 184(1): 153-63.

34. Chumbinho LC, Pereira da Silva LCC, Pizzini CC, Silva Batista W, Souza de Oliveira F, Melo de Oliveira G. Etograma de camundongos em biotério: Quais são as principais atividades destes animais dentro da gaiola? RESBCAL 2012; 1: 255262.

35. Cinelli P, Rettich A, Seifert B. Comparative analysis and physiological impact of different tissue biopsy methodologies used for the genotyping of laboratory mice. Lab Anim. 2007; 41(2): 174-184.

36. Clapcote SJ, Lazar NL, Bechard AR, Wood GA, Roder JC. NIH Swiss and Black Swiss Mice Have Retinal Degeneration and Performance Defi cits in Cognitive Tests. Comp Med. 2005; 55(4): 310-6.

37. Clarkson JM, Dwyer DM, Flecknell PA, Leach MC, Rowe C. Handling method alters the hedonic value of reward in laboratory mice. Sci Rep. 2018; 8(1): 1-8.

38. Crofton EJ, Zhang Y, Green TA. Inoculation stress hypothesis of environmental enrichment. Neurosci Biobehav Rev. 2015; 49: 19-31.

39. Dawkins MS. From an animal's point of view: Motivation, fitness, and animal welfare. Behav Brain Sci; 1990; 13:1-61.

40. Dawkins MS. A user's guide to animal welfare science. Trends Eco Evo. 2006; 21(2): 77-82.

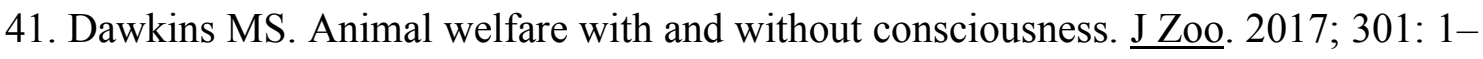
10.

42. Deacon RMJ. Assessing Burrowing, Nest Construction, and Hoarding in Mice. $\underline{\mathrm{J}}$ Visual Exp. 2012: 1-10.

43. Deacon RMJ, Croucher A, Rawlins JNP. Hippocampal cytotoxic lesion effects on species-typical behaviours in mice. Behav Brain Res.2002; 132(2): 203-13.

44. Delgado San Martin JA, Worthington P, Yates JWT. Non-invasive 3D time-offlight imaging technique for tumour volume assessment in subcutaneous models. Lab Anim. 2015; 49(2): 168-71. 
45. Duncan IANJH. Behavior and Behavioral Needs. Poult Sci. 1998; 77(12): 1766-72.

46. Duncan IJ, Petherick CJ. The implications of cognitive processes for animal welfare. J Anim Sci. 1991; 69(12): 5017-22.

47. Eriksen HR, Murison R, Pensgaard AM, Ursin H. Cognitive activation theory of stress (CATS): From fish brains to the Olympics. Psychoneuroendocrinology. 2005; 30(10): 933-8.

48. Euhus DM, Hudd C, Laregina MC, Johnson FE. Tumor measurement in the nude mouse. J Surg Oncol. 1986; 31(4): 229-234.

49. European Union. Directive 2010/63/EU of the European Parliament and of the Council of 22 September 2010 on the protection of animals used for scientific purposes. Official Journal of the European Union, 2010, pp. 33-79.

50. Festing MFW, Altman DG. Guidelines for the Design and Statistical Analysis of Experiments Using Laboratory Animals. ILAR J. 2002; 43(4): 244-58.

51. Franks B. Cognition as a cause, consequence, and component of welfare. Adv Agri Anim Welfare. 2018: 3-24.

52. Fraser D. Assessing Animal Welfare at the Farm and Group Level: The Interplay of Science and Values Assessing Animal Welfare at the Farm and Group Level. Anim Welfare. 2003; 12: 433-3.

53. Fraser D Understanding Animal Welfare: The Science in its Cultural Context. Ames, Iowa, Wiley-Blackwell, 2008.

54. Garner JP. Stereotypies and Other Abnormal Repetitive Behaviors: Potential Impact on Validity, Reliability, and Replicability of Scientific Outcomes. ILAR J. 2005; 46(2): 106-17.

55. Garner JP. The significance of meaning: Why do over $90 \%$ of behavioral neuroscience results fail to translate to humans, and what can we do to fix it? ILAR J. 2014; 55(3): 438-56.

56. Garofalo S, D’Alessandro G, Chece G, Brau F, Maggi L, Rosa A, Porzia A, Mainiero F, Esposito V, Lauro C, Benigni G, Bernardini G, Santoni A, Limatola C. Enriched environment reduces glioma growth through immune and non-immune mechanisms in mice. Nat Commun. 2015; 6: 1-13. 
57. Gaskill BN, Gordon CJ, Pajor EA, Lucas JR, Davis JK, Garner JP. Impact of nesting material on mouse body temperature and physiology. Physiol Behav. 2013a; 110-111: 87-95.

58. Gaskill BN, Karas AZ, Garner JP, Pritchett-Corning KR. Nest Building as an Indicator of Health and Welfare in Laboratory Mice. J Visual Exp. 2013b: 1-7.

59. Gaskill BN, Rohr SA, Pajor EA, Lucas JR, Garner JP. Some like it hot: Mouse temperature preferences in laboratory housing. Appl Anim Behav Sci. 2009; 116(24): 279-285.

60. Golde WT, Gollobin P, Rodriguez LL. A rapid, simple, and humane method for submandibular bleeding of mice using a lancet. Lab Anim. 2005; 34(9): 39-43.

61. Gouveia K, Hurst JL. Reducing Mouse Anxiety during Handling: Effect of Experience with Handling Tunnels. PLoS ONE. 2013; 8(6): 1-8.

62. Gouveia K, Hurst JL. Optimising reliability of mouse performance in behavioural testing: the major role of non-aversive handling. Sci Rep. 2017; 7: 44999.

63. Graulich DM, Kaiser S, Sachser N, Richter SH. Looking on the bright side of bias? Validation of an affective bias test for laboratory mice. Appl Anim Behav Sci. 2016; 181: 173-81.

64. Hall CS. Emotional behavior in the rat. I. Defecation and urination as measures of individual differences in emotionality. J Comp Psychol. 1934; 18: 385-403.

65. Harding EJ, Paul ES, Mendl M. Cognitive bias and affective state. Nature. 2004; 427: 312 .

66. Van der Harst JE, Spruijt BM. Tools to measure and improve animal welfare: Reward-related behaviour. Anim Welfare. 2007; 16: 67-73.

67. Harte JL, Eifert GH. The effects of running, environment, and attentional focus on athletes' catecholamine and cortisol levels and mood. Psychophysiol. 1995; 32(1): $49-54$.

68. Hasegawa H, Saiki I. Psychosocial Stress Augments Tumor Development through $\beta$ -Adrenergic Activation in Mice. Jpn. J. Cancer Res. 2002; 93(7): 729-35. 
69. Hubrecht R, Kirkwood J. The UFAW Handbook on the Care and Management of Laboratory and Other Research Animals: Eighth Edition. Oxford, Reino Unido, Wiley-Blackwell; 2010.

70. Hurst JL, West RS. Taming anxiety in laboratory mice. Nat Methods. 2010; 7(10): $825-8$.

71. Hutchinson E, Avery A, VandeWoude S. Environmental Enrichment for Laboratory Rodents. ILAR J. 2005; 46(2): 148-61.

72. Hylander BL, Repasky EA. Thermoneutrality, Mice, and Cancer: A Heated Opinion. Trends Cancer. 2016; 2(4): 166-75.

73. Idorn M, Hojman P. Exercise-Dependent Regulation of NK Cells in Cancer Protection. Trends Mol Med. 2016; 22(7): 565-77.

74. Institute for Laboratory Animal Research. Guide for the Care and Use of Laboratory Animals: 8th Ed. Washington, Estados Unidos, The National Academies Press, 2011.

75. Jacobsen KR, Jørgensen P, Pipper CB, Steffensen AM, Hau J, Abelson KSP The utility of fecal corticosterone metabolites and animal welfare assessment protocols as predictive parameters of tumor development and animal welfare in a murine xenograft model. In Vivo. 2013; 27(2): 189-96.

76. Jacobsen KR, Kalliokoski O, Teiilmann AC, Hau J, Abelson KS. Postsurgical Food and Water Consumption, Fecal Corticosterone Metabolites, and Behavior Assessment as Noninvasive Measures of Pain in Vasectomized BALB/c Mice. $\underline{\mathrm{J}}$ Am Assoc Lab Anim Sci. 2012; 51(1): 69-75.

77. Jain M, Baldwin AL. Are laboratory animals stressed by their housing environment and are investigators aware that this stress can affect physiological data? Med Hypotheses. 2003; 60(2): 284-89.

78. Jarzynka MJ, Gou P, Bar-Joseph I, Hu B, Cheng SY. Estradiol and nicotine exposure enhances A549 bronchioloalveolar carcinoma xenograft growth in mice through the stimulation of angiogenesis. Int J Oncol. 2006; 28(2): 337-44.

79. Jensen MM, Jørgensen JT, Binderup T, Kjær A. Tumor volume in subcutaneous mouse xenografts measured by microCT is more accurate and reproducible than 
determined by 18 F-FDG-microPET or external caliper. BMC Med Imaging. 2008; 8: $1-9$.

80. Jirkof P. Burrowing and nest building behavior as indicators of well-being in mice. J Neurosci Methods. 2014; 234: 139-46.

81. Jones S, Paul ES, Dayan P, Robinson ESJ, Mendl M. Pavlovian influences on learning differ between rats and mice in a counter-balanced Go/NoGo judgement bias task. Behav Brain Res. 2017; 331: 214-24.

82. Kauleff A, Touhimaa P. Contrasting grooming phenotypes in three mouse strains markedly different in anxiety and activity (129S1, BALB/c and NMRI). Behav Brain Res. 2005; 160(1): 1-10.

83. Kauleff A, Wheaton M, Murphy D. What's wrong with my mouse model? advances and strategies in animal modeling of anxiety and depression. Behav Brain Res. 2007; 179(1): 1-18.

84. Kelland LR. 'Of mice and men': Values and liabilities of the athymic nude mouse model in anticancer drug development. Eur J Cancer. 2004; 40(6): 827-36.

85. Kersemans V, Cornelissen B, Allen PD, Beech JS, Smart SC. Subcutaneous tumor volume measurement in the awake, manually restrained mouse using MRI. J Magn Reson Imaging. 2013; 37(6): 1499-504.

86. Kloke V, Schreiber RS, Bodden C, Möllers J, Ruhmann H, Kaiser S, Lesch KP, Sachser N, Lewejohann L. Hope for the best or prepare for the worst? Towards a spatial cognitive bias test for mice. PLoS ONE. 2014; 9(8): 1-12.

87. Kokolus KM, Capitano ML, Lee C-T, Eng JW-L, Waight JD, Hylander BL, Sexton S, Hong C-C, Gordon CJ, Abrams SI, Repasky E. Baseline tumor growth and immune control in laboratory mice are signi fi cantly influenced by subthermoneutral housing temperature. Proc Nat Acad Sci. 2013; 110(50): 2017681.

88. Kola I, Landis J. Can the pharmaceutical industry reduce attrition rates? Nat Rev Drug Discov. 2004; 3(8): 711-6.

89. Koolhaas JM, Bartolomucci A, Buwalda B, de Boer SF, Flügge G, Korte SM, Meerlo P, Murison R, Olivier B, Palanza P, Richter-Levin G, Sgoifo A, Steimer T, 
Stiedl O, van Dijk G, Wöhr M, Fuchs E. Stress revisited: A critical evaluation of the stress concept. Neurosci Biobehav Rev. 2011; 35(5): 1291-301.

90. Korte SM, Olivier B, Koolhaas JM. A new animal welfare concept based on allostasis. Physiol Behav. 2007; 92(3): 422-8.

91. LaCaille RA, Masters KS, Heath EM. Effects of cognitive strategy and exercise setting on running performance, perceived exertion, affect, and satisfaction. Psychol Sport Exercise. 2004; 5(4): 461-76.

92. Lamkin DM, Sloan EK, Patel AJ, Chiang BS, Pimentel MA, Ma JCY, Arevalo JM, Morizono K, Cole SW. Chronic stress enhances progression of acute lymphoblastic leukemia via b -adrenergic signaling. Brain Behav Immun. 2012; 26(4): 635-41.

93. Langford DJ, Bailey AL, Chanda ML, Clarke SE, Drummond TE, Echols S, Glick $\mathrm{S}$, Ingrao J, Klassen-Ross $\mathrm{T}$, LaCroix-Fralish ML, Matsumiya L, Sorge RE, Sotocinal SG, Tabaka JM, Wong D, van den Maagdenberg AMJM, Ferrari MD, Craig KD, Mogil JS. Coding of facial expressions of pain in the laboratory mouse. Nat Methods. 2010; 7(6): 447-9.

94. Latham N, Mason G. From house mouse to mouse house: The behavioural biology of free-living Mus musculus and its implications in the laboratory. Appl Anim Behav Sci. 2004; 86(3-4): 261-289.

95. Leknes S, Tracey I. A common neurobiology for pain and pleasure. Nat Rev Neurosci. 2008; 9(4): 314-20.

96. Levine $\mathrm{S}$ and Ursin H. What is stress?. In Brown MR, Rivier C, and Koob G (eds.) Neurobiology and Neuroendocrinology. New York, Marcel Decker, 1991, pp. 3-21. 97. Lindsay TH, Jonas BM, Sevcik MA, Kubota K, Halvorson KG, Ghilardi JR, Kuskowski MA, Stelow EB, Mukherjee P, Gendler SJ, Wong GY, Mantyh PW. Pancreatic cancer pain and its correlation with changes in tumor vasculature, macrophage infiltration, neuronal innervation, body weight and disease progression. Pain. 2005; 119(1-3): 233-46.

98. Linklater WL, MacDonald EA, Flamand JRB, Czekala NM. Declining and low fecal corticoids are associated with distress, not acclimation to stress, during the translocation of African rhinoceros. Anim Conserv. 2010; 13(1): 104-111. 
99. Van Loo PLP, Kruitwagen CLJJ, Koolhaas JM, Van de Weerd HA, Van Zutphen LFM, Baumans V. Influence of cage enrichment on aggressive behaviour and physiological parameters in male mice. Appl Anim Behav Sci. 2002; 76(1): 65-81.

100. Macleod M. Why animal research needs to improve. Nature. 2011; 477: 511.

101. Malkesman O, Scattoni ML, Paredes D, Tragon T, Pearson B, Shaltiel G, Chen G, Crawley JN, Manji HK. The Female Urine Sniffing Test: A Novel Approach for Assessing Reward-Seeking Behavior in Rodents. Biol Psychiatry. 2010; 67(9): 864-71.

102. Maple TL, Bloomsmith MA. Introduction: The science and practice of optimal animal welfare. Behavioural Processes. 2018; 156: 1-2.

103. Marashi V, Barnekow A, Ossendorf E, Sachser N. Effects of different forms of environmental enrichment on behavioral, endocrinological and inmunological parameters in male mice. Horm Behav 2003; 43(2): 281-92.

104. Martin B, Ji S, Maudsley S, Mattson MP. "Control” laboratory rodents are metabolically morbid: Why it matters. Proc Nat Aca Sci USA. 2010; 107(14): $6127-33$.

105. Mason G, Mendl M. Why is there no simple way of measuring animal welfare? Anim Welfare. 1993; 2: 301-319.

106. Mason GJ, Burn CC. Behavioural restriction. Anim Welfare. 2011: 98-119.

107. Mason JW. A re-evaluation of the concept of 'non-specificity' in stress theory. J Psychiatr Res. 1971; 8(3): 323-33.

108. Matsumiya LC, Sorge RE, Sotocinal SG, Tabaka JM, Wieskopf JS, Zaloum A, King OD, Mogil JS. Using the Mouse Grimace Scale to reevaluate the efficacy of postoperative analgesics in laboratory mice. J Am Assoc Lab Anim Sci. 2012; 51(1): 42-9.

109. Matzel LD, Townsend DA, Grossman H, Han YR, Hale G, Zappulla M, Light K, Kolata S. Exploration in outbred mice covaries with general learning abilities irrespective of stress reactivity, emotionality, and physical attributes. Neurobiol Learn Mem. 2006; 86(2): 228-40. 
110. Meehan CL, Mench JA. The challenge of challenge: Can problem solving opportunities enhance animal welfare? Appl Anim Behav Sci. 2007; 102(3-4): 24661.

111. Mellor DJ. Enhancing animal welfare by creating opportunities for positive affective engagement. N Z Vet J. 2015; 63(1): 3-8.

112. Mendl M, Burman OHP, Parker RMA, Paul ES. Cognitive bias as an indicator of animal emotion and welfare: Emerging evidence and underlying mechanisms. Appl Anim Behav Sci. 2009; 118(3-4): 161-181.

113. Mendl M, Burman OHP, Paul ES. An integrative and functional framework for the study of animal emotion and mood. Proc Biol Sci. 2010; 277: 2895-2904.

114. Miller A, Burson H, Söling A, Roughan J. Welfare Assessment following Heterotopic or Orthotopic Inoculation of Bladder Cancer in C57BL/6 Mice. Plos One. 2016; 11(7): e0158390.

115. Moberg GP y Mench JA. The biology of animal stress: basic principles and implications for animal welfare. Wallingford, Reino Unido, CABI, 2000.

116. Mogg K, Bradley BP. Attentional bias in generalized anxiety disorder versus depressive disorder. Cognit Therapy Res. 2005; 29(1): 29-45.

117. Mormède P, Andanson S, Aupérin B, Beerda B, Guémené D, Malmkvist J, Manteca X, Manteuffel G, Prunet P, van Reenen CG, Richard S, Veissier I. Exploration of the hypothalamic-pituitary-adrenal function as a tool to evaluate animal welfare. Physiol Behav. 2007; 92(3): 317-39.

118. Munro CJ, Lasley BL. Non-radiometric methods for immunoassay of steroid hormones. Prog Clin Biol Res. 1988; 285: 289-329.

119. Nachat-Kappes R, Pinel A, Combe K, Lamas B, Farges MC, Rossary A, Goncalves-Mendes N, Caldefie-Chezet F, Vasson MP, Basu S. Effects of Enriched Environment on COX-2, Leptin and Eicosanoids in a Mouse Model of Breast Cancer. PLoS ONE. 2012; 7(12): 1-15.

120. Novak J, Bailoo JD, Melotti L, Rommen J, Würbel H. An exploration based cognitive bias test for mice: Effects of handling method and stereotypic behaviour. PLoS ONE. 2015; 10(7): 1-16. 
121. Novak J, Stojanovski K, Melotti L, Reichlin T, Palme R, Würbel H. Effects of stereotypic behaviour and chronic mild stress on judgement bias in laboratory mice. Appl Anim Behav Sci. 2016; 174: 162-72.

122. O'Leary T, Gunn R, Brown R. What are we measuring when we test strain differences in anxiety in mice? Behav Genet. 2013; 43(1): 34-50.

123. Olsson IAS, Dahlborn K. Improving housing conditions for laboratory mice: a review of 'environmental enrichment'. Lab Anim. 2002; 36(3): 243-70.

124. Organización Mundial de Sanidad Animal. Código Sanitario para los Animales Terrestres, 25 $2017 . \quad$ Edición. [online] http://www.oie.int/es/normas/codigo-terrestre/acceso-en-linea/

125. Paceli RB, Cal RN, dos Santos CHF, Cordeiro JA, Neiva CM, Nagamine KK, Cury PM. The influence of physical activity in the progression of experimental lung cancer in mice. Pathol Res Pract. 2012; 208(11): 377-381.

126. Pacharinsak C, Beitz A. Animal Models of Cancer Pain. Comp Med. 2008; 58(3): 220-233.

127. Palanza P. Animal models of anxiety and depression: how are females different? Neurosci Biobehav Rev. 2001; 25(3): 219-233.

128. Panksepp J. Evolution constructed the potential for subjective experience within the neurodynamics of the mammalian brain. En: Ekman P y Davidson RJ (eds.) The Nature of Emotion: Fundamental Questions. Oxford, Reino Unido, 1994, pp. 396-399.

129. Paul ES, Harding EJ, Mendl M. Measuring emotional processes in animals: The utility of a cognitive approach. Neurosci Biobehav Rev. 2005; 29(3): 469-491.

130. Proctor H. Animal Sentience: Where Are We and Where Are We Heading?. Animals. 2012; 2(4): 628-39.

131. Prut L, Belzung C. The open field as a paradigm to measure the effects of drugs on anxiety-like behaviors: a review. Eur J Pharmacol. 2003; 463(1-3): 3-33.

132. Rauw WM, Kanis E, Noordhuizen-Stassen EN, Grommers FJ. Undesirable side effects of selection for high production efficiency in farm animals: a review. Livestock Prod. Sci. 1998; 56(1): 15-33. 
133. Richter SH, Garner JP, Würbel H. Environmental standardization: Cure or cause of poor reproducibility in animal experiments? Nat Methods. 2009; 6(4): $257-61$.

134. Roberts SA, Simpson DM, Armstrong SD, Davidson AJ, Robertson DH, McLean L, Beynon RJ, Hurst JL. Darcin: A male pheromone that stimulates female memory and sexual attraction to an individual male's odour. BMC Biol. 2010; 8: 121.

135. Roelofs S, Boleij H, Nordquist RE, van der Staay FJ. Making Decisions under Ambiguity: Judgment Bias Tasks for Assessing Emotional State in Animals. Front Behav Neurosci. 2016; 10: 1-16.

136. Rogers J, Li S, Lanfumey L, Hannan AJ, Renoir T. Environmental enrichment reduces innate anxiety with no effect on depression-like behaviour in mice lacking the serotonin transporter. Behav Brain Res. 2017; 332: 355-61.

137. Roughan J V, Flecknell PA, Davies BR. Behavioural assessment of the effects of tumour growth in rats and the influence of the analgesics carprofen and meloxicam. Lab Anim. 2004; 38(3): 286-96.

138. Rygaard J. Subcutaneous xenografts. En: Boven E and Winograd B (eds.) The Nude Mouse in Oncology Research. Boca Raton, Estados Unidos, CRC Press, 1991a, p. 44-50.

139. Rygaard J. History and pathology. En: Boven E and Winograd B (eds.) The Nude Mouse in Oncology Research. Boca Raton, Estados Unidos, CRC Press, 1991b, p. 2-9.

140. Samuels BA y Hen R. Novelty-Suppressed Feeding in the Mouse. En: Gould T. (eds) Mood and anxiety related phenotypes in mice. Nueva York, Estados Unidos, Humana Press 2011, p. 107-121.

141. Selye H. A syndrome produced by diverse nocuous agents. Nature. 1936; 138: 32 .

142. Shettleworth SJ. Animal cognition and animal behaviour. Anim Behav. 2001; 61: 277-286. 
143. Sklar L, Anisman H. Stress and coping factors influence tumor growth. Science. 1979; 205: 513-5.

144. Sørensen DB. Animal welfare-an introduction. En Kaliste E (ed.) The Welfare of Laboratory Animals. Dordrecht, Springer, 2007, p. 3-14.

145. Sztainberg Y, Chen A. An environmental enrichment model for mice. $\underline{\text { Nat }}$ Protocols. 2010; 5: 1535-9.

146. Thaker P, Han LY, Kamat A. Chronic stress promotes tumor growth and angiogenesis in a mouse model of ovarian carcinoma. Nat Methods. 2006; 12(8): 939-44.

147. Tomayko MM, Reynolds CP. Determination of subcutaneous tumor size in athymic (nude) mice. Cancer chemother pharmacol. 1989; 24(3): 148-154.

148. Touma C, Palme R, Sachser N. Analyzing corticosterone metabolites in fecal samples of mice: a noninvasive technique to monitor stress hormones. $\underline{\text { Horm }}$ Behav. 2004; 45(1): 10-22.

149. United Kingdom Co-ordinating Committee on Cancer Research (UKCCCR). United Kingdom Co-ordinating Committee on Cancer Research (UKCCCR) Guidelines for the Welfare of Animals in Experimental Neoplasia (Second Edition). British journal of cancer. 1998; 77: 1-10.

150. Ullman-Culleré MH, Foltz CJ. Body Condition Scoring: A Rapid and Accurate Method for Assessing Health Status in Mice. Lab Anim Sci. 1999; 49(3): 319-23.

151. Unión Europea. Directiva del Consejo de 24 de noviembre de 1986, relativa a la aproximación de las disposiciones legales, reglamentarias y administrativas de los Estados miembros respecto a la protección de los animales utilizados para experimentación y otros fines científicos. 1986.

152. Ursin H, Eriksen HR. Cognitive activation theory of stress (CATS). Neurosci Biobehav Rev. 2010; 34(6): 877-81.

153. Veissier I, Aubert A, Boissy A. Animal welfare: A result of animal background and perception of its environment. Anim Front. 2012; 2(3): 7-15. 
154. Verma MK, Miki Y, Sasano H. Sex steroid receptors in human lung diseases. J Steroid Biochem Mol Biol. 2011; 127(3-5): 216-22.

155. Wallace J. Humane endpoints and cancer research. ILAR J. 2000; 41(2): 8793.

156. Van de Weerd HA, Van Loo PLP, Van Zutphen LFM, Koolhaas JM, Baumans V. Nesting material as environmental enrichment has no adverse effects on behavior and physiology of laboratory mice. Physiol Behav. 1997; 62(5):101928.

157. Van de Weerd HA, Aarsen EL, Mulder A, Kruitwagen CLJJ, Hendriksen CFM, Baumans V. Effects of Environmental Enrichment for Mice: Variation in Experimental Results. J Appl Anim Welfare Sci. 2002; 5(2): 87-109.

158. Westwood JA, Darcy PK, Kershaw MH. Environmental enrichment does not impact on tumor growth in mice. F1000Research. 2013; 140: 1-8.

159. Whittaker AL, Howarth GS. Use of spontaneous behaviour measures to assess pain in laboratory rats and mice: How are we progressing? Appl Anim Behav Sci. $2014 ; 151: 1-12$.

160. Workman P, Aboagye EO, Balkwill F, Balmain A, Bruder G, Chaplin DJ, Double JA, Everitt J, Farningham DA, Glennie MJ, Kelland LR, Robinson V, Stratford IJ, Tozer GM, Watson S, Wedge SR, Eccles SA. Guidelines for the welfare and use of animals in cancer research. Br J Cancer. 2010a; 102(11): 155577.

161. Wright-Williams SL, Courade J-P, Richardson CA, Roughan J V, Flecknell PA. Effects of vasectomy surgery and meloxicam treatment on faecal corticosterone levels and behaviour in two strains of laboratory mouse. Pain. 2007; 130(1-2): 10818.

162. Zimmerman M. Physiological mechanisms of pain and its treatment. Klinische Anäesthesiol. Intensivtherapie. 1986; 32: 1-19.

163. Zimmermann E, Critchlow V. Effects of Diurnal Variation in Plasma Corticosterone Levels on Adrenocortical Response to Stress. Proc Soc Exp Biol Med. 1967; 125(2): 658-663. 